\title{
Dietary Intake and Body Composition Changes during a 12-Week Weight Loss Trial in Middle-aged and Older Men
}

\author{
Allison Marie Morris
}

Follow this and additional works at: https://researchrepository.wvu.edu/etd

\section{Recommended Citation}

Morris, Allison Marie, "Dietary Intake and Body Composition Changes during a 12-Week Weight Loss Trial in Middle-aged and Older Men" (2018). Graduate Theses, Dissertations, and Problem Reports. 6267. https://researchrepository.wvu.edu/etd/6267

This Thesis is protected by copyright and/or related rights. It has been brought to you by the The Research Repository @ WVU with permission from the rights-holder(s). You are free to use this Thesis in any way that is permitted by the copyright and related rights legislation that applies to your use. For other uses you must obtain permission from the rights-holder(s) directly, unless additional rights are indicated by a Creative Commons license in the record and/ or on the work itself. This Thesis has been accepted for inclusion in WVU Graduate Theses, Dissertations, and Problem Reports collection by an authorized administrator of The Research Repository @ WVU. For more information, please contact researchrepository@mail.wvu.edu. 
Using Storytelling as a Teaching Strategy to Increase Student Engagement in STEM Classes

Toni Morris

Dissertation submitted

to the College of Education and Human Services

at West Virginia University

in partial fulfillment of the requirements for the degree of

Doctor of Education

in

Curriculum and Instruction/Literacy Studies

Dr. Patricia A. Obenauf, Ed.D. Chair

Dr. Michael J. Mann, Ph.D.

Dr. Joy Faini Saab Ed.D.

Dr. Samuel Stack Ph.D.

Dr. Reagan Curtis, Ph.D

Department of Curriculum and Instruction/Literacy Studies

Morgantown, West Virginia University

2015

Keywords: Pedagogy, Storytelling, STEM instruction

Copyright 2015 Toni Morris 


\begin{abstract}
Using Storytelling as a Teaching Strategy to Increase Student Engagement in STEM Classes
\end{abstract}

Toni Morris

This study investigated whether or not the storytelling strategy could be used to increase student engagement and learning among non-STEM/STEAM majors participating in STEM/STEAM courses required by their programs of study. Specifically, it examined whether or not using storytelling to teach health science content to Early Childhood Development and Elementary Education students contributed to higher levels of student engagement, retention of content knowledge, self-reported preparedness to teach the content as future teachers, and ratings of teacher effectiveness. This study employed a QUAN-qual design. A true experimental design was used for the quantitative portion of the study while semi-structured group interviews were used in the qualitative portion. Forty-seven participants were randomly assigned to the storytelling group or the control group. Ten participated in the semi-structured group interviews. Repeated Measures ANOVA was used to examine difference over time between the treatment and control groups. Dependent sample t-test comparisons were used to examine differences in means at different time points within the treatment group. Qualitative data was analyzed using Hatch's Interpretive Analysis. Findings provided evidence that storytelling is an effective teaching strategy when teaching STEM/STEAM content to non-STEM/STEAM majors. Repeated Measures ANOVA provided strong evidence that the treatment group had higher levels of perceived student engagement, content knowledge, and perceptions of teacher interest and engagement in teaching. Dependent samples t-tests suggested these differences persisted two weeks after exposure to the storytelling strategy. The themes identified during qualitative data analysis supported the quantitative results and indicated that students participating in the treatment condition had high levels of student engagement, believed they retained content knowledge at a higher level, and perceived the instructor as more effective. 


\section{Dedication}

I dedicate this work to my late husband Ron Weaver who was more proud of my accomplishments than I and who loved the fact that I loved stories so much. He was my biggest fan and my strongest motivator. 


\section{Table of Contents}

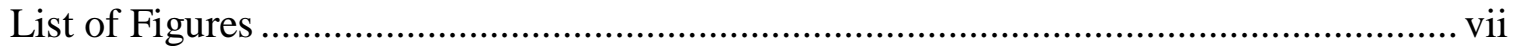

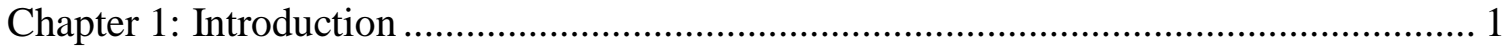

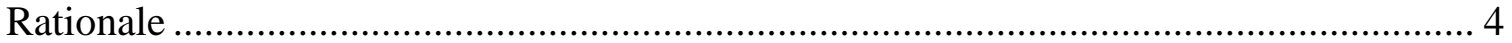

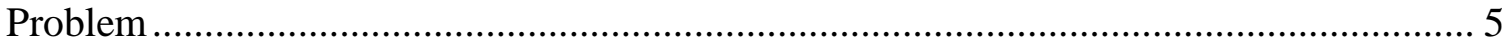

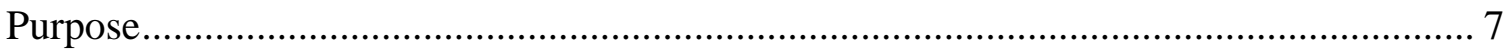

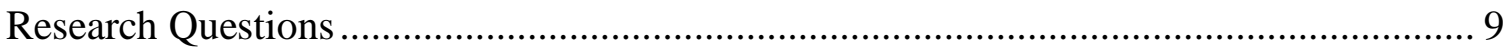

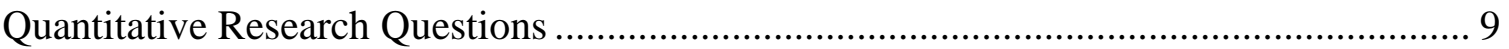

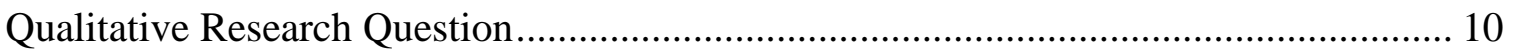

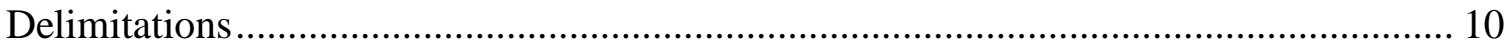

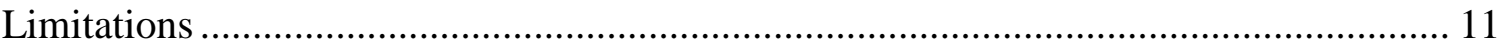

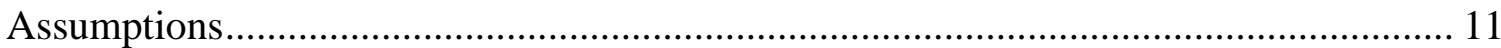

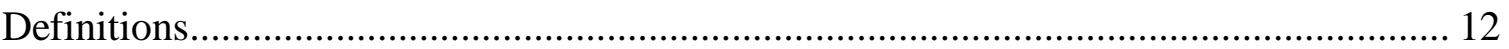

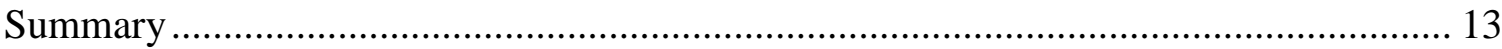

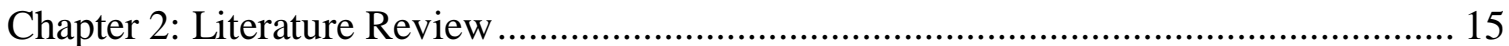

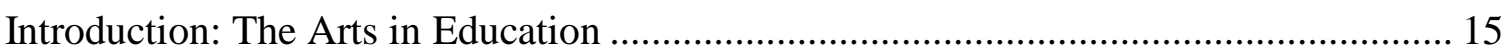

Theory Supporting Storytelling as an Educational Strategy ....................................... 16

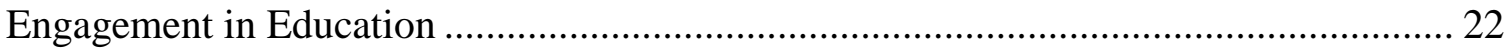

History of Storytelling as an Educational Strategy .................................................... 24

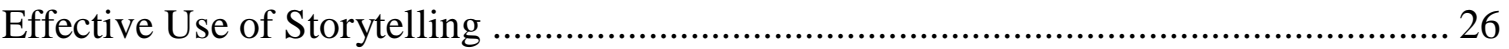

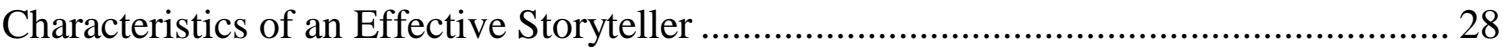

Examples of Effective Storytelling in Education................................................... 32

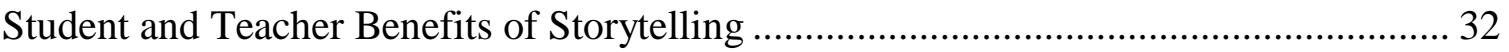

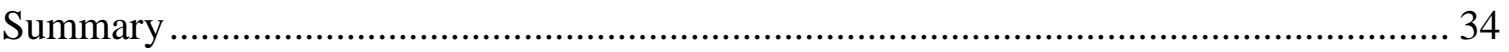

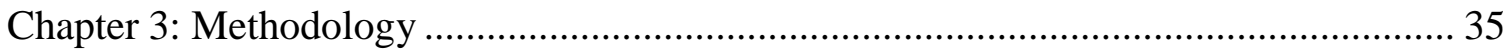

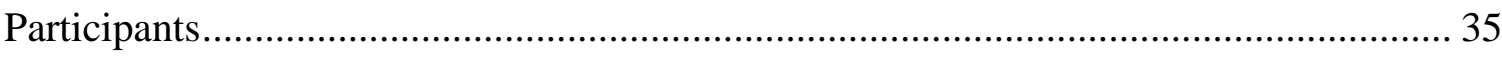

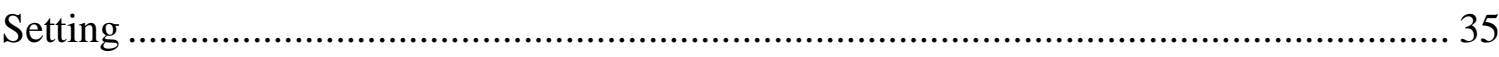

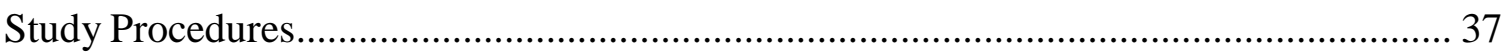

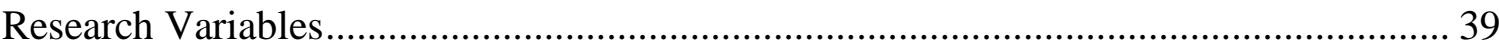

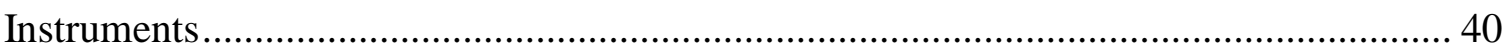

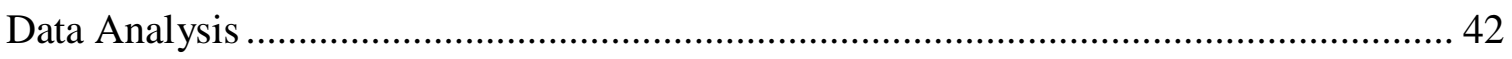

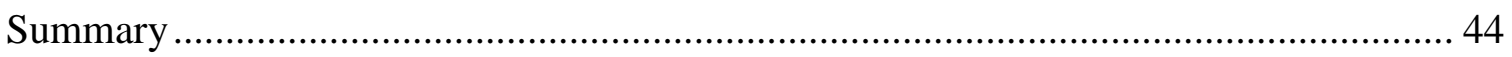

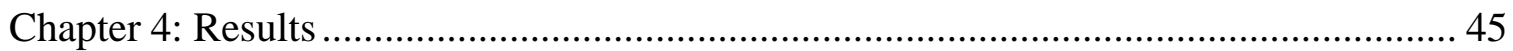

Quantitative Research Question 1: What is the relationship between the storytelling teaching strategy and student perceptions of engagement with the lesson? 
Quantitative Research Question 2: What is the relationship between the storytelling teaching strategy and student retention of content knowledge?

Quantitative Research Question 3: What is the relationship between the storytelling teaching strategy and student perceptions of their readiness to teach the corresponding content?

Quantitative Research Question 4: What is the relationship between the storytelling teaching strategy and student ratings of teacher effectiveness? ................................. 49

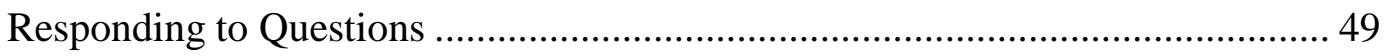

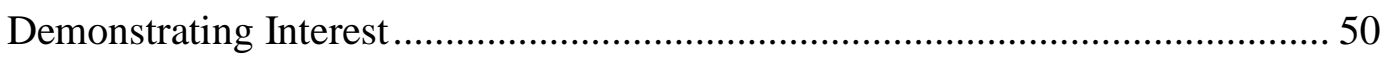

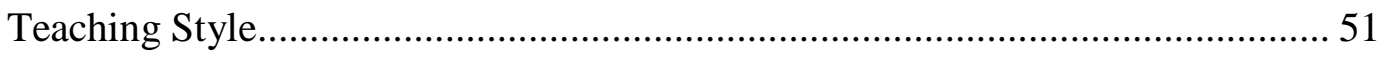

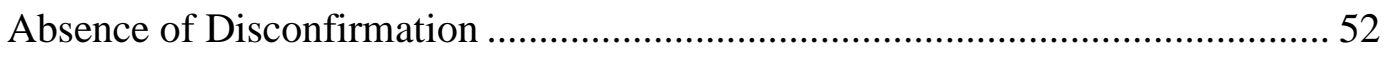

Qualitative Research Question: How do Early Childhood Development and Elementary Education majors in a required STEAM/health science course perceive the value of storytelling as strategy designed to enhance student engagement? ............................... 53

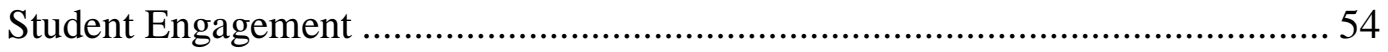

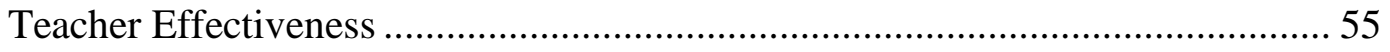

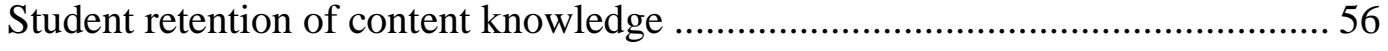

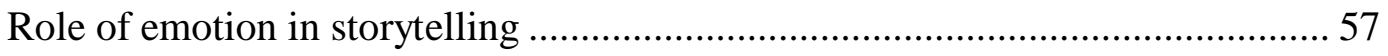

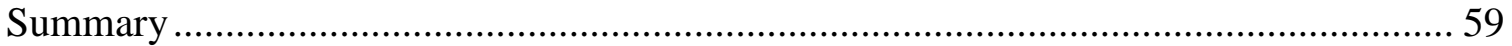

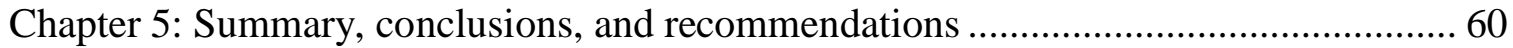

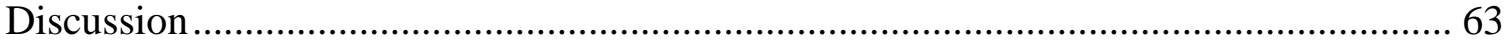

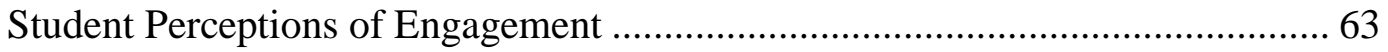

Student Retention of Content Knowledge ......................................................... 64

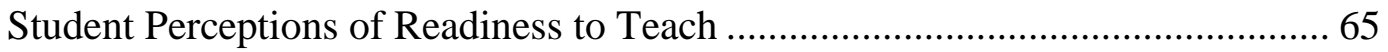

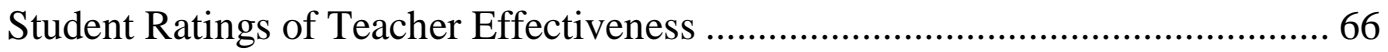

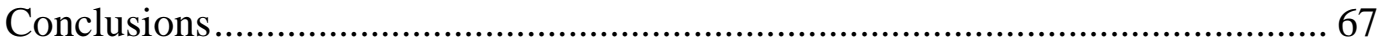

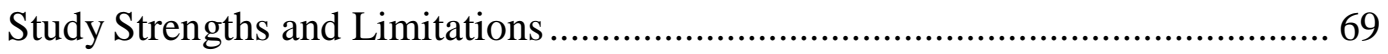

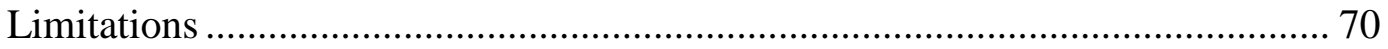

Recommendations for Future Research ..................................................... 71

Recommendations for Professional Practice...................................................... 73

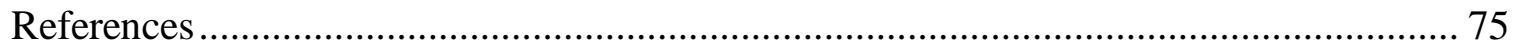

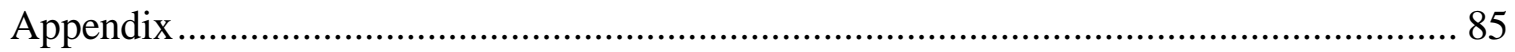

Appendix A: Student Engagement Instrument ................................................. 85

Appendix B: Retention of Content Knowledge Instrument....................................... 86

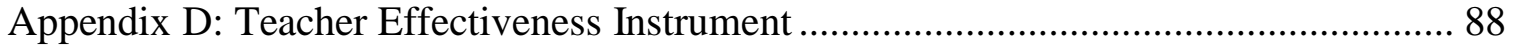

Appendix E: Semi Structures Group Interview Question Guide ................................. 89

Appendix F: IRB and Consent Form ................................................................ 90

Appendix G: Transcript from Storytelling Lecture ................................................. 95 
Appendix H: Hypothermia PowerPoint slides for both lectures ............................... 103

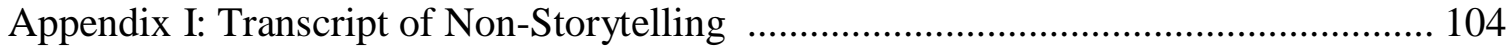

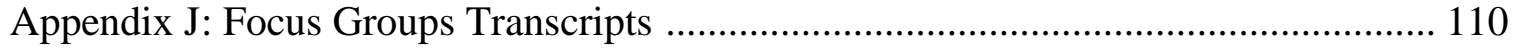




\section{List of Figures}

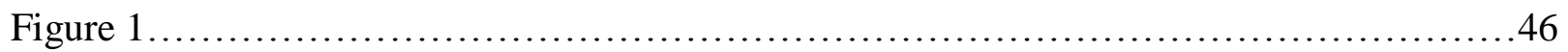

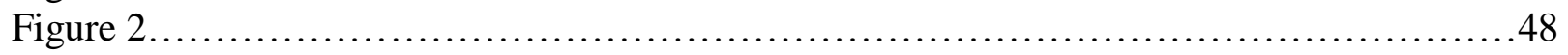

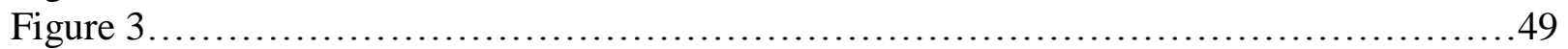

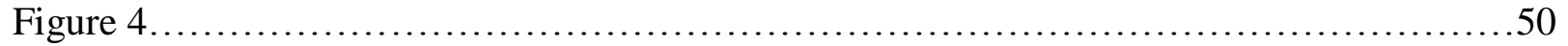

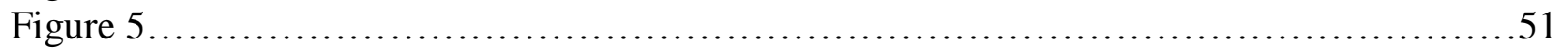

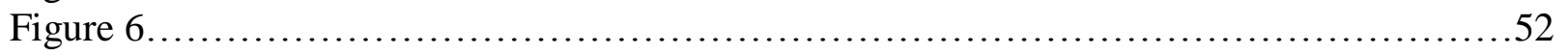

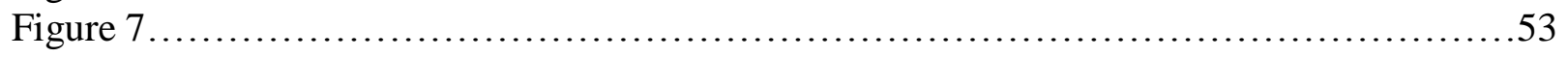


"In the earliest of times, prior to the advent of writing, storytelling was the only tool available by which individuals within their communities could preserve and share their heritage. Stories not only explained life and preserved history, but also ensured the continuity of experiences from one generation to the next. Civilizations survived because of storytelling." (Abrahamson, 1998, p. 440)

\section{Chapter 1: Introduction}

In American colleges, one of the major challenges educators face is a lack of student engagement - especially in science classes, where many students find themselves less interested in the subject matter (Wolter, Lundeberg \& Bergland, 2013). College students often report that science classes are hard to relate to, not well taught, or unexciting (Wolter et al., 2013). Sadly, these reports come during a critical shortage of well-prepared professionals in a wide range of science careers (Hinshaw, 2001; Wells, 2013) and among growing concerns about our national competitiveness in science (Mayo, 2007). As a result, identifying strategies that more effectively engage students in science represents a critical goal for many educators and policymakers.

One factor contributing to lower levels of engagement and retention may be that science professors often rely on delivering didactic, content-driven, teacher-centered lectures as their primary teaching strategy ( Gasiewski, Eagan, Garcia, Hurtado, and Chang, 2011; Seymour \& Hewitt, 1997). Gasiewski, et al, (2011) suggested the majority of attrition in the sciences occurs in the first two years of taking an introductory course in math and science; while Seymour and Hewitt (1997) found Science, Technology, Engineering and Mathematics (STEM) student's performance in their introductory courses was one of the key indicators associated with changing majors during college. Further, both Wolter et al. (2013) and White (2011) found that when science is taught primarily by lecture methods, students often fail to retain the material long-term or understand important ideas or themes. In a study investigating the characteristics of effective and ineffective teachers by Walls, Nardi, von Miden and Hoffman (2002), it was found that 
many students felt that ineffective teachers were consistently characterized as using "inept pedagogy, boring lectures, and [creating] unproductive learning environments." Additionally, some faculty members were found to be overzealous when sharing their knowledge or, although they were competent in their field of study, lacking adequate pedagogical training (Corso, Bundick, Quaglia, Haywood, 2013; Montgomery and Groat,1998). An example of this might include graduate students teaching introductory classes. While they may have the best intentions, they may also get so caught up in teaching content, that they lose focus on student receptivity and engagement. If student success in STEM courses is a priority, then STEM faculty might want to consider incorporating a wider variety of teaching styles, methods or strategies into their courses, especially strategies that demonstrably enhance student engagement.

The STEM movement dates back to 1958 , but was brought to the forefront of educational reform in 2001 by Dr. Judith Ramaley, an assistant director of the Education and Human Resources Directorate at National Science Foundation (Daugherty, 2013). Since then it has become a high priority in education reform. Although, educators and policymakers tend to agree on the importance of STEM subjects, there is some dispute regarding how to approach enhancing STEM-related outcomes (Daughtery, 2013). For instance, many educators have lobbied to add the letter "A" for the arts (Daugherty, 2013; Lichtenberg, 2008; White, 2011), changing the acronym from STEM to STEAM (Science, Technology, Arts, Engineering and Mathematics). These advocates suggest that one of the benefits of including the arts in STEM/STEAM instruction is that inclusion may help students better understand traditional STEM subject matter. Storytelling represents a particularly promising strategy for engaging students in STEAM. Specifically, the professional literature related to STEAM suggests that adding the arts benefits students by helping them develop the imagination and creativity required to be truly 
innovative in these fields (White, 2011; Yakman, 2010). STEAM teachers who integrate storytelling in to their teaching may be stimulating their students' imagination and creativity in manner that helps them engage more deeply in the subject matter. For example, stories may help connect students to real life experiences and listening to stories may excite their imaginations while providing the listener with a context for discovery and inquiry (Eagan, 1986; Isabelle, 2007). When faculty use the storytelling strategy, they demonstrate using imagination, creativity and innovation at work and can provide examples of others doing the same - both of which leads to enhanced student engagement, improved career preparedness, and greater work success (Daugherty, 2013; White, 2011). Additionally, storytelling may engage students at a deeper level than didactic lecturing. Because effective stories are emotionally engaging, the lessons associated with those stories may make them more potent and memorable (Eagan, 1989; Hayward, Gillam \& Lien, 2007). As we know, "When students become curious about a topic, they view it as more relevant to their lives and become more motivated to learn" (Wolter, et al., 2013, p. 26).

This study investigated whether or not the storytelling strategy could be used to increase student engagement and learning among non-STEM/STEAM majors participating in STEM/STEAM courses required by their programs of study. Specifically, it looked at determining whether or not using storytelling to teach health science content to Early Childhood Development and Elementary Education students contributed to higher levels of student engagement, retention of content knowledge, self-reported preparedness to teach the content as future teachers, and ratings of teacher effectiveness. 


\section{Rationale}

Today, didactic lecture remains the most commonly relied upon teaching method in higher education, even though research clearly supports increasing student engagement by using a wider range of teaching strategies (Bland, Saunders, \& Fitch, 2007). According to Bland, Saunders and Frisch, (2007) many professors and teachers continue to rely on age-old instructional strategies, many of which may be ineffective and inefficient for some learners. While many teaching strategies potentially enhance student learning, such as problem-based learning or critical thinking frameworks (Dieckelman, 2001), storytelling also represents a particular promising strategy (Eagan, 1989; Hayward, Gillam \& Lien, 2007).

Storytelling has been used since at least 4,000 BC to teach others, document past details, connect generations, set standards, teach cultural values and share common experiences (Hunter and Hunter, 2006). Many researchers believe that memory in oral cultures are more accurate because the memories have emotions attached to them and events with emotion makes those events more memorable (Alterio \& McDrury,2002). Egan states that, "a thorough review of the literature [suggests] that the story is one of the most important inventions of mankind" (1989). Additionally, McKeachie and Kulik (1975) note that studies that compare didactic lecture to storytelling support the efficacy of storytelling's potential for better engaging students in the learning process, particularly in terms of being able to connect to the subject matter. Historically, storytelling has been one of our most prominent and influential forms of educating young people; and it remains a strategy that, when implemented effectively, can add great value today. Evaluating the efficacy of this strategy in the STEAM context, particularly as related to helping non-STEAM students connect more meaningfully with the material presented in required STEAM courses, will make an important contribution to the student engagement literature. 


\section{Problem}

Students preparing for careers in Early Childhood Development and Elementary Education often appear to be less engaged while taking STEAM courses focused on health science content. Scholars describe engagement as the student being engaged in thought, feeling and action (Fredricks, Blumenfeld, \& Paris, 2004). Examples of disengaged behavior may include students doing poorly on exams, decreased alertness, or completing other tasks while in class such as texting. Students may become disengaged when the course material is outside of their interest area or when material is presented primarily in as a didactic lecture. This disengagement is particularly troubling because these students are pre-service teachers who will be required to teach STEAM content in their careers as educators. Finding ways to increase their engagement with STEAM/health science content not only promises to make an important contribution to their future success as teachers, but also to the health and wellbeing of their future students.

\section{Professional Experience with the Study Problem}

As an assistant professor in the School of Public Health, I have used storytelling in my classes while teaching STEAM content to non-STEAM majors and my student evaluations have been very favorable. Many years ago, my department needed a certified CPR instructor to teach a First Aid and Emergency Care course. During my first semester of teaching, I did not have any formal training in education and I had to find a method of teaching that I was comfortable using. Because my background also included a degree in acting, I quickly discovered that I was most comfortable when I was able to teach while telling a story. Without realizing it, I began to develop a teaching method based on art of storytelling. Through the years, I noticed through student evaluations of the courses I teach, that the stories I tell in class are viewed as an effective 
teaching method. Below are a few examples of the types of student comments I receive on a regular basis. They include:

1. She made the class interesting with visual stories.

2. She was very enthusiastic and interesting, had great stories that related to the topics.

3. She always told true stories about things that related to our topic for the day. I enjoyed her teaching because she knew the material and the way of presenting it was very effective.

4. I loved the stories. I would always go home and tell my roommates about them. (Not something I do in Bio Chemistry). This helped me learn and remember.

5. She honestly is an excellent teacher and person. I could listen to her talk about first aid all day telling stories. She truly made me want to go into the medical field with my whole heart to help save people someday. I really will take her teaching to heart.

6. I enjoyed every story that went along with what we were learning. Showed students many situations can happen at any time. Be Aware!

7. She has great stories and they make the class interesting, it's very relaxed and an enjoyable class for take.

8. She honestly is an excellent teacher and person. I could listen to her talk about first aid all day telling stories. She truly made me want to go into the medical field with my whole heart to help save people someday. I really will take her teaching to heart.

These types of comments have been a constant in my evaluations whenever I use storytelling strategies. It quickly became clear to me that if I wanted to teach the students what I knew about health, then the best way to do that was share my own experiences. I chose to use stories because throughout history it has been an effective way to transfer information. Hearing a good story appears to be engaging for most students and using activities that increase engagement promises to enhance student learning. I believed integrating stories and content would help keep the students interested and engage them in a discussion about the topic.

Historically, students have not only appeared to be engaged by this strategy as evidenced by them responding with their attention, but they also interact by asking questions and often started a dialogue about the topic. I also began to see that although using this strategy seemed simple enough - if it is not done correctly - a teacher might still fail to engage the students. In order to 
be successful, the instructor must show enthusiasm, truthfulness, and fully embrace it. As I began to more successfully incorporate this strategy, I noticed a change from teaching a lecture class that entails delivery of scripted information to a teaching style that includes "active learning techniques that truly engage students in the collective dialogue" (Montgomery \& Groat, 1998).

Based on my professional experiences with this strategy, combined with a thorough review of the peer-reviewed literature related to its use, it became clear that there were still questions about the efficacy and effectiveness of this promising strategy, especially as related to connecting students to material they might otherwise be less interested in or committed to learning. Because my teaching focuses specifically on teaching STEAM courses to non-STEAM majors, and because there was very little evidence in the professional literature related to the effectiveness of using the storytelling strategy in that context, I chose to investigate the relationship between the storytelling strategy, student learning, and teacher effectiveness among those students. My goal was to collect evidence that could guide future practice regarding the use of the storytelling strategy while teaching STEAM content to non-STEAM majors.

\section{Purpose}

The purpose of this study was to evaluate the efficacy of storytelling as a strategy designed to help non-STEAM/non-health science students become more engaged in their required STEAM/health science learning experiences. While doing so, evidence was collected that helps identify the value of using storytelling strategies to help these students: 1) engage the STEAM/health science coursework, 2) retain the content knowledge presented in class, 3) feel more prepared to teach future health science courses, and 4) report greater satisfaction with the course instructor. 
Wolter, Lundenberg, and Bergland (2013) suggest that higher education sometimes fails to make science relevant to non-science majors, while at the same time there has been an increasing focus on using narrative in science education (Abrahamson 1998; Blevins 2007; Egan 2003; Grose, 2010). The first goal of this study was met by contributing to the professional literature concerning student engagement and narrative by documenting evidence that helps educators and policymakers better understand the merits of using the storytelling strategy to help students effectively connect to STEAM subject matter.

Additionally, the second goal of this study aimed to help educators and policymakers develop a better understanding of the relationship between the storytelling strategy and student retention of content knowledge. Because storytelling may help students view the presented content as more relevant, they may also be more likely to retain that knowledge over time. Further, because stories have emotional components and because moderately emotional content is more easily remembered (Kieran Eagan, 1989; Hayward, Gillam \& Lien, 2007), it is important to evaluate the impact of storytelling on retention of content knowledge.

The third goal of this study was to assess the impact of the storytelling strategy on students' feelings of being prepared to teach the STEAM/health science course material. Early childhood education literature supports the use of both storytelling and dramatization. Wright, Bacigalupa, Black and Burton (2008) state that by using storytelling in early childhood programs, teachers can gain insights into the thinking of their students and helps children develop literacy skills, social skills and creativity. Perhaps the combination of role modeling these teaching strategies and using a strategy that helps students better engage the material will contribute to students reporting higher levels of self-efficacy as future STEAM/health science content teachers. 
The final goal of this study was to consider the influence of the storytelling strategy on students' perceptions of teacher effectiveness and the value of the storytelling strategy. Several studies suggest students who rate themselves as more engaged assign higher effectiveness ratings to their highly engaging course instructors (Ellis, 2004; Isabelle, 2007). Additionally, the study author is interested in hearing about the value students who are exposed to the storytelling strategy place on that strategy. In order to accomplish this goal, the study provided participants an opportunity to discuss their personal experience with storytelling, including but not limited to, describing how stories help them connect to STEAM subject matter, encourage them connect to each other's life experiences, contribute to essential human development, and awaken their conscious self.

\section{Research Questions}

This study was designed to answer four quantitative research questions with a fifth qualitative question being used to triangulate the quantitative findings by providing a member cross-check related of the quantitative data. The five research questions included:

\section{Quantitative Research Questions}

Among Early Childhood Development and Elementary Education majors in a required STEAM/health science course:

1. What is the relationship between the storytelling teaching strategy and student perceptions of engagement with the lesson?

2. What is the relationship between the storytelling teaching strategy and student retention of content knowledge?

3. What is the relationship between the storytelling teaching strategy and student perceptions of their readiness to teach the corresponding content? 
4. What is the relationship between the storytelling teaching strategy and student ratings of teacher effectiveness?

\section{Qualitative Research Question}

5. How do Early Childhood Development and Elementary Education majors in a required STEAM/health science course perceive the value of storytelling as strategy designed to enhance student engagement?

\section{Delimitations}

This study was framed within the context of six primary delimitations. These delimitations, otherwise known as choices regarding what will and won't be included in the study, were:

1. The study was conducted in three purposively selected college STEAM/health science classes in the Northern West Virginia geographical region.

2. Participants included Early Childhood Development and Elementary Education majors who volunteered for the study.

3. Data was collected during the 2013-2014 academic year.

4. Study variables were measured using a protocol consisting of the Student Academic Engagement Scale, The Teacher Readiness Scale, The Teacher Confirmation Scale, and the American College of Emergency Physician's First Aid Exam.

5. A demographic data questionnaire was used to obtain information about specific participant characteristics.

6. The study used a mixed methods QUAN-qual randomized experimental group comparison design with a semi-structured group interview. 


\section{Limitations}

This study included six limitations with implications concerning how the results of this study were interpreted. These limitations of this study included:

1. The three STEAM/health science classes purposively selected for the study may not have represented all STEAM/health science classes in the Northern West Virginia area or beyond.

2. Participants who volunteered for the study may not have represented all Early Childhood Development and Elementary Education majors.

3. Data collected during the 2013-2014 academic year may have differed from data collected during other periods of time.

4. Instruments selected for the study protocol may not have fully described their associated constructs.

5. Demographic data obtained from participants may not have captured all pertinent information about participants.

6. Use of a mixed methods QUAN-qual randomized experimental group comparison design with a semi-structured group interview may have limited the range of legitimate options available for data analysis.

\section{Assumptions}

This study included six core assumptions. In the context of this study, the following statements were accepted to be true:

1. The three STEAM/health science classes selected purposively for the study were considered adequately representative of like classes in the Northern West Virginia geographical region. 
2. Participants who volunteered for the study were considered adequately representative of Early Childhood Development and Elementary Education majors.

3. Data collected during the 2013-2014 academic year were considered adequate for the purpose of the study.

4. Instruments selected for the study protocol adequately described their associated constructs for the purpose of the study.

5. Demographic data obtained from participants captured an adequate level of pertinent information about participants.

6. Use of a mixed-methods QUAN-qual randomized experimental group comparison design with a semi-structured group interview provided adequate legitimate options for analysis of data from the study.

\section{Definitions}

This study's core concepts and variables were defined based on the work of researchers who are well established in the areas of storytelling, student engagement and retention, and teacher effectiveness. These key definitions include:

1. Storytelling: The craft of constructing the story's elements, the choices the storyteller makes in the process, and the actual telling of the story (Grose, 2010).

2. Student engagement: There is an emerging consensus among scholars that engagement is composed of three distinct but interrelated "modes":

a. Engaged in thought: involves a psychological investment in learning and mastery of academic material, as well as the desire for challenge, 
b. Engaged in feeling: refers to students' emotions regarding their relationships with others in the school environment. It also involves the students' sense of connectedness to, interest in, and passion for academic content,

c. Engaged in action: refers to the various activates and involvements in school that are directed toward learning and academic tasks. Signs of active engagement include attending and contributing to class, following school rules, completing assignments, studying and concentrating on academic tasks (Corso, Bundick, Quaglia and Haywood, 2013).

3. Student retention of content knowledge: The amount of content knowledge a student can recall and use effectively after the passage of time.

4. Teacher effectiveness: The ability of the teacher to deliver quality instruction, create a caring, structured learning environment, involve students in meaningful tasks with realworld implications, have high expectations of students, to allow students to share knowledge with each other, and to achieve positive student learning outcomes (Corso, Bundick, Quaglia and Haywood, 2013).

\section{Summary}

Storytelling represents the oldest documented method of education and communication. Researchers have found that the telling of one's stories is a way that human beings connect to each other's life experiences and share valuable learning. Sharing stories comprises an essential way that people can share information, learn from one another, and benefit from each other's learning. Using the storytelling strategy to enhance traditional didactic lectures in STEAM/health science courses may help increase student engagement, retention of content knowledge, preparedness to teach the material in the future, and ratings of teacher effectiveness. 
Additionally, further investigating this approach may help us better understand the contribution of the arts in the STEM/STEAM debate. And finally, providing participants with an opportunity to share their experiences with storytelling may help us better understand what students value about the storytelling approach, including its influence on their search for a more conscious and practical connection to the material they are studying - a connection that may help them grow into increasingly dedicated educators who more fully engage their own students. 


\section{Chapter 2: Literature Review}

"Storytelling is a uniquely human experience that enables us to convey, through the language of words, aspects of ourselves and others, and the worlds, real or imagined, that we inhabit" (Alterio\&McDrury,2002).

\section{Introduction: The Arts in Education}

Maxine Green is known as a pioneer in the philosophy of American education today. She has been a huge influence in the exploration of curriculum development from a postmodern aesthetic perspective. Keeping with the tradition of John Dewey, she has practically stood alone trying to incorporate the arts into the integral part of the lives and minds of children and adult learners (Ayers \& Miller, 1998). Her work to establish a relationship between postmodern philosophies and art is a way to improve the quality of education and assist in engaging the learner. In a collection of essays written about Ms. Green, Leo Bostein said, "she has set out to make the arts not a marginal part of how we deal with children and young people, but integral part of their lives and their minds she has sought to integrate the arts into how we teach children and adults" (Ayers and Miller, 1998 p. 62).

Storytelling represents one promising way to incorporate the arts into education. There is sufficient evidence in the research literature to support the use of storytelling in the educational experience. Storytelling is an art form that should be used to help the learner obtain and experience pertaining to the subject matter being taught. In Art as Experience, Dewey (1934) expands on how the use of the arts in education contributes to engaging the students in the learning experience:

Art denotes a process of doing or making. This is as true of fine art as of technical art. Art involves molding of clay, chipping of marble, casting of bronze, laying on pigments, construction of buildings, singing of songs, playing of instruments, enacting roles on the stage, going through rhythmic movements in the dance. Every art does 
something with some physical material, the body or something outside the body, with or without the use of intervening tools, and with a view to the production of something visible, audible or tangible. . Art, in its form, unites the very same relations of doing and undergoing, outgoing and incoming energy that makes an experience to be an experience. (p. 47)

\section{Theory Supporting Storytelling as an Educational Strategy}

There are many theories of learning that can be used to support the use of storytelling as a learning in college courses. Two theories that support the efficacy of the storytelling strategy - and can frame our thinking about how it might contribute to higher levels of student engagement and retention - include Kolb's Theory of Experiential Learning (Chan, 2012; De Jesus, Almeida, Dias-Teixeria \& Watts, 2007; Kolb, 1984;

Schenck \& Cruickshank, 2015) and Constructivist Theories of Learning (Alterio \&McDrury, 2010; Vygotsky, 1987;). "Kolb was purported to integrate the work of Piaget, Kurt Lewin and John Dewey” (Schenk and Cruiskshank, 2015, p.73).

Piaget's Theory of Cognitive Development. Piaget's theory of cognitive development is a comprehensive theory about the nature of experience as a lifelong process of learning through experience, assimilation and accommodation and the development of new knowledge through cognitive development (Chan, 2012; McLeod, 2012). Piaget believed that cognitive development is at the center of human intelligence and that one's childhood plays a vital role in their development (Torres \& Ash, 2007).

There are three basic components to Piaget's theory; Schemas, adaptation to development, and the stages of cognitive development (Piaget, 1945). Schemas, according to Piaget, are the foundation to acquiring new knowledge, they are basically mental maps in an individual's mind based on existing knowledge. When knew knowledge is presented a person goes through adaptation processes including equilibrium, assimilation and 
accommodation. If knowledge is easy to connect to past schemas, assimilation occurs. If new knowledge is more complex or in conflict with past knowledge accommodation must occur to bring an individual back to equilibrium. Finally, there are four stages of cognitive development; sensorimotor, preoperational, concrete operational, and formal operational. According to Piaget's theory each person goes through these stages of cognitive development which helps them to develop knowledge over a lifetime. Humans come to learn, adapt and use the knowledge (Piaget, 1945).

In his study of the field of education, Piaget concentrated on two processes that he called assimilation and accommodation. Assimilation is how humans recognize and adjust to new information. Assimilation is when new experiences are reflected upon and interpreted to connect with previously learned information (Berger, 2008). Accommodation, in contrast, is the process of using information from one's environment and altering it to fit with the new information (Berger, 2008). Piaget's theory has been challenged on many levels but one of the most significant was the fact that it does not take into account that a child's sociocultural environment also plays a significant role in cognitive development. A child also learns from social interactions and life experiences help them learn about the world, which Piaget did not consider (Kail, 2007). Vygotsky (1962; 1987), the Russian psychologist turned educator, added to Piaget's psychological approach to constructivism by adding a greater emphasis on the role of social and cultural/contextual factors and the contribution to learning that can be made when learners are able to connect what they are learning to relevant events and applications beyond the mere facts themselves. 
Constructivist Theories of Learning. The literature also supports the use of a social-cultural constructivist framework. Vygotsky (1962), emphasized the development of self through educational practice that incorporated effective social connection and meaningful communication within the context of that connection (Alterio \& McDrury, 2010). In general, social-cultural constructivists like Vygotsky are most concerned with the communication practice and the influence of social factors when building of knowledge. In his theory of the "Zone of Proximal Development", he observed that when children were learning tasks on their own they did not do as well when tested as they did when they were learning by engaging with others to learn the task. He added that the development of language and verbalization of ideas was key in the process of learning and development.

The storytelling strategy promises to be particularly useful from the social-cultural constructivist point of view. Storytelling supports the view of learning as, "a social and collaborative process that values students' prior knowledge and experience and promotes reflective dialogue as a medium through which knowledge can be constructed" (Alterio \&McDrury, 2010, p. 86). Further, according to Alterio and McDrury (2010), using the storytelling strategy effectively both provides context and enhances social connections in a manner congruent with increased engagement and retention. In this formulation, stories offer at least one context in which knowledge can be embedded and provide a characters with which learners can affiliate and associate outcomes. In this way, storytelling avoids attempting to merely deliver knowledge to learners as though they were receptacles for content, but instead helps provide a social and cultural context in which students can discover their own understanding as connected to authentic and socially relevant events, 
relationships, and outcomes. Constructivists' views are also linked to the notion of learning through reflection in professional practice (Atherton, 2015). In his experiential learning theory, Kolb (1984) expands on Vygotsky theory by including the four learning modes that include "experiencing, reflecting, thinking and acting, in a recursive process that is responsive to the learning situation and what is being learned" (Kolb,1984, p. 194).

Kolb's Theory of Experiential Learning. Kolb's (1984) experiential learning cycle viewed learning as a four-stage cycle which includes a) concrete experience, a feeling of dimension b) reflective observation, a watching observation c) abstract conceptualization, a thinking dimension d) active experimentation, a doing dimension. These four stages are adaptive learning modes. When he uses the word stage, he actually means steps (Evans, Forney \& Dibrito, 1998). Each step provides the groundwork for the next one. This theory has been used widely in learning and is based on the principle that an experience such as attending class and listening or receiving information does not guarantee that learning will take place. For the learning to be significant, the student would need to "involve themselves fully and without bias in learning experiences, (CE), observe and reflect on these experiences from multiple perspectives (RO), formulate concepts that integrate their observations into theories (AC) and put such theories to use in making decisions and solving problems. (AE)", (Evans, Forney \& Dibrito, 1998, p. 209). Kolb (1984) acknowledges although students differ in their capability to complete each of the stages, it is important to complete each stage.

According to Alterio and McDrury (2004), in Learning Through Storytelling in Higher Education, Using Reflection and Experience to Improve Learning, students new to the experiential learning cycle often find difficulty with the reflective observation stage. 
This can be because some of the issues students have with themselves or the teaching style or learning environment. Alterio and McDrury (2004) use Kolb's theory to support using Storytelling in Higher Education by formulating the following five propositions:

1. Experience is the foundation of, and stimulus for, learning.

2. Learners actively construct their experience.

3. Learning is a holistic process.

4. Learning is socially and culturally constructed.

5. Learning is influenced by the social-emotional context in which it occurs (p. 14).

Storytelling is a use of a narrative form that shows characters experiencing problems and taking a particular series of actions in order to work toward a satisfactory outcome. We know from the theory of experiential learning that we get better outcomes if we can connect similar experiences between the students and the stories of the world. Using a narrative dialogue is one way to do this. It may be better if we could use an actual learning experience to give students actual hands on experience. For example, if we wanted to teach students the obstacles of surviving in an oppressed economy, the best experience would be to take the students to an actual place where they can experience oppression. However, that kind of experience is often unrealistic due to the constraints of the class, time, and finances. The creative use of stories to expand a student's horizons of understanding can be a powerful tool to allow the student to make meaning of their interpretations of the events. This association also gives the students the opportunity to make reflections and an emotional connection. Kieran Egan, a professor in the faculty of 
education at Simon Fraser University, suggests that the story could be the missing link to ensure more meaningful learning.

\section{Kieran Egan's Theory the Educated Mind: How Cognitive Tools Shape Our}

Understanding. Egan maintains that much of the current educational theories hinge on three basic concepts of what the goal of education should be:

1. To educate people in the content that would give them reason and knowledge that can provide them with access to the world; education is the epistemological process; knowledge motivates the student's mind development.

2. Every individual, through self discovery, has the right to pursue their own educational curriculum.

3. To socialize the child will ensure children can learn their role in society according to its values and beliefs.

Egan argues that "these three ideas are mutually incompatible, and this is the primary cause of our long-continuing educational crisis" (Egan, 1997).

Egan's main influence comes from Lev Vygostsky. In an article tilted Memory, Imagination, and Learning: Connected by the Story (1989), Egan writes, "If we enable students to master such generic skills as critical thinking, problem solving, and other procedural abilities, we will be doing something that is more educationally valuable than merely drilling them in sequences of facts that will be mostly forgotten anyway" (p. 455). Egan believes that using the story to teach content from any curricular area including math, science and arts and social studies can be used as an affective teaching strategies by thinking of teaching as storytelling (Egan, 1989). 


\section{Engagement in Education}

The research literature on "teacher effectiveness" and reviews written summarizing that body of research provides guidance for an instructor. Richard Walls (1999) in Psychological Foundations of Learning wrote, “The respect you are given as a teacher (instructor, professor) comes from (a) your knowledge of the subject matter and (b) your ability to teach it. When you are a teacher, you have only one major reason for being there. That reason is to facilitate learning." Rosenshine and Furst (1973) concluded that the five most important teacher effectiveness variables are: (a) Clarity, (b) Variability, (c) Enthusiasm, (d) Task - oriented and/or Businesslike Behaviors, and (e) Student Opportunity to Learn Criterion Material. Walls (1999) condensed their findings with other research found to support it into what he titles, "Four Aces of Effective Teaching”. According to Walls, the Four Aces represent a consolidated way of thinking about the 'process' of teaching as it influences the 'product' of student learning. The Four Aces of Learning include Outcomes, Clarity, Engagement, and Enthusiasm. Outcomes, otherwise known as Ace 1, includes letting students know where they are going and driving hard toward clear goals. Clarity (Ace 2) stipulates that a teacher must make the content clear and simple as possible and build on what students already know. In discussing Engagement (Ace 3), Walls encourages educators not to lecture more than 30 minutes before an activity involving all students and also reminds us that people learn as they DO, thus have student DO every concept. Finally, Enthusiasm (Ace 4) provides a reminder that if you hate to teach it, they will hate to learn it and the only key to student motivation is their success. (Walls, 1999)

Walls' summarizes these techniques as follows: Outcomes include good instructors who emphasize academic objectives in establishing expectations and allocating time. No matter what 
form the instructor chooses to write the objectives, the point is that students must know what is expected and what they are trying to achieve.

Clarity includes good instructors who are clear and make learning clear. Instruction is arranged for maximum understanding. They manage this by sending messages that student are able to receive and interpret. Walls states that the best practices of teaching create experiences that paint vivid images and that put the student and the teacher together in a community of learners. If a teacher can assist the student in connecting new information with what they already know, he or she is assisting them in learning and organizing information. The key is to make it as clear and simple as you can.

Engagement has gained more recognition in recent years. Dr. Walls quotes studies by Gage and Berliner (1991) that says that effective teaching includes active learning. In other words, "you learn what you do". Enthusiasm is a necessary component of teaching. If the instructor finds the subject to be dull, then the students will also find the subject dull. However, if the instructor can make the topic fun for his or herself, then the topic will become fun for the students. Enthusiasm is contagious. Walls documents support of this statement by referring to five studies that have shown the ways in which student achievement can be related to teacher enthusiasm. The ACES, or teacher qualities, are not automatic for educators. Many beginning teachers have difficulty mastering the skill to guide collaborative discussions.

In a research study commissioned by the Arts Education Partnership and the President's Committee on the Arts and the Humanities, Catterall, Chapleau, and Iwanga (1999) used data from The National Educational Longitudinal Survey that followed more than 25,000 students in American secondary schools for ten years. The first phase of the study examined involvement in the arts generally, across all disciplines. The second phase examined the potential importance of 
continual participation in a single discipline using theatre arts as a case study. The analysis found significant and important differences in accomplishment and in the attitudes and behaviors between youth highly involved in the arts and those with little or no arts engagement. There were twenty differences found that favored arts involvement that proved to be significant at the $p<.001$ level. The outcomes showed more positive for students in higher achievement, staying in schools and better attitudes about school and community.

\section{History of Storytelling as an Educational Strategy}

Storytelling is the oldest documented method of education and communication. People love a good story existing literature supports the notion that students are without exception. Stories have been used for centuries to teach cultural ideals, educate communities, record past events, and to share history and familiar experiences. It is documented that the earliest civilizations of Greeks, Romans, Gypsies and other cultures carried their stories all around the land in an effort to educate and entertain. Troubadours would travel back and forth from courts to county inns sharing stories as a way of bringing the working class and royalty to an understanding (Abrahamson, 1998; Lamb, 2008) “Great teachers, from Homer and Plato, through Jesus, Li Po, and Gandhi have used stories, myths, parables, and personal history to instruct, to illustrate, and to guide the thinking of their students" (Zabel, 1991, p.32). Prior to the invention of the printing press, cultures used stories to teach history, philosophy, and law to name a few. The use of storytelling has gone beyond the telling of folklores to now being used in science fields such as medical education.

At the beginning of mankind, human beings began to form communities to help ensure their existence. They formed tribes and clans to enhance their survival (Lamb, 
2005). According to Nancy Lamb, in her book titled The Art and Craft of Storytelling, she writes that as humans evolved they needed a way to teach methods of survival to each other and that is how the use of story as a teaching tool began. She states:

Throughout history, story has honored our past, enlightened our present, and envisioned our future. Our forebears communicated knowledge, accumulated wisdom and commemorated common experience through the magic of words. They created myths and entertained crowds. Story has triggered wars and provided building blocks for peace: it has forecast dangers, vilified enemies and celebrated heroes. And story has also illuminated our common humanity. (Lamb, 2005, p. 5)

Prior to the printing press the only way to share stories was through narrative.

Narrative was a standard in education for centuries. Throughout history most great teachers such as Plato and Homer used stories to help learn skills in ways that made sense to their students. Many educators want to teach the "how" of a new skill set without teaching the "why." Using a story allows you to teach people to think about why and how to use a new skill by blending a teaching story while demonstrating a value to the skill (Simmons, 2006). Learning through example is a great way to teach and stories allow educators to teach through providing examples.

Kieran Egan is a professor in the Faculty of Education at Simon Fraser University in British Columbia that has been writing about the use of stories in education since 1986. He has become known for using an inquiry based teaching method called Storyline Approach and narrative in education (Isabelle, 2007). In 1989 he wrote an article called Memory, Imagination, and Learning: Connected by the Story. In this article, he writes: "Information with high emotional coloring within a story is much more easily remembered by than is a random list." He goes on to say that the story could be that missing link that makes learning meaningful (Egan, 1989). Since that time there have been many researchers 
that have used Egan's theory or adapted it to do their own research. Some of these researchers include: Abrahamson (1998), Daniel (2007), and Isabelle (2007). Each of these researchers conclude that the strategy of storytelling in a classroom can be used to teach many subjects from History to Science and that it is an effective strategy to engage the imagination and interest of the learners (Daniel, 2007).

\section{Effective Use of Storytelling}

There are many efforts ongoing to assess student engagement and learning. The challenge for educators is to determine which pedagogy works best with today's diverse group of undergraduate students who are required to take courses outside of the major and possibility outside of their interest area. According to Bland, Saunders, and Frisch (2007), many professor and teachers continue to rely on age-old instructional strategies, many of which are ineffective and inefficient. Notably, because students and teachers are unique individuals, not all teaching techniques will work for all teachers and learners. There appears to be a need to engage our students in more of a collaborative learning that focuses not only on memorization of facts but also in learning problem solving skills, critical thinking techniques and methods for discussion-based learning. The research shows that student engagement often relates to the methods and personality of the teacher (Bryson \& Hand, 2007), to styles of learning (Rodgers \&Raider-Roth, 2006) and to degrees of participation and indifference. In spite of a complexity of meaning, all of these visions of engagement share awareness to the strength and character of the relationships students have with their learning atmosphere (Saunders, 2011). According to Saunders, "a curriculum for engagement is one which seeks to heighten the energy and interaction within a course, by designing challenging learning opportunities that engage the student in 
learning, while providing a space for the student to become engaged with learning."

Storytelling is an underused medium that can enhance student learning by overcoming literacy barriers that address diversity among the students.

Some people are born storytellers. For some educators the ability to use storytelling in their teaching seems to be a gift. Some educators seem to have the instinct to use narrative in their teaching, while others may consider storytelling to be outside of their teaching style. However, Lamb (2006) states clearly that storytelling is an art that can be mastered. Lamb writes, "Art involves instinct, as well as an appreciation for form and structure. Most of us have that instinct. And if we don't, we can cultivate it." So, if educators can learn the act of storytelling, then it is necessary to investigate what makes a story.

There are a myriad of perspectives and references about the elements of an effective story. There are also many examples in the literature of how to use the elements of storytelling in a classroom. One example of how to construct a story is written in an article by A.K. Daniel (2007) titled, From folktales to algorithms: developing the teacher's role as principal storyteller in the classroom, these basic elements to any story were identified:

1. Who is the story about? (Subject) the character around whom the narrative turns.

2. What do they want to do? (Object) what the subject wants to achieve or acquire

3. Why do they want to do it? (Sender) the person(s) or forces(s) that moves the Subject to seek the Object

4. Who or what will benefit if they succeed? (Receiver) the person(s) or force(s) that aid the Subject's successful quest for the Object.

5. Who or what is trying to help them? (Helper) the person(s) or force(s) that aid the Subject in their quest for the Object.

6. Who or what is working against them? (Opponent) the person(s) or forces(s) that opposes the Subject's completion of their quest for the Object. 
Another example of how to construct a story is written by Kieran Egan (2003)

when explaining how the educator can make a story work for any content of any curricular area, Egan identified the following:

\section{Story Form Framework: Elementary}

1. Identifying importance. What is important about this topic? Why does it matter? What is affectively engaging about it?

2. Finding binary opposites. What binary opposites best express and articulate the importance of the topic?

3. Organizing content in story form. What content most dramatically articulate the binary opposites, in order to provide access to the topic? And what content best articulates the topic into a developing story form?

4. Conclusion. What is the best way to resolve the dramatic conflict inherent in these binary opposites? What degree of mediation of the opposites is it appropriate to seek?

5. Evaluation. How can one know whether the topic has been understood, whether its importance has been grasped, and whether the content was learned?

Egan (2003) states, "We must start with what is most profoundly known by the student and build new knowledge on that basis" (p. 444). This includes not only what they know about the concept that is being studied but also the emotional component that connects the content to the student's daily lives (Isabelle, 2007).

\section{Characteristics of an Effective Storyteller}

Stories are used to replicate experience. They can connect with emotions that change thoughts and beliefs. Stories help us to relive a personal experience that helps facts come alive. Facts are static. A story has life, facts do not. But using facts in a story helps the fact come alive. The facts have more meaning when taught in the form of a story. Annette Simons in her book The Story Factor, states, "When you tell a story you invoke a power that is greater than the sum of the facts you report. It has emotional content and delivers a contextual framework and a wisdom that reaches past logical rational analysis." 
To become a good storyteller, there are certain traits you must master. However, one must remember that it is not possible to make others listen to you. You can entertain, charm, or inspire but you cannot guarantee that you will hold a person's attention. If you want to hold someone's attention, you will be most successful if you are able to influence their attention because you have connected to them by linking to what they are feeling. You can do this by listening to your audience. Watch the response to the listeners and respond accordingly.

There are basic communication skills that a storyteller can learn and enhance. When you are telling a story you become the essence of the story. You do not want to tell a story about bravery in a weak timid voice or a story about humility with a loud boisterous voice. Everything about you, your voice, the way you stand, needs to ring true with the story. If the storyteller voice and body don't react to the tone of the story, then there will be mixed messages. An influential story must represent truth at every level to be convincing (Simmons, 2001).

To become an effective storyteller, you must start with what you already know. There are skills that can be polished, but building on your existing communication skills are the beginning. Humans communicate to each other through language, body language, gestures, facial expressions, and the senses. Listeners interpret meaning from stories based on what they hear, feel, see and sometimes smell. According to Simmons, the words you speak are less than 15 percent of what listeners "hear." Simmons (2001) gives the following 8 areas of advice to help learn storytelling traits: 
1. Use gestures. Gestures can create a picture so that the listeners are seeing the picture rather than your gestures. Gestures need to look and feel natural or they become a distraction.

2. Facial Expressions communicate emotion at a level that is deeper than cultural norms. This means your face gives you a communication tool that will transcend language and cultural barriers. This is a tricky element because if you are feeling an emotion, it may be seen in your face even if you are trying to hide it. If you can't persuade yourself you can't persuade others. Once you can understand the emotional content and know the emotions you want to communicate using facial expressions can replace three or four sentences and speed up your story.

3. Body Language can paint the scenes, characters or objects in the story. You can change characters by changing posture. You can set the scene by allowing your posture to communicate an emotional state. Choose well. Whether you are "in character" or just being you, make sure your body is saying what you want it to. There are no rules on body language, the trick to be authentic.

4. Sounds, Smells, and Tastes. Your goal in telling a story is for your listener to see, hear, smell, feel and taste the elements of your story enough for their imaginations to take them there. Some professional story tellers use sound in their stories. If the story has wind in it, they will often reproduce wind by pursing their lips. You can create a powerful memory of smell and taste by invite the listeners to imagine the smell of fresh baked cookies or bad breath. You can ask them to image biting into a fresh slice of lemon and if you describe it well they start to taste it. The use of smells and tastes help the listener experience the story at a visceral level. 
5. Use irrelevant details. If you use just the facts it excludes the subjective emotional aspects of the human behavior. Just because we cannot draw a linear connection of relevance does not mean that a sensory detail is not connected in a nonlinear way to things we choose. An example of this is thinking about what influences people when they buy a new car. Is it the smell of the leather, the difference in the attitude of the salespeople, or the type of car? All of it can relevant in making the decision.

6. Timing and Pause. Pause and Pacing add meaning to the story. Silence and timing can be as important to the story as verbal language. Giving the listeners the time to process the information or connect emotionally can be very powerful. The timing of silences can be too short or too long. Emotions follow a bell curve. They begin, gradually increase, reach a peak, and then they are gone again.

7. Tone is the most important aspect of your oral communication. It will override every message your gestures, body language or the words your story send. Your tone communicates the emotion of your story. If your tone indicates anger, arrogance, or resentment it causes people to put their defenses. Any negative emotions you have toward your listeners will carry through to the story. Don't work on clearing up your tone, work on your emotions and the tone will correct itself.

8. Authenticity. The most important note is for the storyteller to be authentic. The body, voice and posture will betray the storyteller's true feeling and intentions. Be sure to have any internal conflicts resolved before the story is told. Allow the story to become alive. Do not deliver the perfectly recited story; walk through the story in real time. 


\section{Examples of Effective Storytelling in Education}

There are elements to constructing a story that assist the storyteller to effective in their telling. The story needs to provide the students a structure for idea development and for the retention of the idea. In an article titled Teaching Science Using Stories: The Storyline Approach, Aaron Isabelle describes using stories to teach the science about the concept of air pressure. He gave his each of his students a set of suction cups and divided the students up in groups with the instructions to push the cups together and then discuss what was happening. He then asked the students to write the explanations in two or three sentences or draw a picture to explain their ideas. After they discussed the student's ideas on what was happening, he read them a story he had constructed called, "Under Pressure". He also gave the students a copy of the story to help the visual learners. The story explained an experiment about Otto von Guericke's experiment about using air pressure. He supplemented the story with an overhead projector to display a well know drawing the Magdeburg hemispheres experiment that he included in his story. After the story, the students and the teacher discuss the student's perceptions and the connections of the suction cups to the Magdeburg experiment. The science content in the story helped the students to make scientific ideas and conclusions about the

experiment. After the discussions he had the students reflect on what they had learned by having them write it down. During this lesson Isabelle had the student do a Pre-activity reflection, using the suction cups and a Post-activity reflection asking them to write down what they had learned from the story. This is a good example of using storytelling in a science course.

\section{Student and Teacher Benefits of Storytelling}

Higher Education Institutions are faced with a more complex and diverse student bodies than ever before. Sharing experiences of students and instructors is one way to foster learning for 
students who are enrolled in non- majors courses such as science and health. Using Storytelling as a teaching strategy helps the students think through and reflect on the experiences they encounter. Research significantly supports the use of storytelling to help teachers reconsider the ways that students are learning in their classes. Storytelling helps to engage the students in thinking about their experiences from multiple perceptions. Teachers and students can then reflect on how their experiences, expectations and history affect the overall learning process (Ironside, 2006).

Student benefits from the use of storytelling are prevalent in related literature. One benefit is that it can increase a student's engagement. This can be defined as " the quality of a student's connection or involvement with the endeavor of schooling and hence with the people, activities, goals, values and place that compose it" (Skinner, Kindermann, \& Furrer, 2009, p.494). Another student benefit from storytelling is the increase of quantity and quality of learning. Through the use of stories, knowledge is shared, suggestions are given about skill application, and attitudes essential in professional settings are made evident (Alterio \& McDury, 2004). Storytelling also increases retention of course subject matter. "The complexity and quantity of practice-related terms and new ideas could be overwhelming for students. . . Stories can assist them by placing terminology within a known and understood practice experience or framework so that complex jargon is demystified" (Alterio \& McDury, 2004, p. 75). Another important student benefit from storytelling is self-efficacy. Self-efficacy associated with using the information they learn in their lives and careers is an excellent benefit. As students begin to engage more fully in their own professional worlds, they too will have stories to share. These benefits, and many others, can help students to draw conclusions about a content matter and 
foster their preparedness to teach or use such content. The great thing about storytelling is that it does not only benefit students, it also benefits teachers.

Teacher benefits include having more engaged student as shown by participation in classroom discussions and activities, students having willingness to invest in the learning of difficult material or skills, and showing a comprehension of complex ideas. The storytelling strategy also helps to increase perceptions of teacher effectiveness by assisting the students to understand concepts that allows them to connect the subject matter to their own past experiences. The more the students participate in the classroom experience, the better the outcomes.

\section{Summary}

Emotions and beliefs, regardless of whether they are good or bad experiences, are important in any reflective process. The stronger the emotional connectedness, the more likely it is that stories will be shared. All individuals have the need to share their stories. Through the sharing of stories, opportunities are generated to explore these emotions. The ability to successfully address these emotions will have a substantial impact on the learning outcomes students achieve (Alterio \& McDury, 2004).

Through the sharing of stories, students and teachers have an opportunity to connect their experiences, cultures, and create relationships. The more the students are involved emotionally, socially and academically, the more likely they will be to invest the needed time and energy into learning (Tinto, 1997). 


\section{Chapter 3: Methodology}

The goal of this study focused on assessing the effectiveness of incorporating storytelling into STEAM coursework typically taught using traditional didactic lecture methods. In this study, the author collected and analyzed data that will inform educators and policymakers as they make decisions about using storytelling as a strategy to enhance student outcomes in STEAM courses. Specifically, this study provides evidence regarding the influence of the storytelling strategy on student engagement, retention of content knowledge, readiness to teach the material, and teacher effectiveness. This chapter describes the research methods that were used in this study and that will help establish confidence in the corresponding results.

\section{Participants}

Study participants included Elementary Education and Early Childhood majors attending college in Northern West Virginia. Participants were currently enrolled in a STEAM/health science course required by their major department without respect to personal interest. All participants were asked to participate in the study during their regularly scheduled class period. Informed consent was obtained in writing from each participant and participation were completely voluntary. Participants were given the choice not to participate in the study or leave the study at any time without incurring any penalties. All participant responses were kept confidential.

\section{Setting}

The study was conducted at a health science center in a northern West Virginia college. All phases of the study took place in a traditional classroom environment. 


\section{Research Design}

This study used a component mixed method QUAN-qual design that uses both quantitative and qualitative methods (Morse, 2003). Component designs use both types of data collection methods, but both "data gathering methods [are] implemented as separate aspects of the evaluation and remain distinct throughout" a study (Rallis \& Rossman, 2003). When using this type of design, quantitative methods are dominant in data collection and analysis, while qualitative methods corroborate, elaborate, or expand research findings (Rallis \& Rossman, 2003).

For the quantitative portion of the study, a true experimental design was used. Study participants were randomly assigned to either the treatment or control condition. The treatment condition consisted of participating in an instructional session using the storytelling strategy. The control condition consisted of participating in an instructional session using traditional didactic lecture. A battery of surveys designed to measure student engagement, content knowledge, readiness to teach the subject matter, and teacher effectiveness were administered according to the schedule described in the data collection procedures section below.

There are numerous strengths associated with this type of quantitative repeated measures experimental design. A true experimental design provides clear evidence concerning the effects of an intervention and the best defense against threats to validity and increases the power of a study (Creswell, 2005), while repeated measures designs provide evidence regarding the influence of a treatment or control condition over time.

For the qualitative portion of the study, three semi-structured group interviews were conducted with members of the treatment group. In these group interviews, a semi-structured question guide was used to provide an opportunity for participants to 1) describe their personal 
experiences with the storytelling strategy, 2) elaborate on the value they place on the storytelling strategy, and 3) discuss the findings from the quantitative portion of the study. While recording the interviews, the researcher took handwritten notes describing the setting, the participants and recording their impressions of interview process and key points. Semi-structure group interviews provide a "qualitative description that enhances particular aspects of the study" (Morse, 2003). Moreover, group interviews provide opportunities for solid, comprehensive feedback that offer to expand on the quantitative findings of the study.

\section{Study Procedures}

Students from three STEAM/health science classes composed of Elementary Education and Early Child Development students participated in the study during their regular class times. A university instructor who shares the author's interest in this research question was identified. This instructor agreed to let students be recruited from three of her classes and to allow students to participate in the treatment/control conditions during class time. The topic discussed in both the treatment and control conditions was on hypothermia and cold-related illnesses. The storytelling treatment condition included a thirty-minute lecture on hypothermia and cold-related injury using power-point slides that outlined the course material. During the storytelling treatment students were exposed to three stories that provided examples of hypothermia and cold-related injury. The didactic lecture control condition included a thirty-minute didactic lecture on hypothermia and cold-related injury using the same Power Point slides as an outline that was utilized during the treatment condition. However, during this lecture the students were exposed to three examples not delivered in story form.

In both conditions, scripts were developed in advance and used to deliver the session. The content of these scripts included the elements prescribed in the American Red Cross First 
Aid course related to hypothermia. The stories incorporated into the treatment condition were based on stories previously used to deliver that course material during actual administrations of the course.

Data collection procedures. The following list of procedures were used for the study procedure and data collection.

1) Distribute and collect IRB's three weeks prior to implementation of the study.

2) Assign random numbers and use a random numbers table to assign students to treatment and control groups.

3) One week prior to the treatment portion of the study, had both groups take the content knowledge measure (Appendix B).

4) During the treatment, the participants that were assigned to the control group participated in a hypothermia lesson that used storytelling as its primary strategy. Immediately after the treatment, the treatment group took the student engagement, content knowledge, readiness to teach the subject matter, and teacher effectiveness measures. During the treatment, the control group participated in their normal class session with their assigned instructor.

5) The groups were then switched. The control group then participated in a hypothermia lesson that used traditional didactic lecture as its primary strategy. Immediately after the treatment, the control group took the student engagement, content knowledge, readiness to teach the subject matter, and teacher effectiveness measures

6) Two weeks after the treatment/control condition, both groups took the student engagement, content knowledge, readiness to teach the subject matter, and teacher effectiveness measures 
7) Four weeks after the treatment/control condition, the semi-structured group interviews were held with the storytelling participants. These were conducted in three groups of six to ten students. A trained facilitator, not the study author, conducted these group interviews in order to encourage the most candid discussion possible. The group interviews were recorded and transcribed with both recordings and transcripts being provided to the study author. Additionally, the facilitator took notes during the interview and provided access to those notes to the study author as well.

Additionally, participant surveys and survey responses were kept confidential using participant-generated identification codes that are unknown to the study author. All quantitative data was recorded in a password-protected Excel spreadsheet and stored on a password-protected computer. All surveys were destroyed immediately after data has been entered into the Excel spreadsheet. All qualitative tape recordings were kept under lock and key and were destroyed after the study author had listened to them twice. All transcripts of these recordings will be free of participant names.

\section{Research Variables}

Independent Variable. The variable that was manipulated by the researcher included exposure to the treatment or control conditions. In this study, storytelling was used as the treatment condition, while didactic lecture was used as the control condition.

Dependent Variables. The variables that were observed to assess the effect of the treatment included: 1) student engagement with lesson, 2) student retention of content knowledge, 3) readiness to teach the subject matter, and 4) teacher effectiveness. 


\section{Instruments}

A battery of instruments that were used to measure the study's four dependent variables. This battery of instruments included measures related to: 1) student engagement with lesson, 2) content knowledge, 3) student readiness to teach content knowledge, and 4) students ratings of teacher effectiveness. Additionally, the survey included a section soliciting basic demographic data.

Student engagement with lesson. Student Engagement was measured by using Newman's (1992) definition of academic engagement: the "psychological investment in and effort directed toward learning, understanding, or mastering the knowledge, skills or crafts that academic work is intended to promote" (p.12). Student engagement was measured using an instrument created by Lee, Robinson and Sebastian (2012). Participants indicated the degree to which they were interested in the target class and the topic studied. (Lee, Robinson, Sebastian, 2012). This 6 items scale has a Cronbach's Alpha of .65. Example items include "The topic we studied was interesting and challenging" and "I was bored in this class." Please see Appendix A for the full instrument.

Student Retention of Content Knowledge. Content knowledge was measured using an instrument developed by the American College of Emergency Physicians and the American Academy of Orthopedic Surgeons (2012) to determine an individual's understanding of hypothermia and cold-related emergencies. This measure is used as part of a First Aid certification course that is widely used. Although no studies have been published establishing the reliability of this instrument, this measure is used as the industry standard and has a long history of successful implementation. Its content validity has been firmly established by the sponsoring agency. Please see Appendix B for the full instrument. 
Readiness to Teach Subject Matter. Readiness to teach the subject matter was measured by using the Visser-Wijnvenn, Stes and Petegem Teacher Readiness Scale. This scale was developed to study teachers' motivation and readiness to their teach (2012). This questionnaire consists of 25 questions that assess motivation to teach, personal efficacy, interest and effort. The items were scored on a four point Likert scale (from 'strongly disagree' to 'strongly agree'). Cronbach's Alphas range between 0.74 to 0.90 for the three scales. Example items include "I am absolutely confident that I have a sufficiently good knowledge of the content to teach this course module." Please see Appendix C for the full instrument.

Teacher Effectiveness. Teacher Effectiveness was measured by using the Teacher Confirmation Scale (Ellis, 2000). A 27 item Likert-type instrument, the Teacher Confirmation Scale measures the perceived teacher confirmation in the college classroom. Ellis (2000) defines teacher confirmation, "as the transactional process, by which teachers communicate to students that they are endorsed, recognized and acknowledged as valuable, significant individuals". According to Ellis, "The TCS measures low-inference teacher behaviors across four dimensions: (a) eachers' responses to students' questions-comments, (b) demonstrated interest in students and their learning, c) style of teaching, and (d) absence of disconfirmation" (Ellis, 2004, p. 5). In the initial scale development study, the TCS had a Cronbach's Alpha of .95 (Ellis, 2000). Example questions include "Uses and interactive teaching style" and "Uses a variety of teaching techniques to help students understand course material." Please see Appendix D for the full instrument.

Demographics. Additionally, standard demographic items were used to collected information related to participant gender, age, major, year in college and socioeconomic status. These items will be to control for potential confounding during quantitative data analysis. 


\section{Data Analysis}

Data Analysis methods have been selected based on the research questions.

Quantitative Data Analysis. The approach to quantitative data analysis described below is designed to measure the following research questions:

1) What is the relationship between the storytelling teaching strategy and student perceptions of engagement with the lesson? (Appendix A)

2) What is the relationship between the storytelling teaching strategy and student retention of content knowledge? (Appendix B)

3) What is the relationship between the storytelling teaching strategy and student perceptions of their readiness to teach the corresponding content? (Appendix C)

4) What is the relationship between the storytelling teaching strategy and student ratings of teacher effectiveness? (Appendix D)

Primary data analysis focused on using Repeated Measures of Analysis of Variance. This statistical procedure was used to examine differences between groups over time. These results indicate whether or not there is a significant variance in the pattern of change between the group means at different time points. SPSS was used to analyze the data.

Effect size was calculated using partial eta squared which described the strength of the treatments effect on the targeted variables. Effects size estimates were interpreted using traditional ranges (Cohen, 1988). These include small effects/weak relationships (.01), medium effects/moderate relationships (.06), and large effects/strong relationships (.14).

Every variable that shows a significant difference in the treatment by time effect, a follow-up data analysis were used to explore the reasons for differences between the two groups. The data was used to construct line graphs to see the patterns of change for each group. These 
graphs demonstrate whether or not changes in each variable parallel with their assignment to the treatment or control groups.

Next, one-tailed Dependent Samples t-tests were used to examine within group pre- and posttest variances. These tests provide confirmation of the difference between treatment and control groups. These strategies showed whether or not changes occurred as expected.

Qualitative Data Analysis. Semi-structured group interviews were used to allow participants to describe the experience with the storytelling strategy and explain the influence of the treatment had on their engagement, retention of knowledge, readiness to teach the material, and teacher effectiveness.

Qualitative data was analyzed using Hatch's Interpretive Analysis Model (2002). Hatch (2002) described interpretive analysis as a process in which the researcher gives meaning to qualitative data by actively "making inferences, developing insights, drawing conclusions, and extrapolating lessons." Hatch (2002) encourages using interpretive methods to illuminate an otherwise established phenomenon.

Steps used to conduct the qualitative analysis included: 1) Listening to and reading the transcripts from each group interview while attempting to gain a big picture sense of participant comments and recording broad impressions in researcher's notes; 2) Re-listening to and rereading each group interview while making notes and recording observations, 3) Hand coding transcripts from each group interview and developing corresponding theme statements; 4) Studying theme statements and notes for salient interpretations; 4) Reviewing researcher notes, transcripts, and theme statements while looking for places where interpretations were supported or challenged; 5) Writing a draft summary of the participant themes including quotes. Researcher notes were also used when interpreting the qualitative data analyzed in this study. 


\section{Summary}

This chapter described the methods associated with the study including the research design, variables, instruments, settings, procedures, data collection, and data analysis. These methods were used to conduct this study and collect evidence related to the value of using the storytelling strategy to teach STEAM content to non-STEAM majors. Each of the methods selected for this study have been firmly established in the research literature and are appropriate for investigating the study's research questions. 


\section{Chapter 4: Results}

This study examined the efficacy of storytelling as a strategy designed to help nonSTEAM/non-health science students become more engaged in their required STEAM/health science learning experiences. Data collected during the study are presented in this chapter. These data describe students' experience with using storytelling strategies to help students: 1) engage students in STEAM/health science coursework, 2) retain the content knowledge presented in class, 3) feel more prepared to teach future health science courses, and 4) report greater satisfaction with the course instructor.

\section{Participant Demographics}

Participants were recruited from students who were enrolled STEAM/health science courses required by their department without respect to personal interest. They were students enrolled in courses for Elementary Education and Early Childhood majors attending college in Northern West Virginia. A presentation describing the study was made to students in three courses of a university instructor who shared an interest in the author's research questions. To participate in the study, students were required to return a copy of the IRB-approved informed consent. A total of 47 students completed the form and participated in the study. Two students (4.3\%) described themselves as African American/Black, one (2.1\%) as Hispanic, forty-three $(91.5 \%)$ as White/Caucasian, and one (2.1\%) as Bi-racial/multi-racial. Thirty-six (76.6\%) reported being female and eleven (23.4\%) reported being male. Twenty-six students (55.3\%) are Elementary Education majors, two (4.3\%) are Early Childhood Development majors, fourteen (29.8\%) are Physical and Health Education majors and four (8.5\%) described themselves as other majors. 


\section{Quantitative Research Question 1: What is the relationship between the storytelling} teaching strategy and student perceptions of engagement with the lesson?

Results related to Quantitative Research Question 1 were based on participant responses to Lee, Robinson and Sebastian's Student Engagement Scale (2012) found in Appendix A and their random assignment to the treatment or control condition. The treatment group means immediately following participation in the storytelling treatment were $22.00(S D=1.91)$ and $21.91(S D=2.76)$ two weeks after exposure to the treatment. The control group means immediately following participation in the traditional lecture control treatment were 19.13 $(S D=3.70)$ and $18.46(S D=3.44)$ two weeks after exposure to the control treatment. Repeated Measures Analysis of Variance supported significant differences in student perceptions of engagement based on assignment to the treatment group $(p=.00, F=14.41, d f=1)$. The effect size estimate $\left(\eta^{2}=.24\right)$ suggested a strong association between storytelling and student perceptions of engagement with the lesson. No evidence supported a difference in how student perceptions of engagement with the lesson changed two weeks after participating in the lesson $(p=.85, t=.19$, $d f=22$ ). Line graphs depicted patterns for each group as hypothesized. (Figure 1).

Figure 1. Comparison of treatment and control group means for student perceptions of engagement.

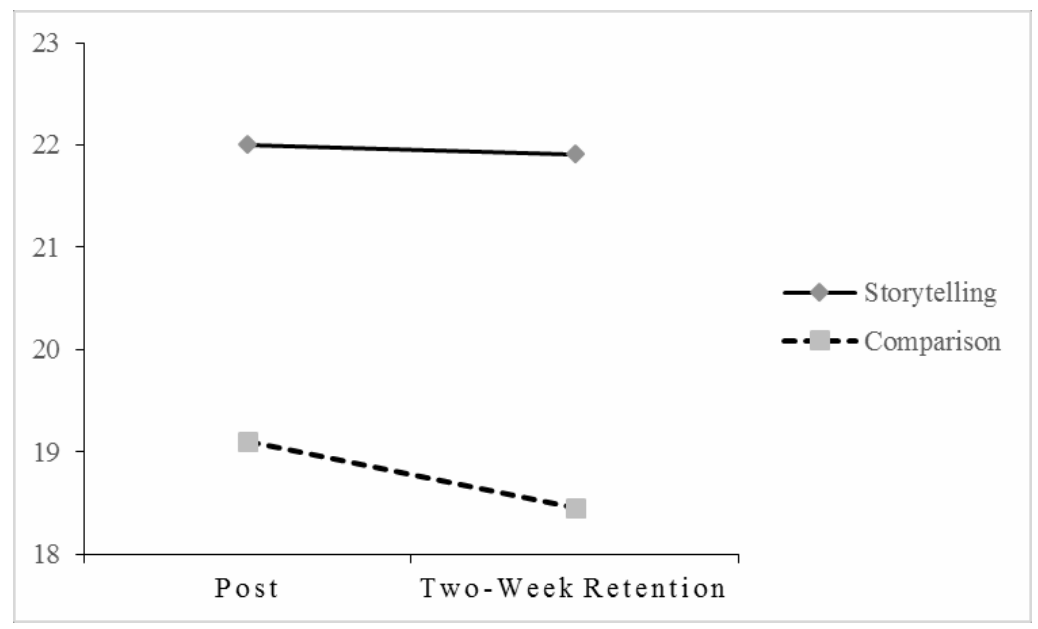




\section{Quantitative Research Question 2: What is the relationship between the storytelling teaching strategy and student retention of content knowledge?}

Results related to Quantitative Research Question 2 were based on participant responses to American College of Emergency Physicians and the American Academy of Orthopedic Surgeons' assessment of student content knowledge related to hypothermia (2012) found in Appendix B and their random assignment to the treatment or control condition. The treatment group means prior to exposure to the storytelling strategy were $8.34(S D=1.94)$, immediately following participation in the storytelling treatment it was $11.87(S D=2.09)$ and $11.30(S D=1.86)$ two weeks after exposure to the treatment. The control group means prior to exposure to the comparison treatment were $8.75(S D=1.98)$, immediately following participation in the traditional lecture control treatment was $9.95(S D=1.36)$ and $9.00(S D=1.69)$ two weeks after exposure to the control treatment. Repeated Measures Analysis of Variance supported significant differences in student retention of content knowledge based on assignment to the treatment group $(p=.01, F=6.65, d f=1)$. The effect size estimate $\left(\eta^{2}=.13\right)$ suggested a relatively large association between storytelling and student retention of content knowledge. Additionally, evidence supported a difference in student retention of content knowledge between the mean pretest score and the mean score two weeks after participating in the treatment $(p=.00, t=-10.39$, $d f=22$ ). There was limited evidence of a statistical difference between the post-test and two weeks after participation in the treatment $(p=.06, t=1.97, d f=22)$. Line graphs depicted patterns for each group as hypothesized (Figure 2). 
Figure 2. Comparison of treatment and control group means for student retention of content knowledge.

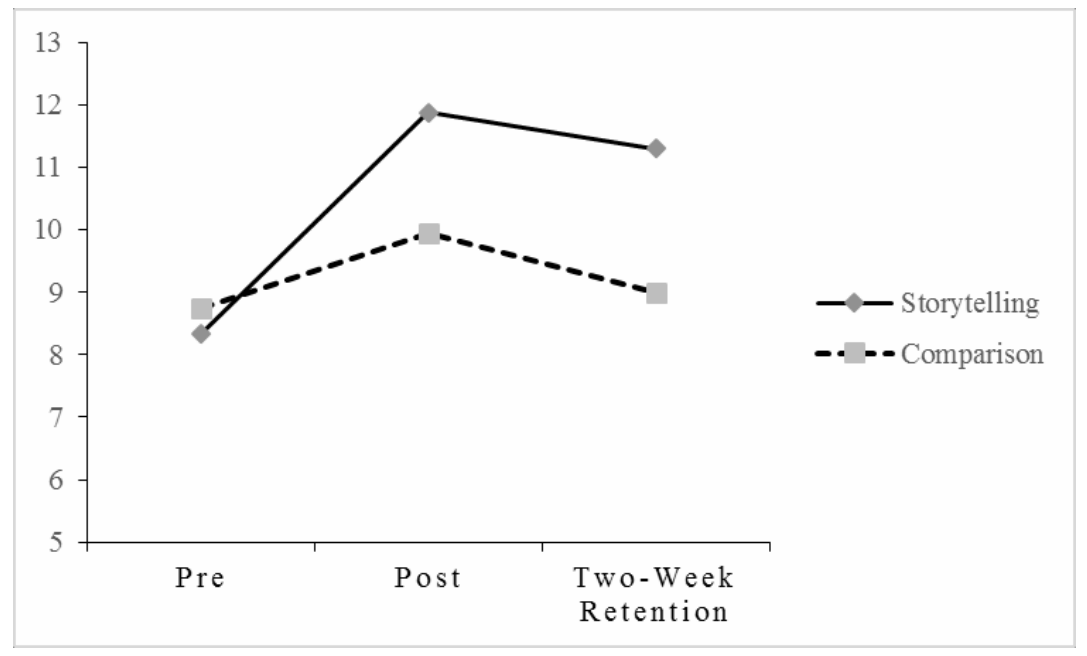

Quantitative Research Question 3: What is the relationship between the storytelling teaching strategy and student perceptions of their readiness to teach the corresponding content?

Results related to Quantitative Research Question 3 were based on participant responses to Visser-Wijnvenn, Stes and Petegem Teacher Readiness Scale (2012) found in Appendix C and their random assignment to the treatment or control condition. The treatment group means immediately following participation in the storytelling treatment were $94.96(S D=9.47)$ and 95.65 ( $S D=10.78)$ two weeks after exposure to the treatment. The control group means immediately following participation in the traditional lecture control treatment were 97.52 $(S D=9.72)$ and $99.35(S D=10.90)$ two weeks after exposure to the control treatment. Repeated Measures Analysis of Variance did not support significant differences in student perceptions of their readiness to teach the corresponding content based on assignment to the treatment group $(p=.28, F=1.19, d f=1)$. The effect size estimate $\left(\eta^{2}=.03\right)$ suggested no association or a small association between storytelling and student perceptions of their readiness to teach the 
corresponding content. Further, no evidence supported a difference in how student perceptions of their readiness to teach the corresponding content changed two weeks after participating in the lesson ( $p=.67, t=-.43, d f=22)$. Line graphs depicted patterns for each group as hypothesized (Figure 3).

Figure 3. Comparison of treatment and control group means for student perceptions of their readiness to teach.

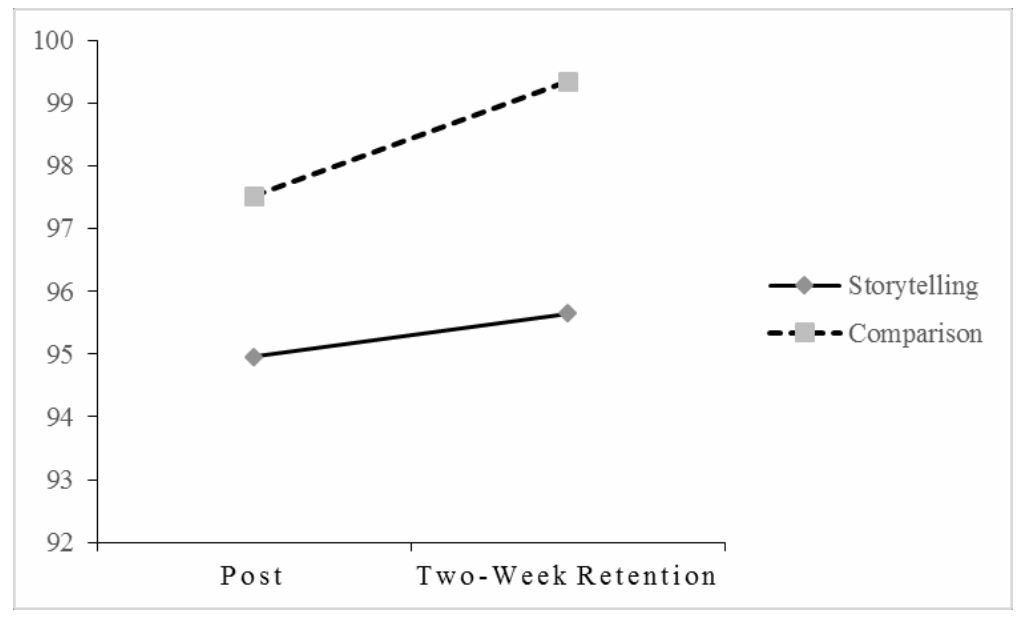

\section{Quantitative Research Question 4: What is the relationship between the storytelling} teaching strategy and student ratings of teacher effectiveness?

Results related to Quantitative Research Question 4 were based on participant responses to Ellis' Teacher Confirmation Scale (2000) found in Appendix D and their random assignment to the treatment or control condition. Student ratings of teacher effectiveness were measured using the instruments' traditional four subscales. These subscales included 1) Responding to Questions, 2) Demonstrating Interest, 3) Teaching Style, and 4) Absence of Disconfirmation. The results of each subscale are presented below.

Responding to Questions. The treatment group mean immediately following participation in the storytelling treatment was $21.04(S D=3.37)$ and $20.65(S D=4.00)$ two weeks 
after exposure to the treatment. The control group mean immediately following participation in the traditional lecture control treatment was $21.65(S D=2.49)$ and $20.56(S D=3.24)$ two weeks after exposure to the control treatment. Repeated Measures Analysis of Variance did not support significant differences in student perceptions of teacher effectiveness related to responding to questions based on assignment to the treatment group $(p=.77, F=.09, d f=1)$. The effect size estimate $\left(\eta^{2}=.00\right)$ suggested no association between storytelling and student perceptions of teacher effectiveness related to responding to questions. No evidence supported a difference in how student perceptions of teacher effectiveness related to responding to questions changed two weeks after participating in the lesson $(p=.54, t=.62, d f=22)$. Line graphs depicted patterns for each group as hypothesized (Figure 4).

Figure 4. Comparison of treatment and control group means for student ratings of teacher effectiveness - Responding to questions.

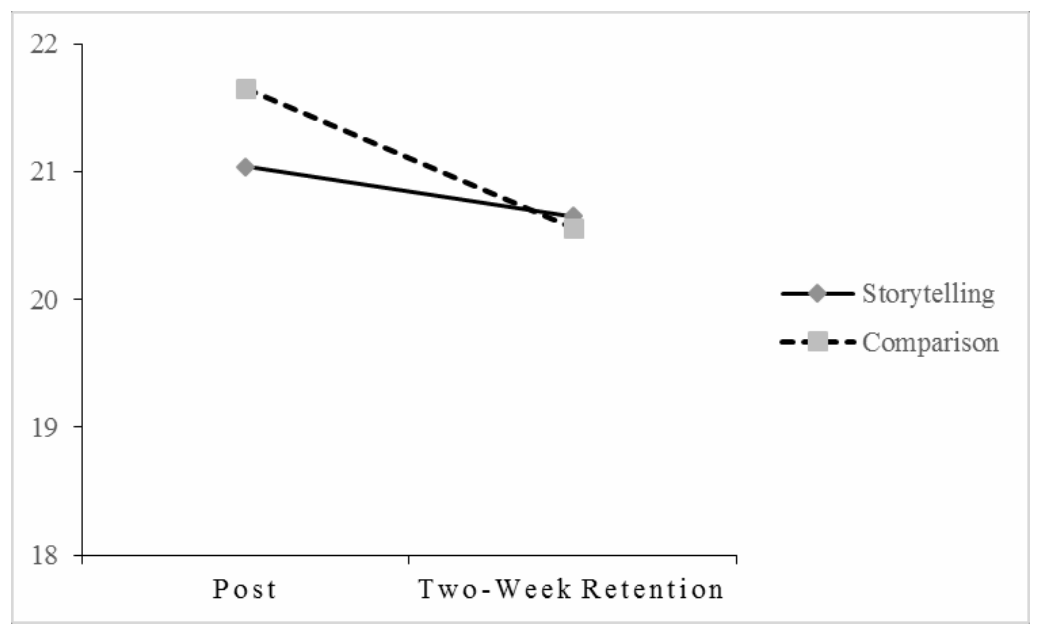

Demonstrating Interest. The treatment group means immediately following participation in the storytelling treatment were $26.61(S D=2.67)$ and $26.17(S D=2.91)$ two weeks after exposure to the treatment. The control group means immediately following participation in the traditional lecture control treatment were $23.08(S D=2.90)$ and $23.13(S D=2.93)$ two weeks 
after exposure to the control treatment. Repeated Measures Analysis of Variance supported significant differences in student perceptions of teacher effectiveness related to demonstrating interest based on assignment to the treatment group $(p=.00, F=18.21, d f=1)$. The effect size estimate $\left(\eta^{2}=.29\right)$ suggested a strong association between storytelling and student perceptions of teacher effectiveness related to demonstrating interest. No evidence supported a difference in how student perceptions of teacher effectiveness related to demonstrating interest changed two weeks after participating in the lesson $(p=.28, t=1.11, d f=22)$. Line graphs depicted patterns for each group as hypothesized (Figure 5).

Figure 5. Comparison of treatment and control group means for student ratings of teacher effectiveness - Demonstrating interest.

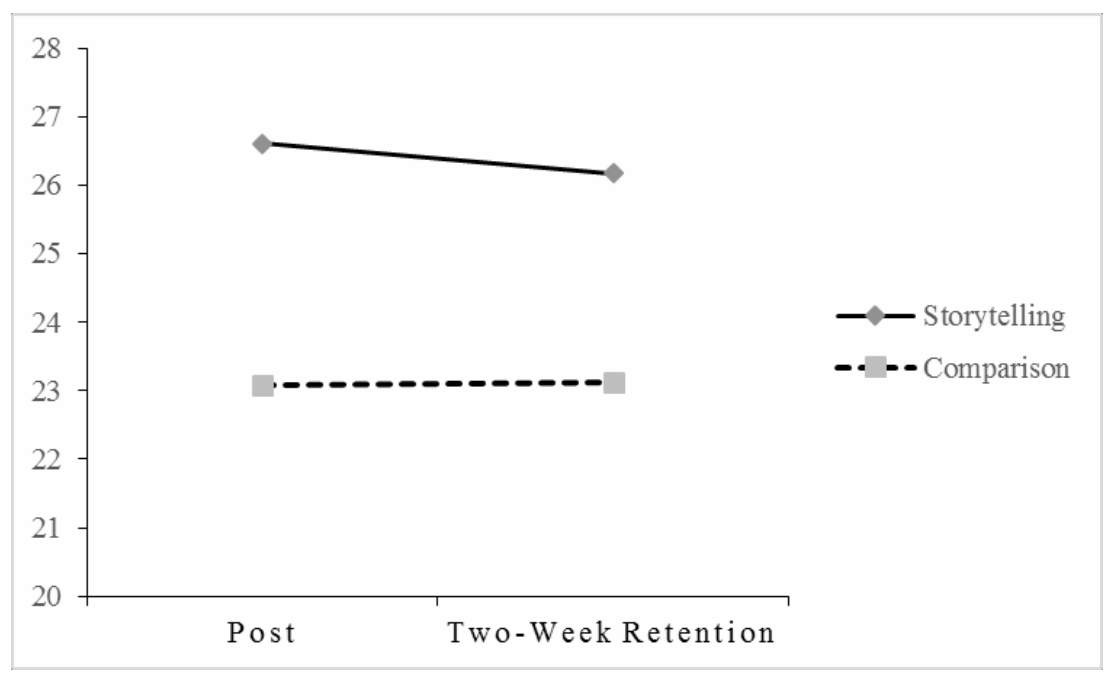

Teaching Style. The treatment group mean immediately following participation in the storytelling treatment was $17.87(S D=3.29)$ and $18.69(S D=4.21)$ two weeks after exposure to the treatment. The control group mean immediately following participation in the traditional lecture control treatment was $18.73(S D=4.13)$ and $19.87(S D=4.99)$ two weeks after exposure to the control treatment. Repeated Measures Analysis of Variance did not support significant 
differences in student perceptions of teacher effectiveness related to teaching style based on assignment to the treatment group $(p=.34, F=.93, d f=1)$. The effect size estimate $\left(\eta^{2}=.02\right)$ suggested no association or a small association between storytelling and student perceptions of teacher effectiveness related to teaching style. No evidence supported a difference in how student perceptions of teacher effectiveness related to teaching style with the lesson changed two weeks after participating in the lesson $(p=.40, t=-.87, d f=22)$. Line graphs depicted patterns for each group as hypothesized (Figure 6).

Figure 6. Comparison of treatment and control group means for student ratings of teacher effectiveness - Teaching style.

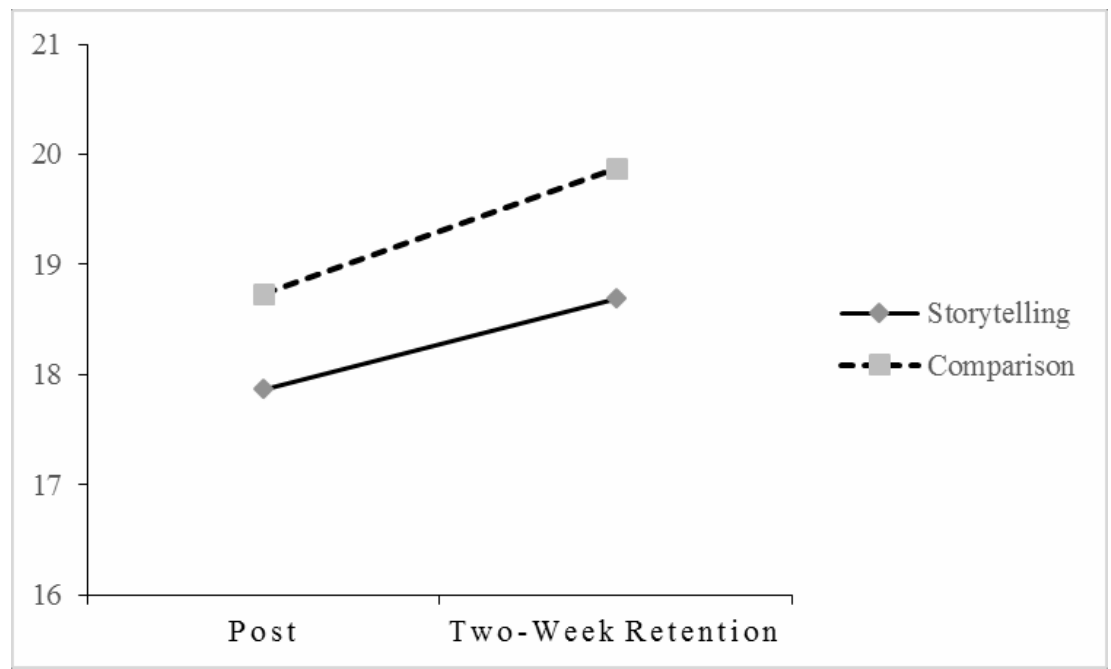

Absence of Disconfirmation. The treatment group means immediately following participation in the storytelling treatment were $51.00(S D=7.51)$ and $51.39(S D=6.11)$ two weeks after exposure to the treatment. The control group means immediately following participation in the traditional lecture control treatment were $49.78(S D=6.10)$ and $49.83(S D=6.97)$ two weeks after exposure to the control treatment. Repeated Measures Analysis of Variance did not support significant differences in student perceptions of engagement based on assignment to the treatment group $(p=.47, F=.53, d f=1)$. The effect size estimate $\left(\eta^{2}=.01\right)$ suggested no 
association or a small association between storytelling and the absence of disconfirmation with the lesson. The evidence did not support a difference in the absence of disconfirmation two weeks after participating in the lesson $(p=.64, t=-.48, d f=22)$. Line graphs depicted patterns for each group as hypothesized (Figure 7).

Figure 7. Comparison of treatment and control group means for student ratings of teacher effectiveness - Absence of disconfirmation.

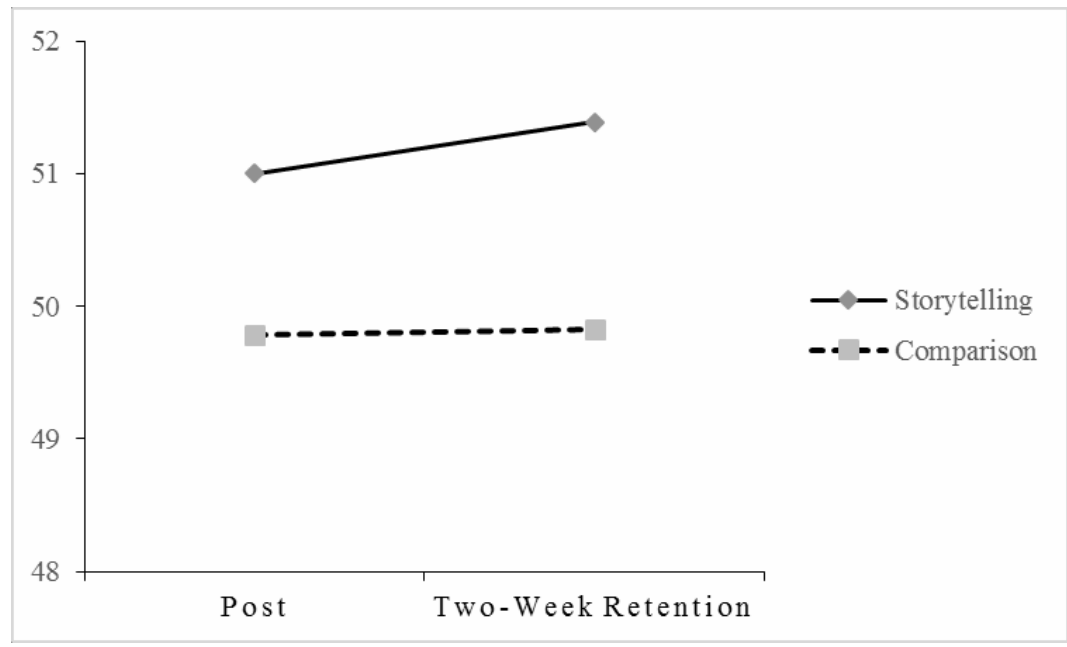

Qualitative Research Question: How do Early Childhood Development and Elementary Education majors in a required STEAM/health science course perceive the value of storytelling as strategy designed to enhance student engagement?

Three themes clearly emerged from the qualitative data that supported the quantitative findings in Research Questions 1,2, and 4. The three main themes that were prevalent and common included - increased student engagement, increased student retention of content knowledge, and teacher effectiveness. Qualitative findings related to the observations of using storytelling as a teaching strategy consistently supported the quantitative findings. Additionally, 
the role of emotion emerged as another theme related to the effectiveness of the storytelling strategy. Each of these themes is presented in detail below.

Student Engagement. Participants consistently described an increase in their connectedness and interest in the academic content. For some time, storytelling has been used as a pedagogical tool that personalizes the content and helps keep the students focused (Davidson, 2003). The research shows that the more students are involved in a shared learning experience, the more likely they will become involved in their own learning and invest themselves into the process. People remember stories if they are well told and focus on ideas the listener can become involved in the experience (Schank \&Berman, 2006; Tinto, 1997;). Some examples of participant comments included:

- "Because she made the story so good and I was just listening really intently, like scared but listening."

- "I think I was definitely engaged in what she was saying"

- "She described it better than I can imagine."

- "She told us facts in a different way."

- "Sometimes teachers get off track. It just depends how good the teacher is at keeping the story in the content they want it to be. I know I have seen teachers get completely off track and talked about something else then it wouldn't have been as effective but, I just feel like she had a set goal of what she wanted us to remember so kept on that path. She was good at keeping on that path but if she hadn't been then it would have went a lot differently."

The comments above and other like them suggest that storytelling helps the student connect to the subject matter. The students described the storytelling experience as one that not only held 
their attention, but assisted them in remembering the material. According to Isabelle (2007), "Listening to a story involves imagination, activation of prior experiences, knowledge and imagery." This assists the students in retention of the concept.

Teacher Effectiveness. There have been many research studies done that show student engagement often relates to the methods and personality of the teacher. When the teacher is telling a story it must represent truth to be convincing. Haigh and Hardy (2011) define story as "reflective, creative and value laden, usually revealing something important about the human condition." If teachers want to transform classroom experiences into real-life experiences, "they need to be real, authentic human beings" (Uhl, 2010). The following comments are examples of how the student's viewed the storyteller's effectiveness.

I think the thing that made it more memorable for me was that she didn't just explain something. You could tell she was passionate about what she was talking about and knew all about it. . I I always relate better to stories when they are told. That's how I relate to things is through stories.

I feel like her stories were like, she stayed real about it. She kind of threw in a little humor in her voice. So it made you like kind of pay attention more. And she made it exciting so we were like waiting to hear what's going to happen. And then she would talk about the consequences in a passionate way.

She was excited about it, she made it sound important.

Her voice, you could tell she was interested in teaching I and that kind of made me want to listen to her.

Humans are drawn to other humans by the ability to communicate through gestures, language, body language, expressions and the senses. Using humor is also a powerful tool. Telling stories 
to enhance learning is a very effective teaching technique that can be learned and enhanced. Bullough (2010) explores using parables (stories) in enhancing teacher education as a means for exploring the beliefs and ethical commitments of teachers as well as creating theories about teaching and learning.

Student retention of content knowledge. We know from Kolb's theory of experiential learning that students can learn if they can connect similar experiences between themselves and the material. Also, the Constructivist Theory that is primarily based on Piagetian ideas says that through interaction with the environment comes an understanding and adaptation to it (Walls, pg.284). If the learner can make a connection to the material being taught, they are more likely to retain the content.

For me, hearing about actual people made it more real, rather than just reading words on a page. Like I could picture the mom and the child. I could picture the woman hiding in a cave and putting her feet in the sunlight. Like I could picture actual human people rather than just reading something off a slide. So I don't know, I think in that sense, it made it more memorable.

A lot of what I remember is from the stories. Like there's a few facts that I kind of remember but a lot of it came from the stories.

I like real life experiences and storytelling because it's like it can happen to someone or it has happened to someone. So it's relating back to real life because it's like you should remember that because of that could be a situation you are put in.

When you hear a story you like imagine stuff within a minute and see images and it's more visual than just reading from a book or lecture. 
The use of stories to connect the student's understanding of the material allows the students to make meaningful interpretations of the information. They can then make reflections and connect similar experiences. John Dewey wrote in How We Think (1910) "Instruction in subject-matter that does not fit into any problem already stirring in the student's own experience, or that is presented in such a way as to arouse a problem, is worse than useless for intellectual purposes"(p. 199).

Role of emotion in storytelling. When students can make a connection to a story and reflect upon it, they often make an emotional connection to the material. This connection helps the students incorporate the new experience into an emotional meaning that helps them to retain the information. People tell stories in an effort make sense of the world and harmonize themselves with reality (Flowers, 1988).

Emotion and Teacher Effectiveness. Kieran Egan, (1989) and Hayward, Gillam \& Lien (2007) state that because stories have emotional components and because emotional content is more easily remembered, storytelling has an impact on retention of content knowledge. Using the process of reflection helps us to make connections between past, present and future events. This allows the teacher to connect their own perspectives and understandings to the material. (Coulter, Michael and Poynor, 2007) Some examples of this are listed below:

Same thing with her emotions. Like if you watched her face and like listened to the way she talked about it, like it made me want to keep listening to see what was going to happen.

So I think just having that initial thing of like yeah what I'm teaching is important and I want you to pay attention really helped out a lot. 
When teachers share their stories and add the components of consciousness and awareness to the issues, the students may become more engaged in the material. Stories are not only used for people to make sense of things around them, but they can also be used to facilitate social change. Stories can instill hope and help us to convey information. (Uhl, 2010).

Emotion and Content Retention. Storytelling is the oldest documented method of education and communication. Sharing stories is a way human beings connect to each other's life experiences and share valuable learning. Storytelling is a particularly promising strategy to increase content retention because of its ability to increase the relevance of emotions in our memory. It is also a documented form of helping students to remember content knowledge as evidenced by the following comments:

Spark some kind of emotion. Like have an emotional connection between the story and the student. ... I am going to be completely honest, aside from the stories I don't remember much from the like power point. A lot of that I remember is from the stories.

Emotions and beliefs regardless of whether they are good or bad experiences, are important in any reflective process. According to Yoder-Wise and Kowalski in The Power of Storytelling (2003), the goal of using storytelling in education is to connect information to the listeners in a meaningful and purposeful way. Stories allow educators to take information and put it in a format that paints a mental picture for the listeners that includes feelings and actions and makes it memorable so the listeners can incorporate the lessons into their own lives (Yoder-Wise \& Kowalski, 2003). 


\section{Summary}

This chapter presents findings related to storytelling as an instructional. Quantitative findings suggested that students who were assigned to the storytelling condition were more likely to report higher levels of student engagement, content retention, and ratings of teacher effectiveness associated with perceived teacher interest and enthusiasm for the subject. Quantitative findings did not support the storytelling strategy as contributing to an increase in student perceptions of their readiness to teach the content or an increase in teacher effectiveness related to responding to questions, teaching style, or absence of disconfirmation. Additionally, qualitative findings confirm the quantitative results and suggest that emotion may play an important role in the effective use of the storytelling strategy. Chapter 5 will summarize the activities associated with this study, discuss the implications of this study, and offer recommendations for future research and practice. 


\section{Chapter 5: Summary, conclusions, and recommendations}

This study examined the relationship between exposure to an educational storytelling strategy and levels of student engagement and learning among non-STEM/STEAM majors participating in STEM/STEAM courses required by their programs of study. The study was guided by four core quantitative research questions that included:

1) What is the relationship between the storytelling strategy and student perceptions of engagement with the lesson?

2) What is the relationship between the storytelling strategy and student retention of content knowledge?

3) What is the relationship between the storytelling teaching strategy and student perceptions of their readiness to teach the corresponding content?

4) What is the relationship between the storytelling teaching strategy and student ratings of teacher effectiveness?

Additionally, the study used qualitative strategies in a supportive role to provide a member check of the study's quantitative findings. This qualitative question was:

1) How do Early Childhood Development and Elementary Education majors in a required STEAM/health science course perceived the value of storytelling as a strategy designed to enhance student engagement?

In order to answer these questions, this study used a component mixed method QUAN-qual design that employed both quantitative and qualitative methods (Morse, 2003). Component designs use both types of data collection methods, but both "data gathering methods [are] implemented as separate aspects of the evaluation and remain distinct throughout a study," (Rallis \& Rossman, 2003, p147). When using a QUAN-qual design, the quantitative methods 
are dominant in data collection and analysis, while qualitative methods corroborate, elaborate, or expand research findings (Rallis \& Rossman, 2003).

The quantitative method was the dominant method of inquiry and employed a Repeated Measures, true experimental design. There are numerous strengths associated with this type of quantitative design. A true experimental design provides the clearest evidence concerning the effects of an intervention, the best defense against threats to validity, and increases the power of a study (Creswell, 2005). Study participants were randomly assigned to either the treatment or control condition. The treatment condition consisted of participating in an instructional session using the storytelling strategy. The control condition consisted of participating in an instructional session using traditional didactic lecture. A battery of surveys designed to measure student engagement, content knowledge, readiness to teach the subject matter, and teacher effectiveness were administered according to the schedule described in the data collection procedures section.

Repeated measures designs provide evidence regarding the influence of a treatment or control condition over time. In the present study, data was collected immediately before and after the intervention or control condition and again two weeks later. Repeated Measures ANOVA was used to examine the impact of the intervention on the participants assigned to the treatment condition as compared to participants assigned to the control condition. One-tailed Dependent Samples t-tests were used to determine differences from baseline over time when the Repeated Measures ANOVA indicated a difference between groups over time.

Qualitative methods were used in a supportive role to cross-validate the quantitative findings. In this portion of the study, three semi-structured group interviews were conducted with the treatment group participants. In these group interviews, the participants were asked to: 
1) Describe their personal experiences with the storytelling strategy,

2) Elaborate on the value they place on the storytelling strategy, and

3) Discuss the findings from the quantitative portion of the study. 


\section{Discussion}

\section{Student Perceptions of Engagement}

Results of the present study suggest that students who participated in the storytelling condition demonstrated higher levels of student perception of engagement than did the comparison group. This finding is consistent with the Bryson and Hand (2007) study which determined that one way to enhance student engagement by using more active practices in the classroom. Further, Kolb's (1984) theory of Experiential Learning supports the finding that the storytelling experience for students is linked to deeper engagement and learning. Kolb (1984) states that learning occurs in four stages: Concrete Experience, Reflective Observation, Abstract Conceptualization, and Active Experimentation. A well told, detailed story can act as the Concrete Experience for students who otherwise would not connect to the experience. Boud, Cohen and Walker (1993) in their book titled Using Experience for Learning, support the idea that a learner can have either a direct or symbolic experience, thus a story acts as a symbolic experience. Boud, Cohen, and Walker (1993) believe that educators often focus on the body of knowledge to be taught and learned, but do not recognize the role and relevance of learning from experience. Educators who create fewer experiences for students, may have less engaged classrooms.

Additionally, Alterio and McDrury (2004) argue that the reflective observation stage of Kolb's theory can be the most difficult for students unless there is some type of experience that connects the student to the content which is also consistent with the finding that storytelling was associated with greater student engagement. If educators can provide an experience with something that is outside the learner's knowledge, then meaning can be created. Storytelling and story analysis can facilitate a type of reflection that is often difficult to do for learners (Mattingly, 1991). Storytelling is one technique that can be used to engage the experience of the 
learner. Results from this study support the theory that story telling can be a useful learning tool by allowing the students to connect to the experiences of others and through these connections construct new knowledge. This is important because a recent study found that one of the main reasons students in introductory science courses switch majors is due to the lack of engagement in those courses (Gasiewski, et al., 2011).

\section{Student Retention of Content Knowledge}

Storytelling represents a particularly promising strategy for engaging students in STEAM classes and increasing their content knowledge. Results indicated the retention of content knowledge of the treatment group was moderately higher than the comparison group. Notably, the retention of content knowledge remained higher over time for the treatment group. Many research studies support the idea that storytelling greatly enhances student learning (Corso, Bundick, Quglia, \& Haywood, 2013; Gramwell, 2005; Tinto, 1997). Further, the literature suggests that adding the arts to STEM classes' benefits students by helping them develop the imagination and creativity required to be truly inventive in their fields (White, 2011; Yakman, 2010). By incorporating storytelling into their teaching, educators can inspire students' imagination and ingenuity in a manner that helps them engage more deeply in the subject matter. According to Eagan (1986) and Isabelle (2007), stories may help connect students to real life experiences and listening to stories may excite their imaginations. Because effective stories are emotionally engaging, the lessons associated with those stories may make them more captivating and memorable (Eagan, 1989; Hayward, Gillam \& Lien, 2007).

Both the qualitative and quantitative results supported the hypothesis that, even over time, students' content knowledge would remain higher for the students who received the storytelling treatment. Students stated the stories helped them to visualize the material and also 
that they were able to remember the material because they had an emotional connection to the stories. This finding echoes Shank's (2006) study which concluded that when a story creates visual images, the listeners can reflect on the images provided by the storyteller to help them understand the concepts. Evidence from the current study seems to suggest that storytelling may have a positive impact on content knowledge and retention of such knowledge over time.

\section{Student Perceptions of Readiness to Teach}

Existing research has indicated that teachers are often motivated to teach based on SelfEfficacy, interest, and their expected results (Bandura, 1994; Visser-Wijnveen, Stes, \& Petegem, 2012). Based on this literature, the present study hypothesized that, when storytelling was rolemodeled as an instructional strategy, students would be more interested in the material and thus have more self-efficacy and motivation to teach similar content. However, research results did not support significant differences in student perceptions of their readiness to teach content based on assignment to the treatment or control condition. The effect size estimate suggested no association between storytelling and student perceptions of their readiness to teach the similar content. Further, no evidence supported a difference in how student perceptions of their readiness to teach similar content changed two weeks after participating in the lesson. Some circumstances of the present study design may have impacted the findings in this way. For example, students were only exposed to the content on one occasion. If the students in the treatment group had been exposed to the content using the storytelling strategy on multiple occasions, the findings may have indicated a significant change in student perceptions of their readiness to teach. Additionally, the instrument we used to measure this construct (The Teacher Preparedness Instrument and Teacher Readiness Scale, Visser-Wijeen, et al., 2012) included questions about how the students felt about their teaching skills. Many students in the study had 
not yet had any formal teaching experience, making the questions not applicable. This was not considered in the original study design, but should be considered in future exploration of this hypothesis. Teachers need to have expertise in content, but they also need to have the pedagogical skills to facilitate learning (Corso, Bundick, Qualia, \& Haywood, 2013). It is possible that the pre-service teachers in this study would not feel prepared to use storytelling as a teaching strategy after having one experience with this instructional strategy, nor would they have gained enough expertise in the content area. This may explain the finding counter to our hypothesis and existing literature.

\section{Student Ratings of Teacher Effectiveness}

The present study hypothesized that student ratings of teacher effectiveness would be higher for those who experienced the storytelling treatment and would remain high over time. Student ratings of teacher effectiveness were measured using four subscales. These subscales included 1) Responding to Questions, 2) Demonstrating Interest, 3) Teaching Style, and 4) Absence of Disconfirmation. Findings support a significant difference in demonstrating interest between the treatment and control groups. The evidence suggested a strong association between storytelling and student perceptions of teacher effectiveness related to demonstrating interest. Although teacher effectiveness was not significantly different across all four subscales, the finding of significant difference in demonstrating interest between the two treatment groups is important. Teacher enthusiasm, or demonstrated interest, is critical to student engagement and learning (Bryson \& Hand, 2007). Qualitative data support this finding. Student comments indicated that the instructor was more effective as a teacher because the use of emotions in her stories and the detailed, honest, and truthful experiences demonstrated the instructor's excitement for teaching the content. 


\section{Conclusions}

There are many definitions and conceptualizations of the act of storytelling, but common elements include feelings, images, creativity, words, sounds, values, facts, and a connection to human experiences (Haigh \& Hardy, 2011). Stories have been told for centuries and have been a key component in education since the beginning of time. Generations of cultures have used stories to communicate their knowledge and personal experiences even before the development of written language. Storytelling is a strategy that is still used for teaching and learning (Schwartz \& Abbott, 2006).

Results from this study suggest that the storytelling strategy can be used to effectively increase a student's retention of content knowledge, increase the student's perception of engagement, and increase the student's perception of teacher effectiveness. Storytelling can help students to experience learning in new ways and, often, encourages better understanding and comprehension (Davidson, 2003).

In terms of theory, in Kolb's Theory of Experiential Learning (1984) there are four stages viewed as a part of the learning cycle. a) concrete experience b) reflective observation c) abstract conceptualization d) active experimentation. This process involves learning through reflection of everyday experiences and making sense of concrete experiences. Kolb (1987) stated that experiential learning involves a direct encounter with the subject matter. This theory encourages more effective pedagogical approaches for teachers. Teaching with storytelling allows students to activate their prior knowledge of the subject matter and make emotional connections to the course materials being taught.

The more students are involved in the learning process and experiences by participating in educationally purposeful activities, the more likely they will be involved in their own learning 
and will invest more time to learn (Kuhl, 2001; Tinto, Goodsell \&Russo, 1993; Tinto, 1997). The more the students hear stories in the classroom, the more enhanced their view of the world becomes (Koki, 1998; Zabel, 1991).

This study adds to Kolb's work by supporting the idea that to have a comprehensive learning experience the learner needs to involve themselves completely into the learning experience and then be able to reflect on those experiences from several perspectives and suggesting that storytelling can provide a reasonable approximation of lived experience under certain circumstances. Though it might be more effective if the learners were able to have a hands-on experience, due to the restrictions of time, finances and the nature of the higher education system this may not be possible. This study suggests that the storytelling experience might be able to be used in lieu of the actual experience as another means of connecting the students to the experiences of the world. This possibility in no way minimizes the importance of actual hands-on experience, however it does appear to provide a reasonable option when resources demand an alternative. The process by which this "reasonable approximation of hands-on experience" occurs should be studied further and incorporated into future updates or revisions to the theory if the accumulated evidence supports the findings of this study.

This study also contributes to the professional literature by suggesting that the storytelling strategy can be used to effectively increase a student's retention of content knowledge, increase the student's perception of engagement, and increase the student's perception of teacher effectiveness. These findings clearly support the idea that storytelling can greatly enhance the learning experience for university students who are non-STEM/STEAM majors required to participate in STEM/STEAM courses as a part of their program of study. 


\section{Study Strengths and Limitations}

There are many strengths and weaknesses associated with this study. A clear strength is the use of a true experimental design with random assignment. From a quantitative perspective, this type of design provides the strongest possible evidence, thus increasing the validity of the results. The study also added a qualitative component to complement and support the quantitative results. The qualitative method was used to confirm or disconfirm the quantitative evidence and give participants an opportunity to describe the factors that contributed to the quantitative outcomes. Research shows that when the two methods are combined, researchers gain a greater understanding of the realities in life and show a greater commitment to understanding people in their environments (Sale, Lohfeld, \& Brazil, 2002).

The Repeated Measures Analysis of Variance design provided evidence about the influence of storytelling immediately after participating in the strategy and two weeks later. There were significant differences in student retention of content knowledge based on assignment to the treatment group. The evidence also showed retention of the content knowledge two weeks later to be significantly more in the treatment group. This study validated the efficacy of storytelling as a strategy to help students retain the content, increase student engagement and demonstrated an increase in teacher effectiveness over a period of time. The repeated measures design also adds power to the statistical analysis by providing data related to multiple time points.

Another strength of the study is that the participants were students in Elementary Education, Physical Education, and Early Childhood Development majors. These students were true non-Stem Majors enrolled in health science courses. The students who participated in the 
study were all pre-services teachers. This is a strength because it demonstrated the effectiveness of storytelling even in a course that was in a field different from the students' majors.

Finally, the idea that storytelling was effective in a Health Sciences STEM course is a strength given the fact that STEM retention is a significant problem facing our colleges and universities. Research using Storytelling as a promising strategy for engaging students in STEM classes contributing to the literature of adding the Arts to change STEM to STEAM to help the students develop the creativity and imagination to be advanced in the STEM fields. In a longitudinal study investigating the impact of arts on education, researchers found that students with high levels of arts participation out performed students who were exposed to less arts in all levels of measure including math, science, and reading (Catterall, Chapleau \& Iwanaga, 1999). This study adds to this notion by demonstrating the effective use of the art of storytelling in a STEM classroom.

\section{Limitations}

Due to the time constraints of the study, the students were only exposed to one treatment of storytelling. Though the results were significant, it would have been beneficial if the students could have been exposed to more than one treatment using storytelling as a strategy and then compare their retention of the content material. Additionally, although two weeks gives us some sense of effects over time, to supplement the validity of the study and to get a sense of influence over longer time periods, this study should be replicated using a more longitudinal and varied time schedule. For example, collecting data on students every ninety days, or even continuing data collection through the students' first year of student teaching. Another limitation of the study was The Teacher Effectiveness Instrument (Ellis, 2004). This measure included questions pertaining to Absence of Disconfirmation. At the time of the first survey, students only had one 
encounter with this professor and most likely did not have the ability to adequately evaluate the professor. Finally, emotion was a theme that was identified in the Qualitative group interviews. Though the literature review spoke about emotional connectedness to the story being an important element, the instrumentation used in this study did not include a measure for emotional connection. Due to time constraints, two weeks was the longest period of time for any post program comparisons to be made between the treatment and control groups. Although the two week time frame did prove to have significant results in increasing student content knowledge, student engagement and an increase in student's perception of teacher effectiveness, two weeks is a relatively short amount of time to use the teaching strategy. Longer periods of using the storytelling strategy for teaching and longer periods between measurements after using the strategy would further validate the storytelling technique as an effective strategy.

\section{Recommendations for Future Research}

This study provides evidence that suggests several directions for future research and practice. Storytelling can be an effective teaching strategy to enhance learning from experience and reflection of that experience. The use of storytelling being used to simulate real life experiences that the students can use in their future teaching practice should be investigated. Another important finding from this study showed that emotional involvement in the story telling event related to the student's production of personal meaning and contributed to the learning experience. Further study involving emotional engagement connected to storytelling and student learning outcomes is warranted.

Future studies should also continue exploring the connection between Kolb's theory of experiential learning with storytelling as the experiential component and how that experience links to reflective observation. Such studies should use the storytelling strategy and measure its 
ability to connect students to real life experiences and enhance student engagement. More thorough theoretical work in the field of using storytelling and story examination to enhance a kind of reflecting that is often difficult to do may be indicated. Many experts believe using stories to connect listeners to life experiences is an effective way to help people gain knowledge and relate the knowledge to their own life experiences and values. These stories can assist students to develop personal theories and imaginings that guide their actions and reflections of life experiences.

Teacher preparedness was a measurement goal of the study. It became obvious to this researcher that only being exposed to the technique one time did not successfully prepare the students to feel confident enough to teach the content learned by using the storytelling technique. Future studies should examine a longer period of time exposing pre-service teachers to the storytelling technique and assess their perception preparedness to teach the content after more exposure to it. Future studies using storytelling techniques as an effective teaching strategy would be enhanced by using improved instrumentation. Adequate instrumentation measuring this element of the study does not currently exist. Therefore, adequate instrumentation used to measure student engagement would need to be developed by future researchers. Another evaluation tool could also be to have the students develop their own story as part of an assessment of how the students perceive themselves as ready to use the teaching strategy in their own practice.

Future research should also investigate the influence of gender on the way students perceive storytelling as an effective teaching strategy for increased student engagement, increased student retention of content knowledge and an increase in student perception of teacher effectiveness. Further, this study focused on Elementary Education and Childhood Developments 
majors as the participants of the storytelling teaching strategy. It could be advantageous to repeat the study with participants of other majors to see if other populations may be more perceptive to the storytelling strategy. It may also be interesting to use the storytelling teaching strategy across different content areas within STEM fields to determine if there are differences in student engagement, content knowledge over time, and perception of teacher effectiveness. In general, providing participants with greater exposure time to the storytelling teaching strategy would be important in future study.

Finally, replication is an important part of the scientific process. The results from an effective study should be replicable by other researchers using the same conditions such as the same or similar students in a similar environment. To be able to generalize a study and further establish external validity, the study should be replicated in other conditions such as high schools, middle schools, and elementary schools using different populations of students and preservice teachers as well as practicing professional teachers. Also the study was conducted in one university setting in Northern West Virginia. To increase generalizability, it would be feasible to replicate the study in different geographic locations.

\section{Recommendations for Professional Practice}

The Stem movement has become a high priority in educational reform. Some educators advocate to add the A to the acronym to change it from STEM to STEAM. Storytelling is an art form that can be used as a teaching strategy to enhance learning, student engagement, and teaching effectiveness. This study showed a significant association in all of these areas.

Storytelling was a significant component to retention of content knowledge in this study. The study results proved to be significant over time and the students in the qualitative focus groups supported the hypothesis that the stories helped them to visualize the content and it 
helped them to remember it two weeks later. Study results support the theory that storytelling influences a student's perception of teacher effectiveness and the value of the storytelling strategy. Many studies have shown that students who report themselves as being more engaged rate the instructor as more effective.

The art of storytelling is a powerful tool that can be used to enhance teacher effectiveness, student engagement in a classroom and retention of content knowledge. Mastering the art and technique of using storytelling as a teaching strategy can be an effective way to teach skills, values, and to create memorable imagery and connection to life experiences. 


\section{References}

Abrahamson, C. E. (1998). Storytelling as a pedagogical tool in higher education. Education, $118(3), 440-441-451$.

Alterio, M. \& McDrury, J. (2004). Learning through Storytelling in Higher Education: Using Reflection and Experience to Improve Learning. London, UK: Taylor and Francis elibrary.

Atherton, J.S. (2013). Learning and Teaching; Piaget's developmental theory (on-line:UK) retrieved 5 December 2015 http://www.learningandteaching.info/learning/piaget.htm

Ayers, W., \& Miller J. (1998). A light in dark times: Maxine Greene and the Unfinished Conversation. New York, NY: Teachers College Press.

Bandura, Albert. (1994). Self-Efficacy. In V. S. Ramachaudran (Ed.), Encyclopedia of Human Behavior 4, pp. 71-81). New York: Academic Press.

Berger, Kathleen Stassen (2008). The developing person through the life span ( $7^{\text {th }}$ ed.). Worth, $\mathrm{p}$. 44-45.

Bland, M., Saunders, G., \& Frisch, J. K. (2007). In defense of the lecture. Journal of College Science Teaching, 37(2), 10-13.

Blevins, D.G. (2007) Storytelling or Storied Telling? Media's Pedagogical Ability to Shape Narrative As A Form OF “Knowing”. Religious Education, 102 (3), 250-263.

Boud, D., Cohen, R., \& Walker, D. (1993). Using experience for learning. McGraw-Hill Education (UK).

Britt, M. (2015). How To Better Engage Online Students with Online Strategies. College Student Journal, 49, 399-404. 
Bryson, C., \& Hand, L. (2007). The role of engagement in inspiring teaching and learning. Innovations in Education and Teaching International, 44(4), 349-362.

Bullough, R. Jr. (2010). Parables, Storytelling, and Teacher Education. Journal of Teacher Education 61 (1-2), 153-160.

Catteral,J., Chapleau, R., \& Iwanaga, J. (1999). Involvement in the Arts and Human Development: General Involvement and Intensive Involvement in Music and Theatre Arts. The Imagination Project at UCLA, University of California at Los Angeles.

Chan, C.K.Y. (2012). Exploring an experiential learning project through Kolb's Learning Theory using a qualitative research method. European Journal of Engineering Education 37 (4), 405-415.

Cohen, J. (1988). Statistical power analysis for the behavioral sciences (2nd ed.). Hillsdale, NJ: Erlbaum.

Corso, M. J., Bundick, M. J., Quaglia, R. J., \& Haywood, D. E. (2013). Where student, teacher, and content meet: Student engagement in the secondary school classroom. American Secondary Education, 41(3), 50-61.

Coulter, C., Michael, C., \& Poynor, L.(2007) Storytelling as Pedagogy: An Unexpected Outcome of Narrative Inquiry. The Ontario Institute for Studies in Education of the University of Toronto Curriculum Inquiry, 37(2)103-121.

Creswell, J. W. (2005). Educational research: Planning, conducting, and evaluating quantitative and qualitative research (2nded.). New Jersey: Pearson Education.

Daniel, A. K. (2007). From folktales to algorithms: Developing the teacher's role as principal storyteller in the classroom. Early Child Development \& Care, 177(6), 735-750. 
Davidson, M. R. (2004). A phenomenological evaluation: using storytelling as a primary teaching method. Nursing Education in Practice, (4), 184-189.

Daugherty, M. K. (2013). The prospect of an "A" in STEM education. Journal of STEM Education: Innovations \& Research, 14(2), 10-15.

De Jesus, H.P., Almeida, P., Teixeira-Dias, J.J., \& Watts, Mike (2007). Where learners'questions meet modes of teaching. Research Education, 78, 1-20.

Dewey, J. (1934). Art as experience. New York, NY: The Berkley Publishing Group.

Diekelmann, N. (2001). Narrative pedagogy: Heideggerian hermeneutical analyses of lived experiences of students, teachers, and clinicians. Advances in Nursing Science, 23(3), 5371.

Egan, K. (1986). Teaching as storytelling: An alternative approach to teaching and curriculum in the elementary school. Chicago: The University of Chicago Press.

Egan, K. (1989). Memory, imagination, and learning: Connected by the story. Phi Delta Kappan, $70(6), 455-459$.

Egan, K. (1998). The educated mind how cognitive tools shape our understanding. Chicago: University of Chicago Press.

Egan, K. (2003). Start with what the student knows or with what the student can imagine? Phi Delta Kappan, 84(6), 443.

Ellis, K. (2000). Perceived teacher confirmation: The development and validation of an instrument and two studies of the relationship to cognitive and affective learning. Human Communication Research, 26, 264-291.

Ellis, K. (2004). The impact of perceived teacher confirmation on receiver apprehension, motivation, and learning. Communication Education, 53, 1-20. 
Evans, N., Forney, D., \& DiBrito-Guido, F. (1998). Student development in college: Theory, research and practice. New York, NY: Jossy-Bass.

First Aid, CPR and AED Advanced, Sixth Edition. (2012). American College of Emergency Physicians.

Flowers, B.S. (1998). Joseph Campbell: The power of myth with Bill Moyers. New York: Doubleday.

Fredricks, J. A., Blumenfeld, P. C., \& Paris, A. H. (2004). School engagement: Potential of the concept, state of the evidence. Review of educational research, 74(1), 59-109.

Gamwell, P. (2005). Intermediate Students' Experiences with an Arts-Based Unit: An Action Research. Canadian Journal of Education, 28 (3), 359-383.

Gasiewski, J., Eagan, M., Garcia, G., Hurtado, S., \& Chang, M. (2012). From gatekeeping to engagement: A multi-contextual, mixed method study of student academic engagement in introductory STEM courses. Research in Higher Education, 53(2), 229-261.

Gravetter, F.J., \& Wallnau, L.B. (2007). Statistics for the Behavioral Sciences. Seventh Edition. Belmont, California: Thomson Learning.

Grose, C. (2010). Storytelling across the curriculum: From margin to center, from clinic to the classroom. Journal of the Association of Legal Writing Directors, 7, 37-61.

Haigh, C., \& Hardy, P. (2011). Tell me a story — a conceptual exploration of storytelling in healthcare education. Nurse education today, 31(4), 408-411.

Hamann, K., Pollock, P. H., \& Wilson, B. M. (2012). Assessing student perceptions of the benefits of discussions in small-group, large-class, and online learning contexts. College Teaching, 60 (2), 65-75. 
Hatch, J. A. (2002). Doing qualitative research in education settings. SUNY Press.

Hayward, D. V., Gillam, R. B., \& Lien, P. (2007). Retelling a script-based story: Do children with and without language impairments focus on script and story elements? American Journal of Speech-Language Pathology, 16(3), 235-245.

Hinshaw, A. S. (2001). A continuing challenge: The shortage of educationally prepared nursing faculty. Online Journal of Issues in Nursing, 6(1), 3.

Hunter, L. P. and Hunter, L. A. (2006), Storytelling as an Educational Strategy for Midwifery Students. Journal of Midwifery \& Women's Health, 51: 273-278. doi: 10.1016/j.jmwh.2005.12.004

Isabelle, A. (2007, October). Teaching science using stories: The storyline approach. Science Scope, 16-17-25.

Ironside, P. M. (2005). Using narrative pedagogy: learning and practicing interpretive thinking. Journal of Advanced Nursing 55(4), 478-486.

Kail, Robert (2007). Children and Their Development ( $4^{\text {th }}$ ed.) Pearson.

Koki, S. (1998). Storytelling: The Heart and Soul of Education. PREL Briefing Paper.

Kolb, D.A. (1984). Experiential learning: Experience as the source of learning and development. Englewood Cliffs, NJ: Prentice Hall.

Kuh, G. D. (2001). Assessing what really matters to student learning inside the national survey of student engagement. Change: The Magazine of Higher Learning, 33(3), 10-17.

Lamb, N. (2008). The art and craft of storytelling; A comprehensive guide to the classic writing techniques (First ed.). Cincinnati, OH: Writer's Digest Books. 
Lee, V. E., Robinson, S. R., \& Sebastian, J. (2012). The quality of instruction in urban high schools: Comparing mathematics and science to English and Social Studies classes in Chicago. High School Journal, 95(3), 14-48.

Lichtenberg, J., Woock, C., Wright, M. (2008). Ready to Innovate: Are educators and executives aligned on the creative readiness of the U.S. workforce? The Conference Board, Research Report 1424.

Mattingly, C. (1991). Narrative reflections on practical actions: Two learning experiments in reflective storytelling. The reflective turn: Case studies in and on educational practice, 235-257.

Mayo, M. J. (2007). Games for science and engineering education. Communications of the ACM, 50(7), 30-35.

McKeachie, W.J., \&Kulik, J.A. (1975). The Evaluation of Teachers in Higher Education. Review or Research in Education, 3 (1), 210-240.

McLeod, S.A. "Piaget/Cognitive Theory”. Simply Psychology. Retrieved 18 September 2012. Montgomery, S. M., \& Groat, L. N. (1998). Student learning styles and their implications for teaching. Occasional paper, (10).

Morse, M. (2003). An exploration of women's experiences of emotional abuse. University of Georgia Theses and Dissertations.

Newman, F.M. (1992). Student engagement and achievement in American secondary Schools. New York: Teachers College Press.

Otero, V., Finkelstein, N., McCray, R., \& Pollock, S. (2006). Who is responsible for preparing science teachers?. SCIENCE-NEW YORK THEN WASHINGTON-, 313(5786), 445.

Piaget, J. (1945). Play, dreams and imitation in childhood. London: Heinemann. 
Piaget, J. (1977). The role of action in the development of thinking. In Knowledge and development. Springer US, 17-42.

Pike, G. R., Kuh, G. D. (2005). First and Second-Generation College Students: A Comparison of Their Engagement and Intellectual Development. The Journal of Higher Education, 76 (3) 276-300.

Polito, T. (2005). Educational theory as theory of culture: A Vichian perspective on the educational theories of John Dewey and Kieran Egan. Educational Philosophy \& Theory, $37(4), 475-4$.

Roberts, A. (2013). STEM is here. now what? Technology and Engineering Teacher, 22, 23-27.

Rodgers, C. R., \& Raider-Roth, M. (2006). Presence in Teaching. Teachers and Teaching: theory and practice, 12(3), 265-287.

Rosenshine, B., \& Furst, N. (1973). Research in teacher education: A symposium (B.O. Smith Ed.) Englewood Cliffs, NJ: Princeton-Hall.

Rossman, G. B., \& Rallis, S. F. (2003). Learning in the field: An introduction to qualitative research. Sage.

Sale, J.E., Lohfeld, L.H., Brazil, K. (2002). Revisiting the Quantitative-Qualitative Debate: Implications for Mixed-Methods Research. Quality \& Quantity, 36, 43-53.

Saunders, A. (2011). Exhibiting the Field for Learning: Telling New York's Stories. Journal of Geography in Higher Education, 35(2), 185-197.

Schank, R. C., \& Berman, T. (2006). Living stories: Designing story-based educational experiences. Narrative Inquiry, 16(1), 220-228. 
Schenck,J., \& Cruickshank, J. (2015). Evolving Kolb: Experiential Education in the Age of Neuroscience. Journal of Experiential Education, 38 (1), 73-95.

Schwartz, M., \& Abbott, A. (2007). Storytelling: A clinical application for undergraduate nursing students. Nurse Education in practice, 7(3), 181-186.

Seymour, E., \& Hewitt, N.M. (1997). Talking about leaving: Why undergraduates leave science. Boulder, Colorado: Westview Press.

Simmons, A. (2001, 2006). The story factor: Inspiration, influence, and persuasion through the art of storytelling. New York: Basic Gooks.

Skinner, E. A., Kindermann, T. A., \& Furrer, C. J. (2009). A Motivational Perspective on Engagement and Disaffection Conceptualization and Assessment of Children's Behavioral and Emotional Participation in Academic Activities in the Classroom. Educational and Psychological Measurement, 69(3), 493-525.

Torres, J. and Ash, M. (2007). Cognitive development. In Encyclopedia of special education: A reference for the education of children, adolescents, and adults with disabilities and other exceptional individuals. Retrieved from http://proxy.wexler.hunter.cuny.edu.

Thygerson, A., Thygerson S., Gulli, B., Piazza, G. American College of Emergency Physicians. First Aid, CPR, and AED Advanced. Sixth Edition. (2012). Sudbury, MA: Jones \& Bartlett.

Tinto, V., Goodsell, A., \& Russo, P. (1993). Collaborative learning and new. Cooperative Learning and College Teaching, 3(3), 9-10.

Tinto, V. (1997). Classroom as communities: Exploring the educational character of student persistence. Journal of Higher Education, 68, 599-623. 
Uhl, C. (2010). Steering Into the Curve: Getting Real in the Classroom. College Teaching,58, 105-108.

Visser-Wijnveen, G., Stes, A., \& Petegem, P. (2012). Development and validation of a questionnaire measuring teachers' motivations for teaching in higher education. Higher Education, 64(3), 421-436.

Vygotsky, L. (1987). Thinking and speech. In Rieber, R.W. \& Carton A.S. (Eds) (1987). The collected works of L.S. Vygotsky, New York: Plenum Press.

Walls, R.T. (2004).Memory: Notes and Notions. Morgantown, WV, West Virginia University. Walls, R.T., Nardi, A. H., von Minden, A.M. \& Hoffman, N. (2002). The Characteristics of Effective and Ineffective Teachers. Teacher Education Quarterly, Winter, 39-48.

Wells, J. (2013). Integrative STEM Education at Virginia Tech: Graduate Preparation for Tomorrow's Leaders. Technology and engineering teacher, February, 28-34.

White,H.(n.d). Our education system is not so much "broken"-as it is totally outdated! In STEAM, Retrieved October, 14, 2011, from http://steam-npt-stem-cpm/artocles/poureducation-system-is-not-so-much-brokne-as-it-is-totally-outdated/

Wolter, B. H. K., Lundeberg, M. A., \& Bergland, M. (2013). What makes science relevant?: Student perceptions of multimedia case learning in ecology and health. Journal of STEM Education: Innovations \& Research, 14(1), 26-35.

Wright, C., Bacigalupa, C., Black, T., \& Burton, M. (2008). Windows into Children's thinking: A guide to storytelling and dramatization. Early Childhood Education Journal, 35(4), $363-369$.

Yakman, G. (2010). What is the point of STE@ M?-A Brief Overview. 
Yoder-Wise, P. S., \& Kowalski, K. (2003). The power of storytelling. Nursing outlook, 51(1), $37-42$.

Zabel, M. K. (1991). Storytelling, myths, and folk tales: Strategies for multicultural inclusion. Preventing School Failure: Alternative Education for Children and Youth, 36(1), 32-34. 


\section{Appendix A: Student Engagement Instrument}

Student Academic Engagement Scale (Lee, Robinson, and Sebastian 2012 and West Virginia University SEI, 2013)

$\begin{array}{lcccc}0 & 1 & 2 & & 3 \\ \text { gly Disagree } & \text { Disagree } & \text { Undecided } & \text { Agree } & \text { Strongly Agree }\end{array}$

1. The topic we studied was interesting and challenging.

2. I was bored in this class.

3. I usually look forward to this class.

4. I work hard to do my best in this class.

5. I was so interested in the class I didn't want to stop.

6. I counted the minutes until this class ended. 


\section{Appendix B: Retention of Content Knowledge Instrument}

First Aid, CPR and AED Advanced, Sixth Edition. (American College of Emergency Physicians. ECSI, 2012)

Directions: Circle Yes if you agree with the statement; circle No if you disagree

Yes No 1. Shivering is a signal that clothing and shelter are inadequate to protect the body from the cold.

Yes No 2. Up to $100 \%$ of the body's total heat production can be lost by radiation through an unprotected head.

Yes No 3. Physically unfit people are more susceptible to cold injury.

Yes No 4. Thaw the frostbitten body part, if possible, even if there is chance of it refreezing.

Yes No 5. Shivering produces body heat

Yes No 6. Rub a frostbitten part to rewarm it.

Yes No 7. Rewarm a hypothermic victim quickly in a hot shower or with chemical heat Packs.

Yes No 8. Replace any wet clothing with dry clothing for a hypothermic victim.

Yes No 9. Seek medical care for a severe hypothermic victim.

Yes No 10. Below-freezing temperatures are required for hypothermia to occur.

Yes No 11. It is difficult to determine if a victim has frostnip or frostbite?

Yes No 12. Frostbite requires freezing temperatures (below 32 degrees F or 0 degrees $\mathrm{C}$ )

Yes No 13. The skin and underlying tissue affected by superficial frostbite feel hard and solid?

Yes No 14. As long as there is no danger of refreezing, you could begin warming possible frostbite in warm water?

Yes No 15. If you do not have warm water, you can rub frostbite extremities to increase circulation? 


\section{Appendix C: Teacher Preparedness Instrument}

Teacher Readiness Scale (Visser-Wijneen, Sites, and Petegem, 2012)

$\begin{array}{cccc}0 & 1 & 2 & 3 \\ \text { Strongly Disagree } & \text { Agree } & \text { Disagree } & \text { Strongly Disagree }\end{array}$

1. I am absolutely confident that I have a sufficiently good knowledge of the content to teach this course module.

2. How much a student learns is determined more by innate talent than by teaching.

3. When a student performs better, very often this is just because I have made an extra effort.

4. I am sure that I have the necessary skills to teach this course module.

5. How well a student performs is more strongly determined by genetic factors than by teaching.

6. When a student achieves a better score than he or she usually gets, this is often because I have found a better way to help that student.

7. I am absolutely confident that I have sufficient didactic knowledge to teach.

8. If a student performs well, this is usually due to his or her innate abilities.

9. If student's scores improve, that is usually because I have found a more effective teaching approach.

10. I really enjoy teaching.

11. I put a lot of energy into my teaching.

12. I think that I am quite a good teacher.

13. Teaching is fun.

14. I am absolutely confident that my students are learning something from me in this course module.

15. Teaching is a boring activity.

16. I try my absolute best in my teaching duties.

17. Now that I've been teaching for a while, I think that I am a competent teacher.

18. It's important to me to be a good teacher.

19. I am satisfied with my competencies as a teacher.

20. Teaching is a very interesting activity.

21. I don't put a lot of effort into my teaching.

22. I have a talent for teaching.

23. Teaching is fairly enjoyable.

24. I am not a very good teacher.

25. When I am teaching, I notice that I enjoy it. 


\section{Appendix D: Teacher Effectiveness Instrument}

Teacher Confirmation Scale (Ellis, 2000; Ellis, 2004)

$\begin{array}{ccccc}0 & 1 & 2 & 3 & 4 \\ \text { Strongly Disagree } & \text { Disagree } & \text { Undecided } & \text { Agree } & \text { Strongly Agree }\end{array}$

Please Rate the instructor on the following:

Responding to Questions

1. Takes time to answer students' questions fully

2. Listens attentively when students asked questions or made comments during class

3. Indicates that she appreciated students questions or comments

4. Is available for questions after class

5. Is willing to deviate slightly from lecture when students ask questions

Demonstrating Interest

1. Communicates that she is interested in whether the students are learning

2. Communicates that she believes students can do well in class

3. Asks students how they think the class is going

4. Makes an effort to get to know students

5. Smiles at the class

6. Establishes eye contact during lectures

Teaching Style

1. Uses and interactive teaching style

2. Uses a variety of teaching techniques to help students understand course material

3. Checks on students' understanding before going to the next point

4. Incorporates exercises into the lecture when appropriate

5. Gives oral or written feedback on students' work

\section{Absence of disconfirmation}

1. Is rude in responding to some students' comments or questions during class

2. Displays arrogant behavior

3. Embarrasses students in front of the class

4. Belittles or puts students down when they participate I class

5. Talks down to students

6. Intimidates students

7. Puts students down when they go to the teacher for help outside the class

8. Focuses on only a few students during class while ignoring others

9. Shows favoritism to certain students

10. Is unwilling to listen to students who disagree

11. Communicates that she doesn't have time to meet with students 


\section{Appendix E: Semi Structures Group Interview Question Guide}

How do Early Childhood Development and Elementary Education majors in a required health science course perceive the value of storytelling as a strategy for enhancing classroom engagement?

1. Write down three moments that you remember about our experience together in the Hypothermia lesson.

2. What are the three most important concepts that you learned from this lesson?

3. Can you tell us why we told the stories?

4. What was the purpose of the stories?

5. Can you give us examples of how the stories helped or hindered your learning in relation to your experience with the lesson? 


\section{Appendix F: IRB and Consent Form}

\section{W. WestVirginiaUniversity. \\ Office of Research Integrity and Compliance}

\section{Approval Letter Expedited}

To

From

Approval Period

Subject

Protocol Tracking

Title

Michael Mann

WVU Office of Research Integrity and Compliance

03/31/2014 Expiration Date 03/30/2015

Protocol Approval Letter

1402218387

Using Storytelling as a Teaching Strategy to Increase Engagement in STEAM

Classes

The above-referenced research study was reviewed by the West Virginia University Institutional Review Board IRB and was approved in accordance with 46 CFR $46.10 \mathrm{lb}$.

It has been determined that this study is of minimal risk and meets the criteria as defined by the expedited categorys listed below:

- Category 6. Collection of data from voice, video, digital, or image recordings made for research purposes.

- Category 7. Research on individual or group characteristics or behavior (including, but not limited to, research on perception, cognition, motivation, identity, language, communication, cultural beliefs or practices, and social behavior) or research employing survey, interview, oral history, focus group, program evaluation, human factors evaluation, or quality assurance methodologies. [NOTE: Some research in this category may be exempt from the DHHS regulations for the protection of human subjects. See Exempt Categories and 45 CFR 46.101(b)(2) and (b)(3). This listing refers only to research that is not exempt.]

Documents for use in this study have been approved and validated and are available in the WVUkc system in the Notes and Attachments section of your protocol.

Thank you.

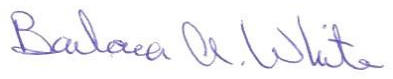

Board Designee Barbara White

Letter Sent By Barbara White on 03/31/2014 at 11:04:27-04:00 


\section{Consent form}

March 4, 2014

\section{Dear Participant,}

This letter is a request for you to take part in a research project to assess how Storytelling works as a Teaching Strategy to Increase Student Engagement in STEM Classes. . This project is being conducted by Toni Morris a graduate student in the College of Education and Human Services at WVU with supervision of Dr. Michael Mann, an assistant professor in the School of Public Health. Your participation in this project is greatly appreciated and will take approximately one to one and half hours of your time.

Your involvement in this project will be kept as confidential as legally possible. All data will be reported in the aggregate. You must be 18 years of age or older to participate. I will not ask any information that should lead back to your identity as a participant. Your participation is completely voluntary. You may skip any question that you do not wish to answer and you may discontimue at any time. Your class standing will not be affected if you decide either not to participate or to withdraw. West Virginia University's Institutional Review Board acknowledgement of this project is on file.

I hope that you will participate in this research project, as it could be beneficial in understanding the impact of grades on student life. Thank you very much for your time. Should you have any questions about this letter or the research project, please feel free to contact Toni Morris at (304) 293-3775 or by e-mail at tomorris@hsc.wvu.edu.

Thank you for your time and help with this project.

Sincerely,

Toni Morris, RN, MS, MFA

Graduate Student 
West VirginiaUniversicy

GCH COL CF PJBLIS HESLTH

Only Minimal Risk

Consent Information Form (without HIPAA)

\section{USING STORYTELLING AS A TEACHING STRATEGY TO INCREASE STUDENT \\ ENGAGEMENT IN STEM CLASSES}

Principal Investigator

Department

Study Title

Co-Investigator(s)
Dr. Michael Mann

School of Public Health

Using Storytelling as Teaching Strategy to Increase Student Engagement in Stem classes.

Toni Morris

\section{Contact Persons}

In the event you experience any side effects or injury related to this research, you should contact Toni Morris, RN, Assistant Professor at (304) 293-3775 or Dr Michael Mann at (304) 293-3560. If you have any questions, concerns, or complaints about this research, you can contact Dr. Michael Mann at (304) 293-3560.

For information regarding your rights as a research subject, to discuss problems, concerns, or suggestions related to the research, to obtain information or offer input about the research, contact the Office of Research Integrity \& Compliance at (304) 293-7073.In addition if you would like to discuss problems, concerns, have suggestions related to research, or would like to offer input about the research, contact the Office of Research Integrity and Compliance at 304-293-7073.

\section{Introduction}

You, , have been asked to participate in this research study, which has been explained to you by Toni Morris RN, Assistant Professor. This study is being conducted by Toni Morris, RN, Assistant Professor in the School of Public Health at West Virginia University.

This research is being conducted to fulfill the requirements for a Doctoral Degree in Curriculum and Instruction with the supervision of Dr. Michael Mann in the School of Public Health.

Initials date

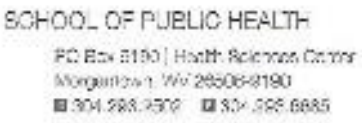




\section{USING STORYTELLING AS A TEACHING STRATEGY TO INCREASE STUDENT ENGAGEMENT IN STEM CLASSES}

\section{Purpose of the Study}

The purpose of the study is to learn more about using nontraditional methods such as the use of storytelling in a traditionally lecture taught health class. WVU expects to enroll approximately 50-60 subjects.

\section{Description of Procedures}

This study involves taking a content knowledge survey on the topic Hypothermia which will take you approximately five minutes, attending a thirty minute lecture on Hypothermia, taking another content knowledge survey on the topic of Hypothermia immediately after the lecture which will take approximately five minutes and completing an additional survey on student engagement, teacher effectiveness and teacher preparedness which will take you an additional ten minutes. Two weeks later you will be asked to repeat the content knowledge survey which will take approximately five minutes and repeat the additional survey to measure student engagement, readiness to teach the subject matter and teacher effectiveness which take approximately ten minutes. Total amount time for this research project will be one to one half hours. You do not have to answer all of the questions. You will have the opportunity to see the questionnaires before signing the consent form.

Additionally, you may volunteer to participate in a semi structured group interview. This group interview will discuss the use of storytelling in a classroom. If you chose to participate in the group interviews, this will take approximately one hour. The interview will be audio-taped.

\section{Risk and Discomforts}

There are no known or expected risks from participating in this study, except for the mild frustration associated with answering the questions.

\section{Benefits}

You may not receive any direct benefit from this study. The knowledge gained from this study may eventually benefit others.

\section{Financial Considerations}

No payments will be made for participating in part one of this study. You may earn extra credit for participating in this study. Other options are available for earning the same extra credit.

If you participate in the semi structured group interviews, you may receive an incentive bonus in the form of a $\$ 10.00$ gift card to Walmart or Sheetz.

\section{Confidentiality}

Any information about you that is obtained as a result of you participation in this research will be kept as confidential as legally possible. Your research records and test results, just like hospital records, may be subpoenaed by court order or may be inspected by federal regulatory authorities without your additional consent. 
In addition, there are certain instances where the researcher is legally required to give information to the appropriate authorities. These would include mandatory reporting of infectious diseases, mandatory reporting of information about behavior that is imminently dangerous to you or to others, such as suicide, child abuse, etc.

Audiotapes will be kept locked up and will be destroyed as soon as possible after the research is finished.

In any publications that result from this research, neither your name nor any information from which you might be identified will be published without your consent.

\section{Voluntary Participation}

Participation in this study is voluntary. You are free to withdraw your consent to participate in this study at any time.

Refusal to participate or withdrawal will not affect your future your standing or grade at West Virginia University and will involve no penalty to you.

In the event new information becomes available that may affect your willingness to participate in this study, this information will be given to you so that you can make an informed decision about whether or not to continue you r participation.

You have been given the opportunity to ask questions about the research, an you have received answers concerning areas you did not understand.

Upon signing this form, you will receive a copy.

I willingly consent to participate in this research.

Signature of Subject or Subjects Legal

Representative

Printed Name

Date Time

The participant has had the opportunity to have questions addressed. The participant willingly agrees to be in the study.

Signature of Investigator or Co-Investigator

Printed Name

Date_ Time

Initials date 


\section{Appendix G: Transcript from Storytelling Lecture}

Name of Transcriber: Maggie Power

Recording Number \#78

Teacher: Your normal body temperature is 98.6 degrees. How far does it have to drop before you guys are considered hypothermic? How many degrees would you guess before you start getting into hypothermia, where you are actually having a cold related emergency?

Student 1: Ten?

Teacher: Ten? Okay.

Student 2: Ten.

Teacher: Ten? It's actually only 3 degrees. So just 3 degrees. At just $95^{\circ} \mathrm{F}$, you guys are slipping into hypothermia, okay. So what makes our body drop down? How come we get cold? There's several different reasons. Basically air that surrounds us, so when it's cold outside, your body temperature is going to start dropping down to reach that same temperature. That's one way we lose. Okay? Alright, your body produces heat but it actually escapes faster than we can produce it. So you can actually become hypothermic pretty quickly. We have two ways that our body tries to warm ourselves up. One is through vasoconstriction. So our body's smart. It knows that your cold and it will start to constrict your vessels, okay? So slowing down your blood to try to warm you up. The other way is we shiver. Right? You've all shivered. That's trying to keep you warm. But when you fall so low as ten degrees, so $90^{\circ} \mathrm{F}$ to $85^{\circ} \mathrm{F}$ your body can't shiver anymore. And so that's when you are severely hypothermic cause you cannot warm yourself up anymore. Okay? So this is when it's really serious. (Page turns) Okay, physical activity produces heat. So if you're outside and you're doing work you're actually going to be a bit warmer because you're moving around. But when you produce heat you also start to perspire and then your clothes become wet. So if you're outside in cold temperatures and you're sweating a lot and your clothes are wet, what's going to happen eventually is your body is going to cool down. Okay? So ways to reduce your susceptibility to being cold is you want to stay hydrated, you want to make sure you have good nutrition. Alcohol is actually a blood thinner. So what's it going to do to you if it thins your blood? What's going to happen? 
Student 3: Makes your colder.

Teacher: Yeah, it's going to make you colder. So how many people have been to a WVU football game and it's really cold outside and you tailgate and you have a few drinks in the parking lot before you go in. Never? Ha ha its okay you don't have to admit anything. It actually makes you colder. You might be drunk and think you are warm, but you're not, you're actually colder. Caffeine does the same thing. So how many of you when you are cold drink something hot like coffee that has caffeine in it will actually make you colder. So will nicotine if you're a smoker. Okay, so if you're really cold you don't want to drink caffeine.

\section{Student 4: What about hot chocolate?}

Teacher: You know there is a little bit of caffeine in chocolate but it's not as much as say coffee. So it's actually better for you, as long as you don't put the nip of whiskey in it. Alright, so how else do we lose heat? Through conduction. So if you were like on a cold bench, sat down waiting on a bus, you are going to lose heat through the bench. Okay, so colder objects like if you touch something cold, will actually take heat away from you. Convection, so cold air just blowing around you. Evaporation, when you sweat or just normal breathing you are going to evaporate heat. And radiation, our body just radiates heat out to colder air. So if it's cold outside you are going to lose heat to whatever it is. So if you touch a hot pan, that pan is going to radiate conduct the heat right to your hand, okay? And you see the fire? She's feeling the heat from the fire. So that's how we lose heat to other things. Okay, who is susceptible to get really cold? If you are physically unfit. The better shape you are the better your body is going to be able to stay warm. If you are dehydrated you are going to be colder. So if it is cold outside you want to drink lots of water. If you are very thin; if you are elderly because as we age our skin actually thins. Did you guys know that? It will actually get thinner and thinner. Or if you are really young and your skin is thinner. So that's who is at risk the most. Again, if you are drinking alcohol, nicotine, if you don't have good nutrition, and if you have experienced a cold injury before, you are actually more susceptible. So when do you freeze? When will your skin actually freeze? Can it freeze? Yes, it can. And it can freeze in two different ways. Something called frost-nip and something called frostbite. So you guys have probably heard of frostbite. Have you heard of frost-nip? So frost-nip is just when, it's limited just to the skin's surface. So we've got, we're made up of water. We have all of this water, about $50 \%$ of your 
weight is water, and there's all of this fluid underneath your skin and that's what's going to freeze in frostnip. Just right under the surface of the skin is actually going to freeze. When it gets down into the flesh, below the epidermis which is your top layer and it gets down into the dermis and the muscle, then it is frostbite. And I want to warn you there are some kind of nasty pictures. So if that kind of um, the next one is kind of yucky I think. This is frost-nip. So you can see, see the water is frozen on the surface, the fingers are blanching they are turning white there, it's because it's actually turning into little ice crystals. If you have frostbite or frost-nip, you would never rub like this. (Demonstrates rubbing motion with hands) Because those little ice crystals can actually damage the cells underneath, okay? You want to heat it up but not rub, alright. So it's going to be red, swollen, very very painful, okay? Then if it continues to happen, your skin is going to dry out. So how do you treat it? You want to get out of the cold? Put something warm on your hands, get inside, warm yourself, but again do not rub. And frost-nip will go away like that (Snaps). Frostbite, not so much. So there is two ways of damaging with frostbite. Number one is the tissue freezing and because you're not getting good supply to the tissue. So usually effects the feet, the hands, the ear, and the nose. Where do you think you're most susceptible?

Student: The nose?

Teacher: Yeah, right here (Points). Think about it. If it's really cold outside you could put a hat on. You do know you lose heat through the head right? So if you are really cold you always want to wear a hat because it's going to keep you warmer. You could warm a scarf, but you rarely see anyone covered up right through here (Gestures to face). So that's why this is most susceptible. The next is going to be where it's furthest away from the blood supply which is your hands and your toes. So what does it look like? It's going to be really waxy and gray, yellow. It's going to tingle, it's going to sting. Have you ever been so cold that your extremities hurt? And then when you warm them up they really sting? Okay, that's probably frost-nip. But when you get frostbite, it's going to be worse. Okay? So the tingling, it's going to sting, it's going to ache. Um, for some of you it might turn into big blisters and it may look like gray wax. Now here is something I wanted to tell you. With frostbite or suspected frostbite, you never rewarm it unless there is no chance of it refreezing. Okay? Because if you do that, every time it refreezes it's going to cause further damage to the tissue. I'm going to give you an example. These are true stories, every one l'm about to tell you. There was a young couple in Oregon and it was Christmas 
time and they decided to go look for a Christmas tree. Well they got lost and they got into a blizzard and it was a whiteout. And they kept trying to drive through the blizzard but they had no idea where they were going and before they knew it there were in the middle of nowhere and had nothing around and just had to sit in their car and wait the blizzard out. It was a young couple and an infant child. They had their car with them some water and some snacks, like maybe a package of crackers or something, which is actually what saved their lives. So if you are going to travel and it is going to be cold, please put some food in your car and water. Just a bottle of water could save your life. They get stranded for days. Nobody comes to help them, nobody knows where they are, and they try to walk out. They leave their car and they try to walk and they can't find anyone and the woman's feet freeze. They become so painful, she can't walk any further so her husband says to her that there is a cave. You stay in the cave with the baby and breastfeed the baby, keep the baby alive. I'm going to walk out and find help. It took him eight days to get back to her. Eight days. In the meantime, she would sleep in that cave and her feet would freeze at night because it was so cold. And then in daytime the sun would come and she would actually put her feet in the sun and thaw them. Not only is that extremely painful, but what she did is create so much damage to her feet, that when they did finally rescue her, and they did, they had to amputate both of her legs below the knee. So you would actually be better in a situation like that, to actually just let them stay frozen. Does that make sense? It wouldn't be as painful for one. And you wouldn't continue to do damage to themselves. Okay, so here are the pictures. Pretty nasty right? So you can see this young lady over here if you can stand it, if it upsets you just look away. You can see her nose, lips, and cheeks are frostbitten. Again, cold air blowing over is going to cause frostbite. And this guy's digits are literally falling off, because the tissue has died and it's falling off. And the feet, too. So that is severe frostbite. Okay, so if that is the case, you want to get out of the cold as soon as possible. If you are wet, take the cold wet clothes off because you are going to lose heat to those things. Always seek medical attention. Of course you would because you would be in a lot of pain. Uh, if the affected part is partially thawed and you are in a warm area and you can continue to thaw it by putting it in warm water. So you would get warm water, about 100 degrees to 105 degrees, and put the part in the water, 20 to 40 minutes, and thaw it. It's going to hurt. It's going to be very painful so you want to give them some kind of pain medicine. If you've got Advil, or Tylenol, or whatever you have, give it to them. Okay, because it's going to hurt. And 
if it's here (gestures), you would put warm wet cloths on it to thaw it. Okay, but again never thaw it unless you are sure it's not going to refreeze. Really important okay. After thawing, you want to treat them as a stretcher case. That means really gently. Also you want to protect them. Put draw gauze between their toes and fingers slightly elevated. If you have aloe, you can put aloe on it and obviously give them pain medicine because it is very painful. Any questions about frostbite before I talk about hypothermia? Alright. Hypothermia I talked to you about already. If you are below, if you drop your temperature below 95 degrees, that's just three degrees, what is going to happen. The colder you get, everything slows down. You're going to get a really slow heartbeat, really slow breathing, and you may think that somebody is actually dead. Okay, because everything slows down so much, you can't detect it. So in Canada, there is this little baby and it was 20 or 30 below one winter, without the wind chill factor, and there was wind this night. This mother puts this two year old to bed and then she goes to bed. In the middle of the night, she hears this banging, banging, banging, of the door blowing open. So she gets up, she goes outside, and it's wide open. The door is wide open and she doesn't know why. So she quickly runs to her baby's room and her baby is not in her room. I think the baby is two. The baby had gone outside for some reason. And at that temperature, that cold, she got hypothermic very, very quickly. She found the baby passed out in the yard. The baby had no heartbeat and had no breathing. The mom brought the baby in, put her on the table, and she sounded like a lump of ice had hit the table that's how frozen she was. She call 911 and it took about eight minutes for them to get there. This baby was so frozen, they couldn't even get an IV in her arm because her veins were so frozen solid. They wrap the baby up, they take her in the ambulance to the hospital. Her core temperature was 60 degrees. 60 . Statistically, someone who is usually $79^{\circ} \mathrm{F}$ is usually fatal. This little baby's core temperature was 60 . So they started to warm her up very slowly, and that's why l'm telling you this story, it's very important when you warm someone who is hypothermic, if you do it too fast, it will cause an arrhythmia in the heart. So they do it very, very slowly. So she went from having zero heart rate, to a very erratic heart rate, to a normal heart rate. Once they got her to thaw enough, they gave her enough medicine to put her in a drug induced coma. They kept her in a coma for two weeks. They woke her up very slowly and she had zero deficits. None. No brain damage. Not even frostbite to her fingertips, just a little bit of frost-nip. It's amazing. Children are very resilient sometimes. They tend to do a little bit better than adults. Okay, 
hypothermia symptoms. How do you know if someone is becoming hypothermic? Say you're out camping, it's really cold, you look over at your buddy and you notice him start to act a little drunk. Um, that would be one of the symptoms. Disorientated; Where am I at; I don't care about anything; they're acting funny. They might be shivering at first but again once they hit 90 degrees, they aren't going to shiver anymore. If you touch their belly, it's going to be really cold. If you were able to take their temperature, it's going to be lower than 90 degrees, okay? Again, slurred speech, having a hard time picking things up, these are all symptoms of hypothermia. Now remember 95 degrees is hypothermic, 90 degrees is severe hypothermia. What do you want to do? You want to get them out of the cold. You want to be careful with them and prevent them from getting any colder. Put blankets around them. A vapor barrier is something you can buy or something they give you in a first aid kit most times. Keep them horizontal. You want to have them lying down. Call 911 if you think someone is hypothermic. Allow them to shiver. Don't try to stop them. If you go see the movies where they get really cold and they get under sleeping bags naked to have body contact. That's okay if they stop shivering but if they are able to shiver you want them to. It's better. And give them warm sugar-free drinks, but no caffeine. Because caffeine again, what happens? It thins your blood and makes you colder. Whenever they stop shivering, that's when they are in severe hypothermia. Their muscles are going to get rigid. They're not going to be able to talk. They're going to have very slow breathing and pulse. They may appear to be dead and, for sure, if you were able to take their temperature, it's going to be around 90 degrees. Get them out of the cold. You want to prevent heat loss and again you want to warm them but do it slowly, okay. So you wouldn't stick them in a hot tub of water. Does that make sense? You'd get a blanket, put them near a fire, give them something warm and sugary to drink, and you'd warm them up gradually. Okay, that's really important. If anybody is ever really hypothermic, not matter what, you want to get them to a doctor because they could have some problems. Again, problems with rewarming - you would need a whole lot of warm water but you wouldn't ever want to use hot. Body to body contact is not better than shivering, I just told you that. And there is also no evidence that chemical heating pads are capable of warming a hypothermia victim. They do make them but they may not really help. So I wanted to tell you one more story about someone who was hypothermic. So back in 1996, there were a bunch of people who went on an expedition to climb Mount Everest. They had really bad luck and a whole bunch of 
people died. And there was a guy on that trip who actually worked for, I think, National Geographic and he wrote a book after this was all over called Into Thin Air. Has anyone ever heard of it? It's a great read. It's all about survival skills. But to climb Mount Everest it takes a lot of skill and people get into trouble because of a lack of oxygen and because of hypothermia. So, there was this physician on this trip. His name was Beck Weathers. And Beck Weathers had been climbing for years and this was his big deal. He was going to climb this mountain. The day of the climb - you work your way up. You go to base camp one, two, three, and four. You have to be acclimated to this thin air, that's why they call it Into Thin Air. Beautiful day, they get you up at two in the morning and you have to reach the summit by two in the afternoon. If you don't start coming down by two in the afternoon, most people die on Everest coming down. This day everything was going great but something happens and people get late and they don't get off the summit on time, it's like three or four in the afternoon. By the time they are coming down, and Beck Weathers is in this group of people, they get this big winter storm and it comes in and it totally kicks their butts. Kicks their butts. They have to stay out in the weather all night in this terrible blizzard. In the morning, when they wake up. He is completely frozen. His hand had come out and his hand was frozen black like this (demonstrates) completely. This whole part of his face (demonstrates) is black already. And he, they think he's breathing, but they don't know for sure, but they know if they don't leave him, they are going to die. So they go on without him. Their camp was only about 100 feet away. Sometime during the day, the sun comes out, warms him up and he regains consciousness. And somehow he gets himself to that camp. He walks in, he is terribly frozen, they've already left him for dead. They do what they can do for him. They thaw his hand - which they shouldn't have done - they show pictures of that. They put him in the tent and they keep him as warm as they can and the next day they are going to try to get him off the mountain, when another storm comes in and kicks his butt again. Blows his tent off of him. They wake up in the morning and guess what? Poor old Beck Weathers is frozen, completely frozen. Guess what they did? They left him for dead. They went down to camp three. Twelve hours later, guess who shows up? Dragging, but by God he's alive today to tell the story. He had to have both his hands amputated and his nose. He lost all of his tissue and they had to re-graft it. But my point of the story is, they may appear to be dead because they are frozen but there could be life inside, so you never take it for granted. Any questions on what I just went over? So I need you guys to do that little quiz for me 
again if you would. See if you change. I need you to write the same four digits, dash, your phone number, and then your birthdate. So we are going to see if I was able to teach you anything about hypothermia in that little lecture. (Distributes papers) This is about the techniques that I used and I want you to write the same number at the top of this page. 
Appendix H: Hypothermia PowerPoint slides for both lectures

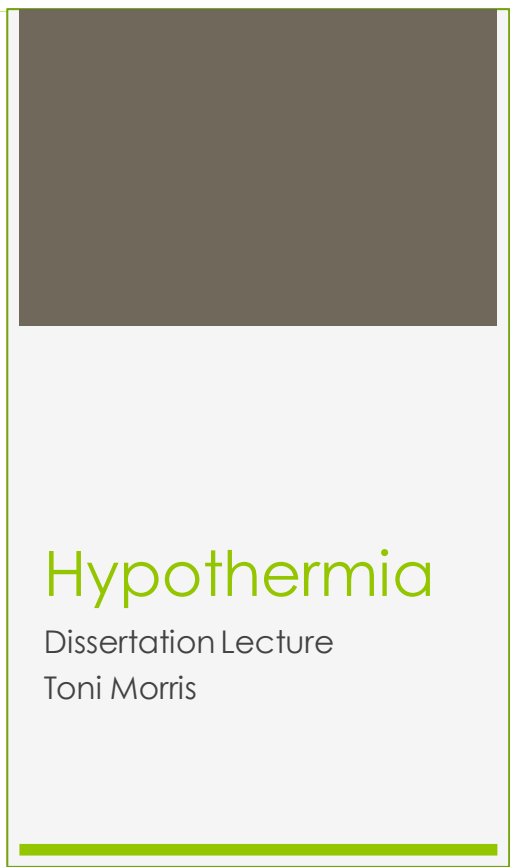




\section{Appendix I: Transcript of Non-Storytelling}

Teacher: What do we know about hypothermia? So hypothermia is considered a cold related emergency and you guys know that your normal, your typical body temperature is $98.6^{\circ} \mathrm{F}$. But we lose heat. When our body is surrounded by air that is cooler than what our normal body is, we lose heat to that. And we also lose heat when we touch other things that can take heat from us. Okay and we'll talk about that in a second. Heat actually escapes faster than your body is able to produce it so if you drop in a certain amount of degrees you could be considered hypothermic. And in a minute l'll tell you what that actually is but what do you think? How many degrees do you think that you would have to drop from 98.6 to be considered hypothermic?

Student 1: $\quad$ Fifteen.

Teacher: $\quad$ Fifteen, okay.

Student 2: $\quad$ Drop to 90.

Teacher: $\quad$ To 90, okay. Any other guesses?

Student 3: $\quad$ Five degrees?

Teacher: Okay let's see how we do here. Okay, so what happens when your body gets cold? How do you warm yourself up? And the way that happens - you know our body is really smart. If we get really hot, it's going to try to cool us down. And if we get really cold, it's going to try to warm us up. And it does that in two ways. There is one way called vasoconstriction. That's when your blood vessels tighten down and you notice when you get cold how your finger and toes get colder faster? That's because our arteries and our veins close down. That's what vasoconstriction's called. So it's going to stop shooting as much blood to your fingers and toes, so it can keep your organs warm. Okay, so it's pretty smart. The other thing is shivering. Have you ever been so cold you can't stop shivering? When you drop to, who said 90 , someone said 90 . Once you drop down to $90^{\circ} \mathrm{F}$, you can't shiver anymore. So that's actually severe hypothermia. When your body cannot shiver to warm itself up, you're severely hypothermic. So how do we produce heat? Well if we are physically active we produce heat. But if our body gets wet because we are sweating and it is cold outside, you're going to drop down colder. So if you're outside working and you're sweating and you're clothes start getting wet, like if you are skiing or doing something physical, you are actually going to get colder if you are sweating. And that coldness and dampness is up 
against your skin. So some ways you could try to stay warmer is right here (points). You want to drink lots of fluid. If you are cold, you want to drink lots of fluid. You also want to make sure you've eaten healthy. Avoid alcohol and caffeine and nicotine. Now why, why do I say that do you think? Why does alcohol, nicotine, and caffeine actually do?

Student: $\quad$ You're not as sensitive. You're not as perceptive I guess.

Teacher: $\quad$ That's right. You don't realize you aren't getting as cold and it actually thins your blood so that you are colder. So how many people have actually been to a football game and a tailgate party where it's real cold outside. Where you see people, I'm not saying you did (laughter), participate in a little alcohol beverage, right, before they go into the game. What it actually does is thin your blood and make you colder. But she's right, the more alcohol your drink and the less you know your cold and you don't realize it, okay. So it actually thins your blood. If it's really cold outside you want to drink hot chocolate that doesn't have caffeine in it. Other ways you are going to lose your heat to outside is conduction. So, how many people sit on those cold benches at those cold football games? So you lose heat to that bench. So next time you go to a football game and it's cold outside, take a blanket or a sweatshirt or something to sit on because you will actually be colder from sitting on those benches, Also, you will lose heat to air blowing over your skin so you want to wear something that has or repels the cold air. Evaporation, you're wet and you're going to lose heat because your liquid is going to lose to vapor and then radiation. We just lose heat to outside temperatures. So the colder it is the colder you are going to be. So this is just a really bad slide of an example (laughter) of radiating heat. (Changes slide) This is conduction so if you touch something hot you are going to lose heat to that or cause you to have heat. So people who are susceptible to cold injury are people who are physically unfit. If you are dehydrated, if you are outside and it's cold, drinking lots of water is actually going to keep you warmer. People who don't have a lot of body fat. People who are elderly have thinner skin. So if you have thinner skin you are going to get colder, easier. Again, alcohol, nicotine, caffeine and inadequate nutrition. Also, if you have had an injury before you are more susceptible. Okay, freezing cold injuries occur when air temperature is below freezing but there are two different types. There is something called frost-nip and there is something called frostbite. Frost-nip is limited just to your skin's surface. So you've got fluid underneath your skin. That's actually going to freeze and your fingers are going to get really cold and l'll show you 
some pictures here in a minute. Frostbite is when it goes deeply and this can be really, really dangerous. I'm going to show you some pictures that are really, really gross so I am just warning you in case you are sensitive to that stuff. Here is frost-nip (displays picture on slide). So the water on the skin's surface has frozen. You see how it is blanching there and it's turning white? That's because underneath the skin is frozen. That's frost-nip. That's the first degree. It's going to be red and painful and it can dry out your skin. So have you ever been outside, probably when you were kids, playing and you never wanted to come in? And you would come in and when you would start to get warm it would sting and burn? You probably had frost-nip. Okay, because that first layer is frozen. Frostbite, I'm sorry frost-nip, to warm it up, you don't ever want to rub it. The reason for that is when you freeze that water underneath your skin, it forms these little ice crystals. If you rub it like this (demonstrates) which you have a natural tendency to do, those little ice crystals can go into the cells underneath and cause damage. Okay, you want to warm it by putting in inside a fire place, putting some gloves on, or holding something warm, but try not to do that. Frostbite is more serious. You can not only have your tissue frozen but you have an obstruction of blood supply. Where does it affect? Usually your hands, feet, ears, and nose and the reason for that is your vasoconstriction. So you're not getting as good of blood supply to those areas. And the other thing is, if you think about being outside and being in the cold and if you were susceptible to frostbite, where of these things would you be most susceptible?

Student: $\quad$ Your face?

Teacher: $\quad$ Your face, exactly. And why is that?

Student: It's not covered.

Teacher: It's not covered! Right! So generally right through here, we generally wear a hat and if it's really cold outside remember, you lose heat through the top of your head. So putting a hat on will really keep you warmer but putting a scarf on is really important too and I will show you some pictures here in a minute. So how do you know if it is frostbite? It's going to be white and waxy. It might turn gray. It starts to feel numb at first and then it may tingle and sting and look kind of crusty. And if you touch it like this (demonstrates) it's going to be soft like a sponge. It's gross. It's also going to feel hard in certain parts and it may blister. (Class groans at pictures) And here are those disgusting pictures I was telling you about. See her face. Remember the frostbite I was telling you about? So you see her face, her lips, her 
nose, her cheeks, and also your ears are susceptible. Here is very serious frostbite. Here what actually happens is, the tissue actually dies and his fingers are falling off. Let me turn that. Making you kind of sick? That's okay, I'm sorry. So you want to get the person to a warm area. If they are wet, you want to take off anything that might be constricting blood supply. You always seek medical care. Now, this is really important. Never thaw frozen tissue if there is any chance it will freeze again. Okay, why would I say that do you think? Don't thaw it if there is any chance it will refreeze.

Student: Would it be worse the second time?

Teacher: It would be. And it will cause more damage and it will be extremely painful. And if you notice on this slide it says to give pain medicine because when it thaws, it's really, really painful. So if you are outside and you are skiing and you get lost say, and you have frostbitten feet and you are there for a couple of days. At night it's going to get colder. They are going to freeze. In the day, the sun is going to come out. If you stuck your feet out in the sun to thaw them, you would go through this excruciating pain and then at night they would freeze again. That would actually be worse than if you just left them frozen. Does that make sense? If you were going to freeze them though, I mean, if you are going to thaw them, you would put them in warm water for about 20 to 40 minutes. Not hot, warm. So you get your circulation back. If it's your face, your nose, or your ears, you would use warm cloths and hold it on there until it thaws. And you always want to seek medical - and you know what, say you are stranded somewhere and you are with somebody and you have some Advil. Give it to them because it's going to hurt. After thawing you want to, when it says treat them as stretcher case that means gingerly. So if you were to touch them you would want to do it very carefully. Protect them. If their toes or fingers are frozen put some gauze in between so they don't stick together. Slightly elevated, that will help with the pain. And you want to give them some aloe if you have it. It will help keep it from drying out and hurting. Any questions so far? Am I going too fast? Alright, hypothermia is actually just three degrees. Three and a half degrees. Mild hypothermia, if you get cold three and a half degrees, you are already mildly hypothermic. It doesn't take much to lose that much heat. So you want to be really careful if you are outside in the cold. As people start to get hypothermic, everything starts to slow down. It's going to slow down. My heart is going to slow down and their breathing. And when they become severely hypothermic, you may actually think they are dead when they are not. Now, you are going to see a 
change in mental status. They are going to be disoriented. They may not know what is going on. First they are going to shiver but eventually they are going to get so cold that they can't. And what was that temperature when you stop shivering? Ninety or below. If you touch them, they are going to be cold. You want to feel somebody's core temperature and you don't have a thermometer, feel their belly. Whether they are too hot or too cold, if you feel the belly you are going to be able to tell. Again, they are going to start slurring their speech. They might act like they are drunk, alright, and be staggering. Eventually they are going to drop down to below 90 degrees. Now statistically, $79^{\circ} \mathrm{F}$ is fatal. You want to get them out of the cold. You want to handle them gently. You want to stop anymore heat loss. So get them out of wet clothing. Wrap them up in blankets. A vapor barrier is something that might be in a first aid kit. You may not have one though so just put blankets on them. This is important - Call 911 immediately if you think someone is hypothermic and keep them in a horizontal position. Let them lie down. If they are shivering, let them shiver because that's their body trying to warm them up. And you want to give them warm sugary drinks because they might also be getting hypoglycemic. If it is severe, again, they are not going to be able to shiver. They are going to start turning blue on you. They are going to have really stiff muscles. They may not be even conscious. They are going to have slow breathing, again, and pulse and they may appear dead. Never give up on somebody. Think that even if they appear to be dead they could still be alive in there because there has been many cases where they appear dead and they bring them to the ER and they'll warm them up very slowly. And this is important. They warm them up too quickly, they could get a fatal heart arrhythmia. So you want to warm them up slowly and then all of a sudden, they will start having a heartbeat. Okay, so you have heard of cases where people have fallen into icy cold water and been trapped underneath for 45 minutes and they bring them back. That's because they are frozen. When you get them out of the cold, you want to prevent heat loss. Keep them warm. Always call 911. And when remote, weary of available heat. That means again, be careful warming them. Okay, because here are the problems with rewarming. It can cause a heart arrhythmia. Also, it's hard to warm somebody up fast anyway. If you were to put them in a tub, you'd need a whole lot of water to warm them up. And this important - body to body contact is not as good as shivering. You see that in movies when they all get cold and they are sitting out there and they all get naked and get in the same sleeping bag. That's good if you're not shivering. If you are shivering its 
better to let them than to try to stop them. Does that make sense? Okay. And there is no evidence that chemical heating pads are capable of rewarming them. So, they do make them. A chemical heating pad example would be those little hand warmer things you put in your hands. Okay, it's not really good for a hypothermic person. Any questions about anything I just went over? What I need you to do is repeat the same quiz and if you would, put your four digits, phone number, and birthday on that. And also, I am going to give you a survey about what I just did and if you could put the same code on this survey and fill it out l'd really appreciate it. 


\section{Appendix J: Focus Groups Transcripts}

\section{Focus Group \#1}

Moderator: What our study is about is whether or not storytelling helps people, who honestly don't care very much about health sciences content in general, stay more engaged than in lessons that don't use storytelling. So in your group she told a story of some kind somewhere, if not more than one. In the other group she did kind of straight, very technical lecture of the same material and then you guys took surveys indicating how much people remembered between each survey or between each treatment. Um, people uh how they ranked the teacher in terms of being likable and the value of the course and that kind of thing. So all we are going to do today is, we're just going to talk about your experience in the storytelling group. Whether Toni, uh, I would have done this no matter what, whether Toni had life circumstances or not. The reason she asked me to do this is because, obviously it's hard to give people um really honest feedback with them in the room, especially if you don't like them at all. So if you said, I guess what I'm trying to get at is, it's totally okay for you to say - Yeah all the storytelling stuff was boring and I wish it never happened because she'll never know it's you and it will be okay. It's equally okay to say you thought it was the best thing since sliced bread. This is about whatever your honest opinion is about storytelling and that kind of thing. So the first thing I'm going to ask you guys to do to get us where we can kind of generate some conversation is take a few minutes... If you could just grab something to write with. I'm just going to give you a few a seconds to kind of collect (grabs paper and distributes). Okay, the first thing I'm going to ask you to do to collect your thoughts is write down three moments that you remember from the hypothermia lesson. Three things she talked about, parts of the story, three things you learned.

Student 1: $\quad$ It can be like facts?

Moderator: It can be anything. Whatever three things stand out from that lecture. It happened now over three weeks ago so whatever three main things you can think of. (Students write)

Moderator: By the way, while you guys write. This is a group interview and one thing that's totally okay to do is you can say anything whenever you want. Ask any questions. It's really okay to talk. It's better if this is a conversation. So let's say (student's name) says something that (student's name) finds interesting. You don't have to wait to be called on. You can just say oh yeah I totally agree or oh no what's wrong with you. It's a conversation so whatever is easiest. Does anyone want to volunteer and say what they remember was particularly you know interesting, good, valuable about the lesson or about the storytelling in general.

Student 2: $\quad$ Uh yeah, you can look dead, but not be dead, when you have like hypothermia. Like the person on Mount Everest who they left because they thought that he was dead. He kept going when they left him.

Moderator: Cool. What else?

Student 3: I put that too.

Student 4: I did too.

Student 3: Because she made that story so good and I was just listening really intently, like scared but listening.

Moderator: Okay, so three of you, at least, have that, that fact from that story. So she made that story so good. What do you think made the story, good enough in the sense that, two or three weeks later, you still remember it and you still, I mean you still have a little bit of energy. You still feel like - Oh yeah! Like what was good about it? What did she do that made it stick out to you like that? 
Student 4: I think it was just so crazy and like, I don't even know. When she was telling us I just felt like oh that's awful.

Student 3: She described it better than I can imagine.

Student 2: She made it sound appealing. You know?

Student 3: $\quad$ She really did.

Moderator: Okay, you said appealing? How would you....

Student 2: $\quad$ She made me like want to listen to it. Because sometimes when you tell a story you're like oh this is going to suck but she kind of had like

Student 3: $\quad$ She had interest.

Student 2: Her voice, you could tell she was interested in teaching it and that kind of made me want to listen to her.

Moderator: Okay. You said interest. He said she had interest in teaching it like she was into it. What did you mean by interest?

Student 2: $\quad$ She just found it like to be an important thing so really wanted to like portray that. Moderator: How do you think she communicated that to you? I mean as it like her tone of voice? What did she do that made you know she's really into this and also kind of drew you in? Student 1: She was also humorous. Like it wasn't a funny story but like she would just be like... like when he did come back she was like Oh! She was very kind of made it like... Moderator: She was humorous about the dead person in the snow? Good! No, that's impressive! (Laughter)

Student 1: No, she just wasn't like so serious but it wasn't boring. You know what I mean? She made you like listen and all that.

Moderator: Okay.

Student 4: $\quad$ Same thing with her emotions. Like if you watched her face and like listened to the way she talked about it, like it made me want to keep listening to see what was going to happen.

Moderator: Okay. Is that... were all the things you guys listed very different from the average lecture that's not based on storytelling.

Group: Yeah.

Moderator: How?

Student 2: $\quad$ I didn't fall asleep.

Student 3: It's usually very monotone the whole way through. Not really interested just reading off the slide.

Student 1: And you would just, just daydream pretty much. You wouldn't be interested in the thing and they would be pretty much just reading off the slide.

Moderator: Cool. Anything else? You guys wrote three things down. We talked about one cause a lot of people had that one on their brains. Is there anything else that stands out? If the answer is no that's okay too but is there anything else that you just kind of... every person might know or is this just inaudible?

Student 3: $\quad$ Not wanting to rewarm a body part that is going to refreeze.

Student 1: $\quad$ Yeah I wrote that down too.

Student 2: Me too.

Student 3: About the story, she told the story about the mom with the baby and like rewarming her feet and they had to be cut off. Makes me never want to do that. I will never, I mean if I freeze, I will never warm myself back up if I'm feeling cold. 
Moderator: I have a baby so I just threw up in my mouth a little when you said that.

(Laughter)

Moderator: Her feet had to be amputated?

Student 3: The mom's feet. The mom was holding the baby.

Moderator: So you all wrote one down attached to a story. This is another thing you wrote down attached to a second story. Dare I ask what the third thing was? Is there something else? If it's all attached to the same story I think that will make Toni's day. She'll probably be really stoked.

Student 1: I wrote too she added like the snacks they had in the car and stuff like saved their life. So that's what I put like if I ever go on a trip like that or something try to have like snacks and water. And that story made me remember all that.

Moderator: Is there anything about that story you found particularly... It sounds like you had some of those similar elements like it was kind of extreme. There were details. Was anything about that story that was different from the other ones or was it a similar experience?

Student 4: I mean the dad went looking for help for like three days and didn't come back. Like I think it took him three days to come back.

Student 2: $\quad$ Yeah it was a long time.

Student 4: $\quad$ Yeah that's a really to be like looking.

Student 3: $\quad$ Especially to remember where he like left her and stuff.

Student 4: Yeah.

Student 3: $\quad$ After hiking for days, it would be a tough call.

Moderator: Okay, great. Anything else from those moments of the three things you wrote down?

Student 1: With the storytelling, it just made you also think of ways they could have helped themselves, like actually going through the stories and how they could have done it differently. (Coughing)

Moderator: Okay. So as opposed to her just saying something you're supposed to remember it, it made you think a little bit about it. What was possible, what could have happened, how it could have been different? Okay, cool. What do you think are the most important concepts you learned from this lesson?

Student 2: $\quad$ How to take care of yourself if you ever get like frostbite or hypothermia like what to do.

Moderator: Okay.

Student 1: Go to the hospital if you're body temperature drops below like 95. Never rub an area that is frostbitten.

Student 3: That would be one of the first things I would do if it was cold out was like rub it so...

Student 1: We know not to.

Moderator: Okay. What else? What important things do your remember about the lesson?

Student 4: Never thaw something if it's been frozen again. Like the woman with her feet. If it's going to be cold the next night they will just refreeze.

Student 3: I just couldn't believe it was better to leave something frozen than to unthaw it because that would be my first thought is to unthaw something instead of leave it frozen.

Moderator: Okay. That's interesting the idea that we remember things that surprise us and maybe a story helps it to surprise us whereas if it was just something you'd read. A story helps the surprise. Um, from your point of view, what do you think Toni was trying to accomplish 
with the stories that she told? You told me what you remember but what do you think she was hoping to accomplish with you guys in that session?

Student 2: $\quad$ Spark some kind of emotion. Like have an emotional connection between the story and the student.

Moderator: Okay.

Student 1: Just so we will remember them.

Student 3: $\quad$ Trying to tell us facts in a way other than just telling us.

Student 4: Just if we are ever in that situation with a friend or something we will be able to take care of it.

Moderator: Okay. The last question, well second to last question, is this. Can you give me any examples of how stories, be it this one or anything else in your learning, has either helped you learn something in class or has kept you from learning something. There's a chance that stories do the opposite. That people remember less. So can you just talk about maybe your experiences of people who use storytelling in class more generally and times that you think it's been helpful or how you felt about it in general? Or maybe times it has actually not helped and it's made things more difficult.

Student 3: $\quad$ Someone who had maybe gone through that. Maybe they actually had frostbite or had a situation like that and maybe they just didn't want to hear it. Like I've been through this I don't want to live through that again.

Moderator: I thought want you meant was Toni was saying raise your pant legs and she would call on you if you'd been through it but you're saying it would be harder to listen to if you had been through it because it would feel more real.

Student 5: I was just going to say, I'm going to be completely honest, aside from the stories I don't remember much from like the power point. A lot of what I remember is from the stories. Like there's a few facts that I kind of remember but a lot of it came from the stories.

Moderator: Okay.

Student 3: I think too if you tell a story and then see something you'll instantly remember that story. Like if you tell a story about Mount Everest, every time I see Mount Everest I will be like, whoa! That dude, they thought that dude was dead like 15 times down the mountain but he wasn't. So I'm just going to remember that every time I see something about Mount Everest.

Moderator: Yeah that is cool. It's like being retaught it every time.

Student 3: $\quad$ Yeah.

Student 2: $\quad$ I like real life experiences and storytelling because it's like it can happen to someone or it has happened to someone. So it's like relating it back to real life because it's like you should remember that because that could be a situation you are put in.

Moderator: Anything else? Any times other than this one where you feel like storytelling has gone particularly right or wrong?

Student 1: I know for me I have seen storytelling go terribly wrong.

Student 4: Sometimes teachers get off track. It just depends how good the teacher is at keeping the story in the content they want to be. I know I have seen teachers get completely off track and talked about something else then it wouldn't have been as effective but... I just feel like she had a set goal of what she wanted us to remember so she kept on that path. She was good at keeping on that path but if she hadn't been then it would have went a lot differently. Moderator: Okay. 
Student 3: $\quad$ Yeah I was just going to say like it wouldn't have been meaningful like you wouldn't have remembered. Like we remembered content that was important but if she went off track we would have remembered something that had nothing to do with the content.

Moderator: The fact that she used them very intentionally and on purpose. She thought it through. She picked stories that really made you remember what she wanted you to remember and not just said whatever.

Student 2: $\quad$ And also, it went well with the uh, lesson and sometimes people will tell stories and I'm just like why are you telling this story?

Moderator: Yeah, it feels like a waste of time sometimes. The last questions is just this. Is there anything about your experience with her lesson or storytelling in general that you think... You know often times... One reason people do focus groups and group interviews in addition to just taking surveys is often times the survey only tells you what Toni though was going to be important. Does that make sense? So just having some open response time that you can just say whatever you think is important either about the time you spent with her or storytelling in general. You know something that you think might be helpful to her or helpful to her study. That is our last question. So is there anything anybody can think of that would be helpful to keep in mind when it comes to storytelling?

Student 1: $\quad$ She could have added a story that wasn't relevant to see if we still remembered it. About like a baby but not about being amputated to see if we remembered that story as well. Moderator: Okay.

Student 3: Like in the other group she did she could have done something like that to see if they even remembered. If she told a completely irrelevant story.

Moderator: Anybody else? Storytelling in general? Alright if you could do me a favor and

the three things you wrote down if I could have those please. Fantastic. Is there anything you

guys need from me before you head out? Thank you very, very much we really appreciate it.

Thank you I know Toni really appreciates that you participated. Hopefully this was relatively painful. Don't do drugs. 


\section{Focus Group \#2}

Moderator: Alright so, what we are doing to is, is you have very kindly volunteered to participate in a group interview about um, storytelling. As I'm sure you guys maybe figured out already, maybe not, what Toni did was she conducted a true experiment with the class. Um, in one half of the class she conducted a lesson on hypothermia using storytelling as a strategy and then with the other half she taught a lesson on hypothermia using just a straight lecture. Just the facts and PowerPoint only, just very kind of standard lesson with no stories at all. And what she is curious about is the influence of storytelling on the learning experience in terms of lots of things, like how you retain content and how you feel about the instructor, how able you feel to use the information and that kind of thing. So today we are just going to talk. She has, uh, six questions here and I am just going to talk about. The thing about group interviews is like um, you can respond to each other. It's not like I have to give people permission to talk. If you have a thought you know - if student is saying something and student thinks its genius you can just jump in. Don't worry about, you know, I'm not going to coordinate traffic. If student says something that student thinks is ridiculous, then you can deal with that is well. So the first thing I need to ask you guys is if you have something to write with? This is terrible that I don't have something. But if you could just grab something to write with and we're going to start with you guys writing down the three moments you remember about the hypothermia lesson that you were a part of. So we are looking for three things that really stood out to you about those lessons and then we will talk about those things. (pause) By the way, obviously Toni is not here and so please, she would have had me do this no matter what so people would feel comfortable being candid, honest, open so she'll never hear this. She'll never hear what anybody said. I will just give her a typed transcript of responses. (pause) Great, so what did you guys come up with? What were some things that stood out to you as particularly memorable?

Student 1: The thing that definitely stood out for me was the story about the child being outside and freezing completely. And you know the fact that when the child was thought out, I think it was a girl I can't remember, the child was completely fine. No problems whatsoever. I was just so stunned by that.

Moderator: Okay, so I wasn't there for that so this is just a story about?

Student 1: Oh yeah, she told a story about, um, a girl was with her grandma maybe and she went outside and it was below freezing, far below freezing, and the child froze solid. Completely frozen. And the grandma called 911 immediately and they got her taken care of. And I think because they got her taken care of so quickly was why she was okay. The fact that she was completely frozen and no neurological problems, no nervous problems. It just is really shocking to me so.

Student 2: Just something to add on to that. They were out in a cold environment, the child had snuck out at night, and I think it's just a testament to making sure your kid is monitored properly during the night so something like that doesn't happen. She touched on that a good bit too.

Moderator: What was it about that story that made you spend at least two week now, I think it's been longer than that now, I mean it's been awhile. What was it about that that made it stick out in you guys' brains? It has been awhile you know. 
Student 1: I think the shock factor. Like, if I were watching somebody or if I had a kid and that happened to them or even if that happened to me. Like I kind of made it personal a little bit because it was just. Like if it happened to me, that would be so crazy.

Moderator: Okay, cool. Um, anything else? We wrote down three things. That was one that both of you shared. Are there any other things that stood out to you as particularly memorable? Or was that the one?

Student 2: I thought it was really interesting the danger of freezing, thawing, and refreezing. Like, uh, if a person is frozen, you are not supposed to rub it together. She mentioned crystals form in your um, in your blood I think.

Student 1: Yeah, right under the skin or whatever.

Student 2: And um, if you try to rub your hands together and try to warm it up, your friction can actually damage the tissue and make things worse. Um, and also, if you think it's going to refreeze, don't thaw it, just keep it frozen. Until you can get help. Student 1: Yeah I put that too, just to keep it frozen.

Student 2: Right keep it frozen so you can actually thaw it without it refreezing. I thought that was really interesting. Definitely something that I didn't know.

Moderator: Okay. What made those facts stick out in your head? Same question as before. It's been two and a half weeks. What made those facts stick out so much to you do you think?

Student 1: I mean, I think for me, because it was something I didn't know before. It was something new that I learned. I mean I've never really been in a situation like that, so it's good to know.

Student 2: Yeah, no. If that does happen, you can take care of yourself.

Moderator: Were those part of the story too, or were those just independent things you talked about?

Student 1: It was independent. And she also added the story with that about a mom and a baby. They got stuck in the snow. They found a cave and built a fire and froze overnight. Like their hands froze during the night. But it got warm during the day, so they stuck their feet out of the cave. Then later that night they went back in the cave and everything refroze.

Student 2: For like eight days, I think?

Student 1: Eight days, I think this woman had to get her legs amputated.

Moderator: Whew. Okay.

Student 1: It would be kind of hard in a real life situation.

Moderator: Yeah, I was kind of attached to the story too, maybe not directly. Anything else?

Student 2: I thought the story about the people climbing Mount Everest and that guy getting caught in the snow and they thought he was dead like four different times. He just kept coming back to their campsite. They just left him for dead because they thought he was. But he kept coming back and they would just freak out every time. But just because you're frozen doesn't mean you are dead. You have to try to take a little more care of them, so.

Student 1: I mean of course with that, if you are in a situation like that in a group would be don't leave anybody behind, even if you think they are dead, because they might not be. 
Moderator: Okay. What do you think, you told me the things you remembered the most after all this time, what do you think the three most important concepts you learned from the lesson were or like facts or ideas?

Student 1: Definitely the don't thaw it if you think it will refreeze.

Student 2: With hypothermia, I mean will hypothermia it doesn't have to be freezing outside for it to set in so, um, always take precautions when you go in the winter, for example.

Moderator: Anything else? Those were the main ones? Don't refreeze, don't thaw, you know back and forth. And hypothermia can happen at..

Student 2: Almost any temperature. You know like be prepared.

Student 1: Yeah.

Moderator: Can you tell me why you think that Toni chose to tell these in the context of stories?

Student 1: I think that kind of gives people a more personal reason to remember things. And when you are at a personal level I feel like it's easier to remember things because it affects you on a deeper level.

Moderator: Okay.

Student 2: I think it's also, it makes sense she's been a first aid provider so she can relate to those stories because she's been there so it makes it easier for her to talk about the facts about hypothermia and freezing and thawing.

Moderator: When you think back to the stories she told, in the beginning you just listed three different things, what is it about those stories or the way she told them that you think made them important to you or helped them stick with you over all this time? I think this is another way of saying, what makes telling stories work? Or what about the stories make them stay in your brain?

Student 1: It could happen to anybody. I mean we're talking about, um, how it helps? I mean the emotional strategy for helping people and people want to survive. I'm a physical education major. I like the outdoors. I like exercise so personally for me I can relate to that. I hunt, so. With those things we were talking about it just makes me a little bit more aware.

Moderator: Did she describe situation where it would make sense that if it would happen you would be like...

Student 1: Connections were a really strong aspect of the stories and like real life experience and examples, I guess.

Moderator: Can you tell me anything about how she tells stories? I know it's like a tricky thing to get at, but if you can think back. You know we've seen people do a good job telling stories, like oh yeah, and we've also seen people do a bad job at telling stories. What are the good job things that made these stories stick out to you? What made the stories work?

Student 2: She has a, I think she has a lot of emotional behind them. She's not like theatrical, but just the way she explained them. She explained them very well and she was like a good storyteller in this instance.

Moderator: So maybe that's the question I'm asking. What makes her a good storyteller? It's tricky,

Student 1: She knew the stories really well. I mean, there was no gray area.

Student 2: She had a lot of detail in it. 
Moderator: So emotion, detail. She painted a picture that you could envision really well. Anything else?

Student 1: And the pitch of her voice would change. With stories if it's just monotone you just kind of lose interest but she went out of it on certain parts of the story to seem like, oh this is an important part.

Moderator: Um, what do you think the purpose of the stories she selected were?

Student 2: To further explain the topic. I mean you shouldn't necessarily have them all the time but they can be helpful if you are not educated on the subject.

Student 1: I agree. She, sorry I just totally lost it.

Moderator: What was the purpose of her telling the stories?

Student 1: Sorry my brain just totally shut off. Yeah, to give a real life aspect to the stories that she is presenting. And I guess to show her knowledge of what can really happen in these situations.

Moderator: Okay, two questions left and the last question is just is there anything else you want to add so this is the last real question. Can you name any examples of how the stories helped or hindered your learning about this lesson? So in what ways do you think her using these stories helped you learn the material, um, maybe better than you would have if someone would have just said, hypothermia, point one, point two, point three?

Student 2: It makes the class a lot more interesting. It gives you something other than to just look up on the screen. I mean we can all go back and review PowerPoints but you can't...

Student 1: It's kind of like an entertainment factor. Cause it kept me entertained and that made me remember a lot easier by being interested in it.

Student 2: Definitely entertainment. I think I learn more when I'm actually interested in it instead of looking at a PowerPoint she's reading off of.

Moderator: Another question that is kind of attached to this is, we've all seen people tell stories and it go well. And we've all seen people tell stories and it go not as well. What do you think makes it go well over the other? Does that make sense? We've all had teachers and thought oh here is another story. What makes it, because in this situation it sounds like it worked? You can still tell me things three weeks later you can still tell me the three main stories that she told. What do you learn from that? What do you think makes this better? The works versus the what doesn't work stuff. Student 2: She didn't drag the stories out. She gave the information that was pertinent but she didn't just go like on and on and on about things that didn't matter to the story. Everything she said had a purpose.

Student 1: I think some teachers when they try to tell a story kind of struggle with staying on topic. Not that it's so far off the topic but....

Student 2: They just keep rambling....

Student 1: Yeah, they ramble

Student 2: But she didn't know that.

Moderator: I understand what you mean because you have been in class with me and I ramble. Now you, I'm offended by you. (Laughter) l'm just kidding. Uh, last but not least is this, is there anything else you want to add? You know part of the reason Toni chose to do group interviews is because she gave you surveys, but surveys just tell you what like her best guess is. And is there anything else that you think might be important 
to know about storytelling or your experience with it. You know, just anything else you might like to add that you think is important.

Student 2: I'm a really big storyteller too, so l'm all for the whole storytelling thing.

Student 1: Like we said before, it just helps us visualize it better putting it into real life situations. I'm all for it too.

Moderator: When you say real life situations, you mean like apply it?

Student 1: Yeah, like if we were ever in that situation where we had to use this I think we could.

Student 2: I would definitely remember the stuff that she taught us because it was more personal and I can potentially think about situations where I could be in that situation.

Moderator: Cool, well thank you both very much and if have nothing else to add than that's it. 


\section{Focus Group \#3}

Moderator: As you guys have probably figured out, you guys volunteered to participate in an experiment with Toni and half the people who volunteered went into a lesson in which storytelling was used to teach about hypothermia. The other half of the people went into a room in which they got a very straight lecture with no stories whatsoever, just a point-by-point on the PowerPoint kind of experience. So what we are going to talk about today is the impact of, or the influence of storytelling on your experience and whether it was good, bad, whatever. You know please feel free to offer any comments that you have. This is a group interview which basically means, the last thing I want to do is be a traffic cop and tell people when they can't... just its a conversation. If, if uh, who is who, I'm sorry? (Student gives name) Yeah so if student says something that student thinks is ridiculous, student be like student you are crazy pants. And then you know vice versa if you think it's great or whatever we can just talk about whatever. If we can start with this, what Toni would like - these are questions Toni gave me to use - if you could write down three moments you remember about your experience in the hypothermia lecture. Either, just three main things you remember when you think back to that lesson she taught. Whatever they are. I'm going to take these things from you. If you just write down the three things you remember the most that would be super helpful. (pause) Alright so, what did you guys remember? At this point it's been like two or two and half weeks later. What stood out as memorable to you from that lesson?

Student 1: I mean for me, um I remember she told us a story, and basically the whole point of the story was, you shouldn't thaw out your fingers or toes if there is a chance of it refreezing. One because of like nerve damage and it can be really painful. And then two, if someone appears to be dead they might not be. They might not have a heartbeat and stuff but, they might, they could come back to life I guess. And then three, coffee and caffeine are really bad, well not really bad, but they are not as helpful on a cold day as like hot chocolate.

Moderator: What made those things stand out to you do you think?

Student 1: I don't know. I remember the stories that she told us really well. Like for number two, I think she told us two stories. So like, there was one story about a guy climbing like Mount Everest or something and like his friends or whoever he was hiking with left him because they thought there was no chance of him coming back or whatever. And then he showed up at base camp and they were like oh, what's going on. And then there was another story about like a young child that went out in the cold and the mom thought they were dead or something but she called 911 and was freaking out and the child was fine. So I don't know, I just think that they kind of stood out in my mind more.

Moderator: Okay.

Student 2: That's what I remember, too.

Moderator: The same three things?

Students: A lot them were the same. Yeah I remember that you shouldn't rub the area if you have frostbite because you might damage the nerve cells. Um, that you shouldn't let your frostbite areas thaw if there is a chance they might refreeze. I remember that too because of the story she told us about this woman who would let her 
feet thaw in the sunlight but at night they would refreeze and she ended up losing her legs because of it. And if she wouldn't have done that she probably would have had a better chance of not losing it that much. Um, she also told us you can thaw your frostbite in warm water if it's not going to refreeze and you'll have a better chance of not damaging the cells.

Moderator: Okay.

Student 1: I remember on days that it was kind of cold between then and now, I remember being like oh, I should drink hot chocolate today or things like that. I don't know why and I would be talking to my friends about it, too. I would be like don't drink soda.

Student 2: Yeah, we actually talked about it in class one day with some of our friends after that lecture. Because there was something about it being such a cold winter and we were talking about it. Like I used to do that all the time, like rub my hands together when they're cold or whatever but, because you'd think that would be something that would be smart to do but.

Moderator: So I guess the question, or the follow up question would be, three weeks or almost three weeks and this stuff still stands out. What is it about how it was taught or the stories that she told that makes this memorable after so much time. Because let's be honest, most people say something and you don't remember it for three minutes, much less three weeks. So what is it that you think worked in this situation? Student 1: For me, hearing about actual people made it more real, rather than just reading words on a page. Like I could picture the mom and the child. I could picture the woman hiding in the cave and putting her feet in the sunlight. Like I could picture actual human people rather than just reading something off a slide. So, I don't know, I think in that sense, it made it more memorable.

Student 2: I think the thing that made it more memorable for me was that she like she didn't just explain something. You could tell she was passionate about what she was talking about and knew all about it. And maybe also the fact that like helping people is something we're passionate about, and like the stories were like shocking stories. Like you don't hear stories like that like often, so they kind of stick with you. I always relate better to stories when they are told. That's how I relate to things is through stories.

Moderator: That's great, thank you. Um, what do you think the three most important concepts you learned from this lesson, and if it's similar to what you wrote that's okay, but what do you think the three main concepts or ideas that you learned were?

Student 1: I mean, I don't know, I think it's more along the lines of prevention. Like things you could do to not be in a position. Like putting on the right clothing and like keeping your head covered so you don't lose body heat that way and um, I don't know bringing, what are those things called that you sit on so you don't sit on cold benches for a whole game? So like prevention stuff and what to do in the event that you are extremely cold. And yeah um, to not thaw out frozen things and parts when they are cold and not to rub your hands when they are damaged. And I think um, yeah I don't know, to seek actual medical help too because people who are in the field have way more knowledge than like the average human being so.

Student 2: I would say I took away that same information. Um, making sure that you are always prepared for cold weather, whether you're just going to be outside for a little bit or not. Or whether you are traveling somewhere. Um, something about the stories 
she told is people got trapped when they were in their car but they didn't know how to, they didn't have all the necessary things that could have had. Um, they, I mean, they didn't have enough gas really. I mean they might have had gas stations so, if you are somewhere there could possibly be a blizzard you might want to think of something like that. Um, but I would also say something else that stood out to me that I remember or that I would take away is, if you are more physically fit you have a better chance of not getting hypothermia. That really made an impression on me. So I mean for that's just another reason people should care about their health because you can prevent it that way. But also you shouldn't give up on somebody who might have frostbite or hypothermia. Another one of the stories she told the people like gave up and were like oh mygosh, like okay they're dead. You should always still call for medical help cause they might be more competent that you are...

Moderator: To determine that.

Student 2: $\mathrm{Mmhmm}$.

Moderator: Okay, great. No that's really good. Can you tell us why you think it was that she told those stories? Like what was the, what was she hoping to achieve by telling stories?

Student 1: I think what kind of what student was saying before. Like people relate to stories, especially if they are more interesting because you like, I don't know, if a similar situation happens to you or someone that you know, you're going to remember that. Because you are going to be like, oh yeah my friends Rachel did the same thing, or something like that. And like once it becomes more relatable, students are going to remember it more because it's real. Its real life situations. It's not just reading out of a book or listening to someone lecture for 45 minutes. Like its actual real life situations. Student 2: Yeah like again I feel like stories stick with people better because it's not just a fact in a book, as you know this is what frostbite can do and you shouldn't thaw frostbite because there is a chance of it refreezing. It's more interesting if you are like, this is why you shouldn't. Let me tell you this story about somebody. Because then you start thinking like more critically about the whole thing because you get those stories in your head. Like how everything played out. And then like you know, when you're in a situation and its cold, you're kind of like rethink about those. I feel like it's hard to just think about some fact that you talked about for one second a long time ago. But when you hear a story you like imagine stuff like within a minute and see images and its more visualize than if you were just reading from a book or lecture.

Student 1: Yeah I was just going to say, if I were in that situation that I didn't learn this through stories I would say, we learned something on hypothermia in class but I don't remember what is was. Like I remember learning about it but I don't remember what it was. Like if it was just like in a textbook reading facts.

Moderator: One of the complaints that people sometimes have about stories is, that people remember it in the situation that the stories is told in but can't apply it outside that situation. Does that make sense? So if someone says you should take seats or take pads for the metal seats at a football game, it's about losing heat and heat conduction right? Then if someone was sitting around a campfire, on the ground, they wouldn't necessarily think to put something underneath them on the ground because it's not the football stadium. Do you think that's, what, I don't know. You guys brought it up and I know that's something someone will ask her about this. So say what do you 
think? I don't know, do you think, does that seem to hold water to you? Or does that seem...

Student 1: I can see how that would happen. I mean, part of it is probably the way that it is told. Like if you plan the whole situation, like yeah you have to put this down because you're losing body heat through conduction then that would probably stick with people more than just, yeah bring this on a, or to a football stadium because you are going to lose body heat. I think if you explain it more and explain how to adapt it to other situations then....

Student 2: Which I feel like she did, Student 1: Yeah I agree with that.

Student 2: I don't know. Even if she didn't though I kind of feel like...I guess she did. Like it does depend on the thought process. Like when I tell a story and I think about that, I automatically think of other situations where that could be useful or where the same type of problem could occur. Just because there is this couple with a child who got stuck out in a blizzard looking for a Christmas tree, doesn't mean that it could only happen to somebody like that. It could happen to somebody who went out on the slopes one day to go snowboarding. You know? They didn't have enough covering on or they weren't prepared. Or they didn't know a lot about hypothermia or frostbite. I think about it that way for myself or like other activities. So I guess it depends on the way that you really think about it.

Moderator: What was, sorry l'm using the questions guide that have and this transition is a little tricky for me. So the last question was why we told the stories. What do you think the purpose of the stories she told where? This is a very similar question so it can be a bit tricky.

Student 1: Um, I mean I think she told about people and not, oh I saw this movie once where this happened. Like you could picture a friend in this situation. Or you could picture your mom in this situation. I don't know you could picture actual people instead of just a movie or a book you read or something like that. I mean I think she could have read a book about something but it wouldn't be as meaningful as real life stories. Student 2: It seems like more factual because it's not just something that Hollywood thought up. It's not just like, oh yeah well that was a good movie. It's actually true. Student 1: Yeah it makes it seem credible. Like she's not lying. She's not making this up. Like I want to pay attention to this.

Student 2: I mean it takes the facts about it and applies it to what can really happen to you or somebody that you know.

Moderator: Cool. Can you give me any examples of how the stories helped or hindered your learning about hypothermia? I guess part of this question is, we talked a little bit about helped already but other ways in which stories may have made it harder to learn or made it harder to stay with the lesson. We're just trying to be balanced right and not load one way or another.

Student 1: I mean for me, I don't think it really hindered me that much. I think I was definitely more engaged in what she was saying. Like I didn't doodle on my paper. I was listening to her the whole time. And I don't know. I was thinking about it in situations when I was cold from then until now. I mean I drank hot chocolate today because I am freezing and stuff like that. So I don't know, I think it more helps you rather than hinders you. 
Student 2: Yeah I would say the same thing. I don't, I don't think it hindered me at all. I think it just helped me because she like gave us this fact and then she told a story about it so she went more into depth about what that was. It wasn't just a sentence and you were like oh okay. She would tell us something and then she related a story to it, so she told, really it wasn't a story. She told more in depth about the dos and don'ts of different things.

Moderator: So it sounds to me, and again I wasn't there. I don't know any of the things that she did. But it sounds to me from what you guys and the other groups have said, is that um, Toni does a pretty good job of telling stories. Or at least she did on this day. Um, and so this is like a two part question. One is, as specifically as you can, I know that's tricky, what is it about how she told the stories that you think was effective. And then the flip side of that is this, maybe both of these things together might help you answer this question a little bit. We've all been in situations where people tell stories and it didn't work so well. (Laughter) Does that make sense? So what are some of the things that made her stories effective? And some of the things that mess people up when they tell stories. Does that make sense at all?

Student 1: I mean I remember her being very animated and using a lot of hand gestures. And her voice went up and down for parts she really wanted to emphasize and stuff like that. For things she really wanted to stand out. Whether that was just the facts of what she wanted to get across to us or whether that was a turning point in the story. I just feel like for the important parts she played it up a lot. That stood out to me. And I think for people who don't really tell stories or who don't tell stories well, it's just kind of like, okay. Like they don't really get to a point. They kind of go a roundabout way of getting to what they want to say.

Student 2: I feel like her stories were like, she stayed real about it. She kind of threw in a little humor in voice. So it made you like kind of pay attention more. And she made it exciting so we were like waiting to hear what's going to happen. And then she would talk about the consequences in a passionate way. And you were like, like the person who had frostbite and it would refreeze, she would be like, if only she had known she wasn't supposed to do that, that she wasn't supposed to let it thaw and refreeze, she could have saved like, she could have saved her legs. I mean maybe she wouldn't have had to amputate her legs. I mean like that, that's something important. You start thinking about that and you're like, oh my God. Like it puts more feelings in you because you, like that would be horrible to lose your legs like that. When it could have been prevented by something so, so simple. And I think people who tell stories that aren't effective, they kind of make like a punch line or they aren't very enthusiastic about what they are saying. Or they just kind of tell it really quick and move on. Or sometimes like, when they are storytelling they kind of stumble over their words. Or they, "like yeah this person this happened and I don't really remember why exactly that happened. Or I don't know but I know this is what is supposed to happen or whatever. I'm not really sure why I just know that it can make you sick or something." But if you don't really have your facts straight and you don't really think about like what you are saying then people are just not going to be interested in what you are saying if you don't state it as well. Because again it doesn't' sound like you really know what you are talking about. But she definitely knew like she sounded like she knew what she was talking about. 
Student 1: She was very prepared and well thought out before she spoke to the class.

Moderator: Another way to ask this question. We've all been in classrooms where someone tells a story and we're like interested. We've been in classrooms where someone starts to tell a story and we're like, oh god not another story. You know what I mean? What is it? What makes us have that dread? I know you guys were saying part of it is preparation and like a reason to tell the story or if they've thought it through. How or just the way with detail, tone of voice, things that sound like they are important. So last questions is really just super open ended. When people give surveys, you know that was Toni's best guess at what she thought was important. I asked some follow up questions to hopefully get you to tell us a little bit more detail about what could be important. The last thing is just open ended. If there is anything else that you can think of that you think is important about you know storytelling or how to use it effectively, or anything else you can think of about that lesson that you think is worth saying, hey this is something I thought was important but none of your questions gave me an opportunity to say this was important. Is there anything else that you would just like to add or anything other thoughts you might have?

Student 1: I mean, the only thing I can say we haven't had a chance to talk about is just like we were learning about hypothermia. And anybody be can like, yeah we're going to be talking about hypothermia today guys and I like know it can be pretty boring but please hang with me. She was like, okay we're going to be learning about hypothermia and she was excited about it. She made it sound important. That kind of came over to us on the other end of the room and we were like, we should pay attention. We should listen. What she has to say is important and I want to hear it and learn from it. So I think just having that initial thing of like yeah what l'm teaching is important and I want you to pay attention really helped out a lot. Like if a teacher kind of downplays whatever you are talking about then.

Moderator: Interesting.

Student 2: I think something else that you pointed out was that, she didn't just give you some vague fact about something, like oh l'll just tell them what they really need to know. She goes into more detail about things. And will tell you things that like, you know, you don't really hear that all the time. Like with her stories, you don't really hear that often. A part about the fact that is interesting. So you are like, oh that's weird. Like it strikes you in different ways. When you are like rethinking about it, you kind of remember that strange little fact that she told you. Or that strange little part of that story that she told you. And it makes you remember like the basic concepts she was trying to teach you. I think I don't know, I think that's a really good strategy to have.

Moderator: A word that all three groups used, you guys used it early, was shocking. All three groups said oh if the story was shocking or the set of detail that surprised me because I always thought it was okay to rub stuff, like l've done that a bunch of times, and the fact that it was something that you thought was right but then you were wrong or a strange little fact that made you surprised. I feel like every group in some way has kind of said that, you know, that element of surprise maybe or that element that made you go what. You know, that those are a part of that process. In the story if there is nothing surprising or unexpected, than you are like eh been there done that. But if there 
is something that is unexpected it kind of makes you pay a little more attention. Does that seem right?

Student 1: Mmhmm, yeah. Especially if it happens in the beginning of it and it like grabs you in. You are like I want to pay attention. I want to learn more about that shocking thing or whatever.

Student 2: I think that's so true. I think that's the other thing about storytelling is that you want to grab people's attention at the beginning not just halfway through because, if you get their attention at the beginning they are going to be interested the whole time. But if you want until the middle or the end to say something interesting, no one is really paying attention. They just feel like whatever, we've hear this before and I don't know why you are wasting time doing this. But she definitely didn't do that.

Moderator: Cool. Anything else you guys would like to add? Great thank you both. 